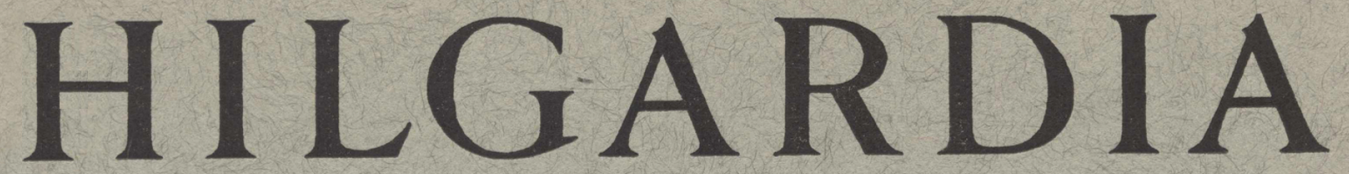

A Journal of Agricultural Science Publisbed by the California Agricultural Experiment Station

\title{
PHLOEM STRUCTURE IN THE GRAPEVINE, AND ITS SEASONAL CHANGES
}

KATHERINE ESAU

UNIVERSITY OF CALIFORNIA - BERKELEY, CALIFORNIA 
In order that the information in our publications may be more intelligible it is sometimes necessary to use trade names of products or equipment rather than complicated descriptive or chemical identifications. In so doing it is unavoidable in some cases that similar products which are on the market under other trade names may not be cited. No endorsement of named products is intended nor is criticism implied of similar products which are not mentioned. 


\section{H I L G A R D I I A}

A Journal of Agricultural Science Published by

the California Agricultural Experiment Station

VoL. 18

MAY, 1948

No. 5

\section{PHLOEM STRUCTURE IN THE GRAPEVINE, AND ITS SEASONAL CHANGES ${ }^{1}$}

\section{KATHERINE ESAU ${ }^{2}$}

\section{INTRODUCTION}

The PRESEnT investigation of the phloem of the grapevine, Vitis vinifera L., was undertaken to provide a background for a study of the anatomical effects of the virus-induced Pierce's disease upon this plant. According to the previous studies of Pierce's disease (Butler, 1910; Houston et al., 1947) ${ }^{8}$ the xylem appears to be the tissue affected primarily, but the irregularity in the maturation of the bark suggests a possible disturbance in the phloem also. The close relation of the causal agent of Pierce's disease to the xylem places this virus in an uncommon category. With regard to their tissue relationships, viruses have been divided, thus far, into those that are largely restricted to the phloem and those that are not so restricted and invade various types of parenchyma (Bennett, 1940). To determine whether Pierce's disease affects the phloem at all, a detailed study of this tissue in healthy and diseased vines was carried out. The present paper deals with the phloem of plants that showed no symptoms of any disease.

A study of the grapevine phloem promised to be of interest also from the standpoint of phloem anatomy in general. The phloem of Vitis shows an unusually long life. Its sieve tubes function more than one year, becoming inactive during the winter and resuming activity in the spring. Though the general structure and development of the grape phloem was thoroughly investigated by Wilhelm (1880), the phenomenon of reactivation of this tissue seemed to merit a renewed consideration in the light of the modern concepts of phloem structure. Moreover, it seemed that information relating the seasonal changes in the phloem to the various manifestations of growth and reproduction in the plant would further explain the connection between structure and function of the sieve tubes.

\section{REVIEW OF LITERATURE}

The histology of the grapevine phloem and its various transformations have been considered by Wilhelm (1880), Strasburger (1891), and Hill (1908) and the findings of these workers are evaluated throughout the present study. However, information on seasonal changes in secondary phloem and the rela-

\footnotetext{
${ }^{1}$ Received for publication May 28, 1947.

2 Associate Professor of Botany and Associate Botanist in the Experiment Station.

${ }^{3}$ See "Literature Cited" for citations, referred to in the text by author and date.
} 
tion of these changes to cambial activity is rather fragmentary in the individnal papers, and the data require a separate review at this time.

Judging from the literature (see review by Esau, 1939), the secondary phloem of most plants shows only one period of activity. After the sieve tubes reach maturity, they remain in this state for periods of time which vary mainly in relation to the plant species ; the sieve tubes then become senile and functionless. As senility approaches, the callus ${ }^{5}$ on the sieve areas thickens until it reaches its maximum development. This accumulation of callose constitutes the definitive callus whose presence signifies that the sieve tube is no longer concerned with the primary activity of the phloem, the conduction of food. The definitive callus usually disappears later, but the sieve tubes then have no living contents and may become filled with gases, if they are not crushed.

Commonly the sieve tubes function only one season. (See reviews by Strasburger, 1891; Esau, 1939.) Recently Schneider (1945) considered the phloem of Prunus (peach and cherry) from a developmental standpoint and also found that a given phloem increment lost its activity at the end of the first season. Few exceptions to such behavior have been recorded for angiosperms. Janczewski (1881) considered that the same sieve tubes functioned for four seasons in Tilia. He based his estimate on the assumption that each season two tangential bands containing sieve tubes (and alternating with fiber bands) were produced. Hence, finding eight bands with active sieve tubes, he concluded that the outermost were in the fourth season of their function. Though such an estimate is obviously unreliable-the number of tangential bands produced during one season could be expected to vary-Janczewski reported also that the winter sieve tubes did not appear functionless in Tilia. Lecomte (1889) stated that the sieve tubes of the rose functioned two years. According to Lodewick (1928), the sieve tubes of Liriodendron remained active possibly for two years, though in several other forest trees, which he considered, these elements showed the usual loss of function at the end of the first season.

As mentioned in the introduction, Vitis contrasts with most plants in having sieve tubes that pass through more than one period of activity (Wilhelm, 1880 ; Strasburger, 1891; Lecomte, 1889; Hill, 1908). Before the onset of winter dormancy, the Vitis sieve tubes develop provisional (dormancy) callus. Their protoplasts ${ }^{6}$ do not die, however, and in the spring the sieve tubes again acquire the same characteristics of active elements that they showed when they first differentiated from the cambium. In the present paper, the term reactivation designates this phenomenon of resumption of activity by sieve tubes that have passed through a period of dormancy. Wilhelm (1880) implied that reactivation could occur more than once in the same sieve tubes.

One of the outstanding features of the reactivation process is the removal of the dormancy callus. This phenomenon is not identical with the disappearance of the definitive callus in functionless sieve tubes. When the definitive callus is gone, no callose at all remains on the sieve plate: the latter is then

- For definition of maturity in sieve tubes, see Esau, 1947.

' Callus is used here, as in most literature on phloem (see review by Esau, 1939), to designate the more or less large deposits of callose on the sieve areas.

- Although a mature sieve-tube element has no discrete nucleus, the substance contained within such an element is here designated as "protoplast" because it continues to exhibit some properties of an organized protoplasmic unit after the disintegration of the nucleus. 
simply a cellulose net with openings that were formerly occupied by the callus cylinders encasing the connecting strands (Esau, 1938, 1939). When the provisional callus disappears, the sieve plate shows no free openings: the callus cylinders and the included connecting strands remain within the sieveplate pores (Wilhelm, 1880; Hill, 1908).

Few other genera besides Vitis have been named in the literature as having more than one period of activity and, with regard to the phenomenon of reactivation, none were investigated in such detail as the grapevine. Janczewski (1881) mentioned that the sieve tubes of Phragmites, and apparently those of other monocotyledons, were "reopened in the spring." He also found, in Tecoma, that the winter contents of the sieve tubes (whose sieve plates were calloused over) were in such a state that they could be considered capable of resuming activity. Lecomte (1889) described the reactivation of sieve tubes as a general characteristic of the perennial monocotyledons. He stated that in such plants the sieve tubes, presumably not those of the protophloem, remained alive nearly as long as the organ in which they occurred. During the winter these sieve tubes showed increased amounts of callose, but in the spring the latter was reduced to its original thickness.

The occurrence or nonoccurrence of phloem reactivation bears upon the question of the relative time when activity is resumed in the spring by the cambium and by the phloem. If phloem reactivation takes place, does it begin before or after the cambium becomes active? If the phloem is not reactivated, is any functioning phloem present when cambial divisions begin? If such phloem is available, what is its origin? Does some mature phloem remain in an active state through the winter or does some immature phloem differentiate in advance of cambial reactivation? Or does the cambium become active in the absence of any functioning phloem?

The first question is not answered in the literature. The students of Vitis phloem did not consider the cambium (Wilhelm, 1880; Strasburger, 1891; Hill, 1908), whereas Knudson (1916), who studied radial growth in Vitis labrusca $\mathrm{L}$., did not investigate the phloem.

With regard to plants having no reactivation, the literature previously reviewed by the writer (Esau, 1939, p. 419-21) and certain other references (Knudson, 1913; Huber, 1939) suggest that, if in the given species the phloem functions only one season, some cambial derivatives on the phloem side pass the winter in an undifferentiated state and complete their maturation in the spring before the cambium resumes its activity. Occasional narrow sieve tubes formed at the end of a season may be carried over into the second season (Huber, 1939). Reports on gymnosperms are similar to those on angiosperms except that, according to Huber (1939), in the Abietineae part of a given phloem increment is not crushed until the second season.

In plants with sieve tubes that function for several years and develop no provisional callus during the winter, some sieve tubes can be expected to be ready for function in the spring as soon as the growing season begins.

In contrast to the scarcity of information on the beginning of phloem activity in the spring, there is an abundant literature on cambial reactivation. Furthermore, this topic was previously reviewed in the literature as, for example, by Grossenbacher (1915) and Priestley (1930). Since these reviews 
were written, a growth hormone was found to be one of the agents inducing cambial divisions in the spring, and this discovery has much clarified the picture of cambial reactivation (Avery et al., 1937). Thus, the commonly observed inception of cambial growth beneath the buds and the basipetal progression of this growth through the branches and trunk toward the root is now, at least partially, explained by the observation that the growth substance is formed in buds emerging from winter dormancy and then appears in measurable amounts at successively lower levels of the tree in advance of cambial reactivation (Avery et al., 1937).

Because of the basipetal progress of cambial activity, the root usually begins radial growth considerably later than the aerial parts of the plant. As an example, Cockerham's (1930) observations on Acer pseudo-platanus L. may be cited. In this tree, nine to ten weeks elapse between the inception of xylem differentiation in the twigs (late in April) and that in the proximal portions of roots (early in July). Cessation of activity occurs in the same order and, again citing Cockerham, in Acer the formation of xylem ceases in the twigs late in July and in the roots late in September. Thus the period of inactivation lasts eight to nine weeks. In conifers the relation between the buds and the reactivation of cambium seems to be less obligate than in the hardwoods (Priestley, 1930; Wight, 1933).

The morphologic details of cambial reactivation have been treated in some references (Brown, 1915 ; Cockerham, 1930 ; Knudson, 1913 ; Lodewick, 1928; Priestley, 1930 ; Priestley et al., 1933). In the first phase of resumed cambial activity, a radial enlargement of the meristematic cells occurs. In the second phase, cell division takes place. Priestley and his co-workers (1933) describe cambial reactivation in some detail. Assuming that the dormant cambium is a single layer of cells, they characterize these cells as being as "tough and resistant as any of the layers between the lignified wood and the bark." The first sign of resumption of cambial activity is a "swelling" of the cells in the cambial layer. In other words, the cells enlarge, and since the enlargement is in the radial direction, the radial walls become thinner, while the contents of the cells seem to change from a "solid to a liquid consistency." As soon as this stage is reached, the cambial walls break readily when the stem is handled, and the bark "slips" over the wood. After the divisions are initiated in the cambium, the bark continues to slip along the cambial layer. According to Lodewick (1928), the dormant cambium cells have rather dense protoplasts and the ray initials contain starch; when cambial activity is resumed, this starch disappears.

Reports vary regarding the relative time when the first xylem and phloem are formed by the cambium (Brown, 1915; Cockerham, 1930; Knudson, 1913, 1916 ; Lodewick, 1928 ; Priestley, 1930; Priestley et al., 1933). A proper evaluation of these reports is difficult because writers usually make no clear distinction between the maturation of cells left over from the cambial activity of the previous season and the differentiation of cells formed by the new growth. The various patterns of radial growth suggested in the literature are : (1) that the formation of xylem begins before that of the phloem; (2) that the formation of xylem and that of phloem begin and cease at the same time (Vitis labrusca L. follows this pattern, according to Knudson, 1916) ; (3) that phloem 
initiation follows that of the xylem and lasts longer; (4) that more cells are cut off on the xylem than on the phloem side.

Judged from the literature just reviewed, the information on the seasonal cycle of secondary phloem in woody species may be tentatively summarized as follows. Plants fall into two major groups regarding longevity of the phloem : (1) plants whose phloem functions one season only ; (2) plants whose phloem functions more than one season. In the second group two further subdivisions can be made. In one, the phloem does not become inactive during the winter ; in the other, it becomes dormant and is reactivated in the spring. In the much larger group of plants whose phloem functions only one season, all the mature phloem becomes functionless at the end of this season. There are, however, some immature cambial derivatives on the phloem side of the cambium. These differentiate into functioning phloem at the start of the growth season. In the plants with long-lived phloem, active sieve tubes are present when spring growth begins. These sieve tubes are active either because their structure remains unchanged during the winter or because they become reactivated in the spring. In all plants new phloem is added by the cambium in the presence of functioning phloem of earlier origin.

\section{MATERIAL AND METHODS}

The material used for the present study was obtained from grapevines that were growing under field conditions at Davis, California. The most complete collection was made from the Sultanina (Thompson Seedless) variety; for certain studies other varieties were sampled. The vines used for the samplings were several years old. Material of different ages, including some from the main trunks, was examined, but the most complete study was carried out on canes in their second year of growth. In 1945 the collections were made every week, sometimes more than once during the same week ; in 1946, at fortnightly intervals. Root and stem phloem were compared. Lateral roots $1 / 4$ to 3/4 inch thick were sampled 15 times during 1945 from the Sultanina variety.

In 1945 the material from each collection was used partly in fresh state and partly in preserved condition. In 1946 all of the material was killed before it was sectioned. Two formalin-acetic-alcohol mixtures, one prepared according to the formula No. 1 of Rawlins (1933), the other according to Sass (1940, p. 16), and the chrome-acetic-formalin combination Craf III (Sass, 1940, p. 19) were the killing solutions employed. The latter was the most satisfactory of the three for the study of cytological details in the sieve tubes. After a fixation of several days, the material was rinsed in alcohols and then preserved in 70 per cent alcohol.

The fresh material was sectioned on a sliding microtome and examined either fresh or after treatment with $\mathrm{I}_{2} \mathrm{KI}$ and aniline blue (Foster, 1942, p. 142). Plates $4, A ; 12 ; 13 ; 14, A$ to $C$, and $E ; 15$; and $19, D$, exemplify material treated in this manner. The killed material was cut on a sliding microtome either directly, if the pieces were sufficiently large, or after it was encased in diglycol stearate (Diglycol Stearate S of the Glyco Products Co. Inc.), a wax that is dispersible in hot water and soluble in hot alcohol. Some of the material was imbedded in paraffin after a dehydration with tertiary butyl alcohol; it was then sectioned on the sliding microtome. 
To prevent curling of sections obtained by the use of the sliding microtome, the block to be cut was covered with a small piece of thin wet paper as recommended by Varrelman (1931). As the knife passed across the block, the paper slid onto the knife together with the section. The paper and the adhering section were picked off the knife with a pair of forceps and the section was floated off in water or alcohol. If the sections were obtained from paraffin material, they were placed directly on a slide covered with Haupt's adhesive and flooded with a 4 per cent formalin solution (Johansen, 1940, p. 20). Most of the sections were cut 20 microns thick; some were thinner, others thicker.

The sections from the killed material were stained either in iodine and aniline blue or in a combination of three stains : Bismark brown, iodine green, and resorcin blue. This combination proved very useful for a detailed study of the sieve plates because it clearly differentiated between the callose and the connecting strands. In killed material preserved in alcohol the callose stains very well. With the aniline-blue technique, the slime, the cytoplasm, and the callose are distinguished by different tones of blue. With the three-stain combination, the callose is blue and the connecting strands brownish purple. The callose is also well differentiated from the cellulose wall, which acquires different shades of yellow and brown (the Bismark-brown staining). The iodine green is described in the literature as a stain for chromatin and for lignified walls (Johansen, 1940, p. 59). The latter are supposed to become green in this dye. The iodine green used in the present study - an old noncertified samplegave the lignified walls a purplish color. This stain was employed not for its effect upon walls, however, but to stain the slime and to contrast the latter with the callose. Plate 20 shows how sharply the sieve-tube slime may be differentiated, in all its states, by the use of iodine green. (No resorcin blue was used in plate $20, A$.)

Plate 1 illustrates the color contrasts obtained by staining with Bismark brown, iodine green, and resorcin blue. This combination is effective not only in color photography but also in the preparation of black and white photomicrographs. (See, for example, plates $7,10,11$, and 16.)

The schedule for the use of the Bismark brown-iodine green-resorcin blue method of staining is given in detail in the following paragraphs. Most of the material stained by this method was sectioned by the use of the diglycol stearate. Since the textbooks on microtechnique (Johansen, 1940, p. 22-23; Sass, 1940, p. 99) give few suggestions for the use of this "encasing" medium, the method employed in the present study is described in connection with the staining procedure. The combination of the two schedules is as follows.

The material, previously stored in 70 per cent alcohol, is passed through two or three grades of lower alcohols to distilled water. It is left in distilled water overnight, since the material is too brittle if sectioned directly out of the storage alcohol.

The stem pieces are then removed from the distilled water, wiped off lightly, and placed in melted diglycol stearate that has been poured into paper molds. To avoid desiccation of material, only as much of it is encased in the stearate as can be cut on the same day.

The cooling and hardening of the stearate may be speeded up by the placing of paper molds, with contents, in a refrigerator. After the stearate has hard- 
ened, the individual pieces of material are cut out; enough of the stearate should be left about each piece so that the encasing medium does not split off from the encased material.

The pieces of stearate with the encased material are then mounted on wooden blocks and sectioned on a sliding microtome. To prevent curling of sections, paper strips moistened in water are used upon the side to be cut (see Varrelman, 1931).

The stearate, which usually enters the large pores in the sections, may be dissolved out by placing the sections in 70 per cent alcohol on a slide-warming plate and leaving them there at least overnight.

The material is now ready for staining and is treated with the following media for the specified lengths of time :

1. Distilled water, $1 / 2$ to 1 hour.

2. Bismark brown in $1 / 5,000$ dilution in distilled water, 2 hours. (Stock solution of the stain : 1 gram of Bismark brown, 5 grams of phenol, $100 \mathrm{cc}$ of distilled water.)

3. Distilled water, 1 hour.

4. Iodine green in 1/5,000 dilution in distilled water, 2 hours. (Stock solution of the stain : 1 gram of iodine green, 100 ec of 30 per cent alcohol.)

5. Distilled water, 1 hour.

6. Resorcin blue in 1/5,000 dilution in distilled water, overnight. (Stock solution of the stain : 1 gram of resorcin blue, 100 ce of 30 per cent alcohol.)

7. Distilled water, $1 / 2$ hour or less. (Longer time in water will cause resorcin blue to fade.)

The sections are now ready for mounting on the slides. Each section is brushed gently on both sides with a camel's-hair brush and mounted on slides in dark Karo sirup. (Johansen, 1940, p. 24, recommends this grade of Karo sirup as a mounting medium.) Weights are used on cover glasses for about three days, shell vials with mercury making convenient weights for this purpose.

The schedule just presented may be variously modified, especially with regard to the time limits in the individual stains, and, probably, different schedules will give best results with different materials. The method used in the present study has certain imperfections. A uniform balance between the Bismark brown and the iodine green is difficult to get. The resorcin blue gives a dark precipitate (hence the need for brushing) and sometimes causes a general darkening of the sections. The last washing in distilled water must be carefully watched so as to prevent the fading of resorcin blue.

The permanency of the staining combination is yet to be tested. Some slides that were made in September, 1945, had their original brilliancy a year and a half later; in others the resorcin blue had faded.

The process of mounting in sirup also is somewhat awkward. Since this sirup has a relatively high surface tension, it does not spread well and tends to trap bubbles of air. Its spreading quality may be improved by the use of very clean slides and cover glasses and by the addition of distilled water to the sirup to thin it. However, air bubbles may appear under the cover glass later, when the sirup loses water upon drying. To overcome this difficulty, one should 
use the sirup in excess and let it accumulate around the edge of the cover glass. If neater slides are desired, the excess may be cleaned off and the cover glass sealed with Canada balsam around its edge. None of the manipulations just suggested, however, gives a complete insurance against the appearance of air bubbles under the cover glass.

If a quick detection of callose is not essential, Bismark brown and iodine green, without the resorcin blue, are a practical staining combination. The callose remains colorless with this treatment but the connecting strands are deeply stained. Bismark brown and iodine green, followed by mounting in Karo, have been used successfully also on paraffin material (plate 20, $A$ ).

Though the iodine green was employed for differentiating the sieve-tube slime, it also added to the quality of the slides by its effect upon the lignified tissues. Plates $6, B$, and, particularly, $16, A$, illustrate the well-balanced staining of lignified and nonlignified walls that may be attained with these two stains. Bismark brown used without the iodine green leaves the lignified walls too pale (plate $17, A$ ).

Because of their deep staining, the substances usually referred to, in the literature, as tannins detract from the appearance of the black-and-white photographs. Since, however, an excessive denaturing of the material was not desirable in this study, no attempt was made to remove the tannins. These substances were much less conspicuous in sections that were treated only with $\mathrm{I}_{2} \mathrm{KI}$ and aniline blue (plates 13 and 15) than in those that were killed in chrome-acetic-formalin or formalin-acetic-alcohol combinations. (Contrast, for example, plates 13 and 15 with plates 8 and 9 ; the latter illustrate killed sections stained with iodine and aniline blue.) In material that is stained with fast green and safranine, the tannins are usually deep red and can be made less conspicuous in photography by the use of red filters (plates 2 and 3). Such treatment, however, makes the lignified walls less distinct. (Observe the xylem in plates $2, A$ and $B$; and 3.)

The combination of the fast green-safranine staining with a red filter in photography is very satisfactory for showing the early stages in the ontogeny of the primary phloem (plate 2 ).

Most of the photomicrographs were prepared from sections of the Sultanina variety. Plates 8 and 9 were made from the Ohanez variety.

\section{GROSS ANATOMY OF THE AXIS OF THE GRAPEVINE}

To orient the reader regarding the spatial relation of the phloem to the other tissues in the stem and root of Vitis, the axial parts of the latter are briefly described. As was stated in "Material and Methods," samples were taken from stem parts of different ages. At the end of the primary growth, the internode of a current-year shoot or of a seedling stem (plate $4, B$ ) shows the usual structure of a primary stem of a dicotyledonous vine. The stem is ribbed, with the largest vascular bundles appearing beneath the ribs. Later, as the stem undergoes expansion through secondary growth, the ribs disappear. The cortex is differentiated as collenchyma near the surface of the stem. The collenchyma cells have smaller diameters than the rest of the cortical cells and usually form strands, the largest in the region of the ribs. (In plate $4, B$, the collenchyma is rather thin-walled.) One to about four layers of parenchyma 
separate the collenchyma from the epidermis. The cortical cells contain chloroplasts, but these are very small in the collenchyma cells. Many cortical cells have tannins. Starch usually accumulates in the cortical plastids. Strikingly large starch grains develop in the starch sheath, that is, in the cortical layer that touches the vascular bundles (plate $4, A$ ).

On the inside of the cortex is the vascular region that consists of vascular bundles of various sizes, separated from each other by wide multiseriate parenchymatous rays, the primary rays. Since the bundles have a long parallel course (according to D'Arbaumont, 1881a, the leaf traces of Vitis traverse not less than two or three internodes without joining other bundles, and this junction occurs at the nodes), the primary rays also have a long course in longitudinal direction. Thus the primary rays of Vitis are both wide and high. The vascular bundles have caps of primary-phloem fibers on their outer sides (plate 4). Beneath the fibers lies the conducting part of the primary phloem. Then follow cambium, xylem, and pith (plate $4, B$ ). Toward the end of primary growth, cambium occurs in the bundles and in the rays, that is, it consists of the fascicular and interfascicular portions.

Secondary growth causes two changes in the stem structure: an increase in the amount of vascular tissues through the activity of the vascular cambium and a casting-off of the epidermis, cortex, and part of the primary phloem through the activity of the cork cambium. Plate $5, B$, shows a transverse section of a shoot at the end of the first year of growth (that is, a "mature cane" of the viticulturist), in which the secondary growth has largely obscured the primary structure. One important feature remains unchanged after the secondary growth occurs-a feature that characterizes the Vitis stem as a vine typenamely, the division of the vascular cylinder into strands by the wide parenchyma rays. The interfascicular cambium forms parenchyma cells and thus the primary rays are continued as secondary rays within the secondary vascular cylinder. New rays arise from time to time within the fascicular areas. These rays, of course, are not continuous with the primary rays. For convenience, the secondary rays that are continuous with the primary are here referred to as secondary rays of the first order; those that are formed later within the vascular strands themselves, secondary rays of the second order." Both kinds of secondary rays are multiseriate, though the rays of the second order are often narrower than those of the first. Vascular elements cross the secondary rays, usually in an oblique direction, and connect the vascular strands with each other. Tracheary elements or fibers form these connections in the xylem region, sieve tubes or fibers in the phloem region (Strasburger, 1891, p. 242 and 250). A phloem connection of this sort is shown in plate 14, $C$. Because of the constant addition of new rays, the subsequently formed parts of the longitudinal vascular system continue to be separated into narrow blocks as they were when secondary growth began. (Compare plates $5, B$, and $6, B$.)

Though the subepidermal layer in a Vitis stem is as clearly set off from the deeper cortical layers as it is in species that show a subepidermal origin of

7 To differentiate between the secondary rays that arise from initials in the interfascicular regions and those that are formed within the bundles through conversion of fusiform into ray initials, Barghoorn (1940) used the terms "primary ray" and "secondary ray," respectively. Since both kinds of rays are secondary in origin, Barghoorn's terminology is somewhat ambiguous. 
the phellogen (plate 2, $A$ ), and though occasional periclinal divisions occur in this layer, the first cork cambium is regularly initiated in the primary phloem and rays of seedling axes and of shoots on several-year-old vines. This deep position of the first phellogen in certain Vitis species, including $V$. vinifera, is a well known fact in the literature (Solereder, 1908, p. 224). The cortex and some primary phloem-including the primary-phloem fibers-are cut off by the cork and, after their death, form the dead bark ${ }^{8}$ on the surface of the shoot. Plate $5, A$, shows a transverse section of a seedling stem at the stage

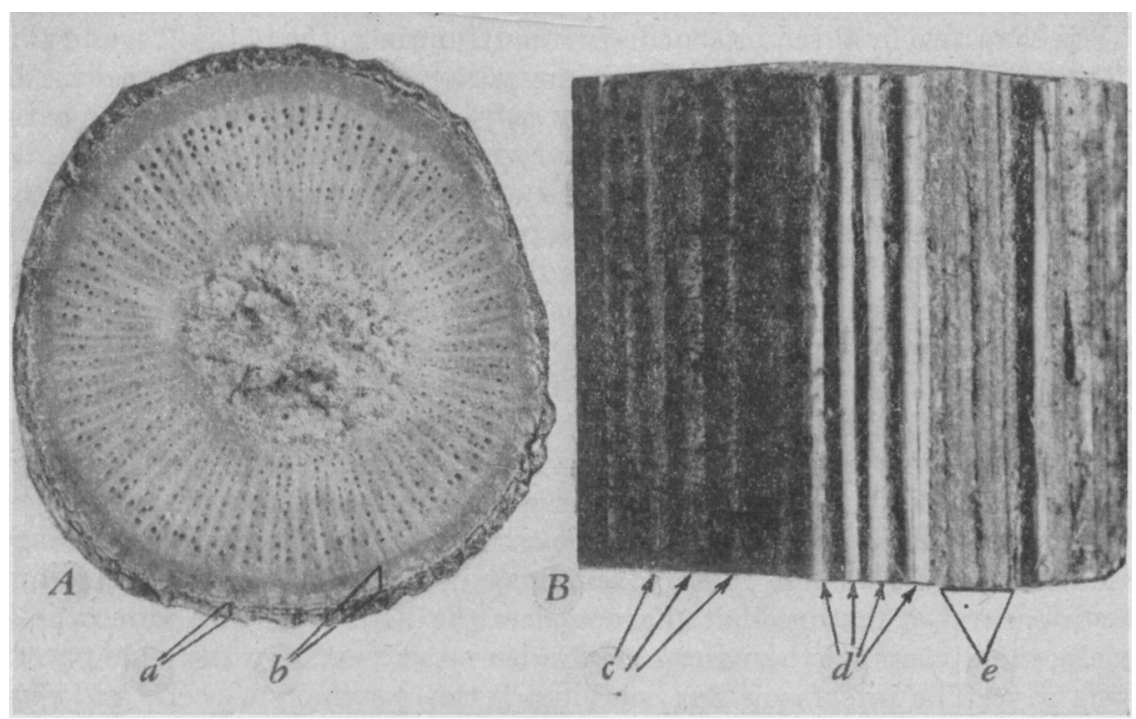

Fig. 1. Transverse $(A)$ and surface $(B)$ views of a cane of the Sultanina variety of the grapevine. Details are: $a$, dead bark consisting of cortex and some primary phloem with fibers; $b$, phloem; $c$, primary-phloem fibers covered by dead cortex (dead bark); $d$, primary-phloem fibers exposed; $e$, first cork exposed by removal of primary-phloem fibers. The ridges are the vascular bundles; the grooves are the rays. (Both $\times 5$.)

when cork has been formed and the cortex has dried up (black layer on the surface of the section). The primary-phloem fibers are visible beneath the dead cortex outside the cork.

When cork is formed in a current-year shoot, the latter becomes the "mature cane." A piece of such a cane is shown in sectional and surface views in figure 1. The dead bark (cortex and primary phloem with fibers) is still attached to the cane. Beneath the dead bark appears the phloem (with cork on its outer side). Most of the latter is secondary in origin. Inside of the phloem is the secondary xylem (the cambium is not detectable at this magnification), and next to the pith is the primary xylem. In the surface view, part of the dead bark is intact (to the left in the photograph). Here the primary-phloem fibers form ribs on the surface (fig. 1, $B$, at $c$ ) because the cortex is collapsed and shrunken. At $d$ the primary-phloem fibers have been exposed by peeling off the dead cortex. At $e$ these fibers and the adjacent dead cells have also been removed and the

8 "Bark" is used here in an old-fashioned way to designate tissues outside the vascular cambium; "dead bark" refers only to the tissues that have been cut off by the cork cambium. 
cork is exposed. The surface at $e$ corresponds to that which forms the outermost layer (cork) in plate $5, B$. The latter illustration shows that, when the dead bark is removed, the surface of a mature cane is slightly undulate. The surface of the blocks containing the xylem and phloem of the longitudinal system is convex, that of the rays is concave. The undulations appear also in figure $1, B$, at $e$, where the vascular blocks form the raised strips and the rays occur in the grooves between the strips.

New layers of cork are formed more or less regularly each season around the circumference of the stem so that a "ring bark" is formed (Solereder, 1908, p. 224). Thus every year the vascular cambium adds new phloem, but since the cork cambium cuts off some of the old phloem, the bark remains relatively thin while the wood becomes thicker from year to year. This is shown for a three-year-old branch in plate $6, B$.

In the present study the root was considered in less detail than the stem. The root samples were taken rather infrequently (see "Material and Methods") and consisted of portions of lateral roots that were several years old. No roots in primary state were studied. According to Penzig (1882), the primary-root xylem is diarch or triarch. Secondary growth later produces a solid wood core traversed by many wide rays (plate $6, A$ ). The rays are multiseriate and many are wider than those in the stem. (Compare $A$ and $B$ in plate 6. )

As in most woody roots, the phellogen in the root of Vitis arises beneath the endodermis and causes the sloughing off of the cortex. Kroemer (1906) and Szigethi-Gyula (1905) regarded the pericycle, Penzig (1882) the phloem as the place of origin of the first phellogen. Probably both situations occur. In plate 6, $A$, in the lower left-hand part of the section, pericyclic cells appear outside the phloem; this indicates that the cork cambium did not arise in the phloem in this part of the section. In subsequent years cork formation in the root must be rather irregular as compared with the same activity in the stem : the root bark usually appears more uneven and considerably thicker than that of a stem of simliar age. (Compare $A$ and $B$ in plate 6 .)

\section{STRUCTURE OF THE PHLOEM}

Primary Phloem. The first sieve tubes appear in an internode that has not yet elongated. In transverse sections these sieve tubes are easily distinguished by their somewhat thick, deeply staining walls (plate $2, A$ ). The first sieve tube of a given procambial bundle differentiates before the first xylem element of the same bundle (plate 2, $A$, bundle to the left). During the initial stages of phloem development the procambial bundle shows active divisions in the phloem region, with new walls being laid down concentrically about the first sieve tube (plate $2, A$, bundle to the left). The xylem region appears somewhat less dense than the phloem region; also the cells there are mostly of larger diameters, and early show radial seriation in their arrangement. Thus in the bundle to the right in plate $2, A$, several radial files of cells appear in the xylem end of the bundle and the first xylem element $(x)$ occurs at one end of the median of these files.

Concentric divisions continue in the phloem until many sieve tubes differentiate. The further addition of phloem cells occurs by tangential divisions in that part of the procambium located between the xylem and the phloem. The 
bundle in plate $2, B$, shows the stage of development when the last evidence of concentric. divisions appears on the flanks of the phloem, and when the most abundant divisions occur on the inner margin of this tissue. Most of the latter divisions occur in tangential planes but are not restricted to one layer of cells. When the procambium is converted into cambium, at the end of primary growth, the periclinal divisions become restricted to a narrow zone and give rise to cells in both directions, toward the xylem and toward the phloem (plate 3 ). Thus the transition from the concentric arrangement of cells to the radial seriation occurs gradually. Though a sharp line of demarcation cannot be drawn between the protophloem and metaphloem, the first part of the phloem that arises mainly by concentric cell divisions (plate $2, A$ and $B$ ) can be conveniently interpreted as protophloem. This part of the primary phloem is most affected by the elongation of the axis and is profoundly modified at the end of this elongation.

The behavior of the sieve tubes is characteristic of protophloem sieve tubes; they function for a short time, are crushed by the adjacent cells, and, finally, are completely obliterated. Plate $2, B$, shows several stages of this obliteration. Companion cells seem to be lacking, at least in the earliest part of the.protophloem. The cells surrounding the sieve tubes in this tissue appear at first as elongated parenchyma cells, some with tannins in their protoplasts. After the sieve tubes are obliterated, the elongated cells differentiate into septate fibers. As is typical of primary-phloem fibers, these cells, before they mature, become many times longer than originally. They grow longer in part by keeping pace with the elongation of the internode, in part by apical intrusive growth. Because of the latter mode of elongation, the ends of the fibers are much pointed and the cells overlap each other. The elongation is accompanied by a lateral expansion. During this active growth, the future fibers appear as very thinwalled, highly vacuolated cells (plate $2, C$ ), some of which show dense accumulations of tannins.

After the elongation is completed, the cells lacking tannins develop secondary walls. Some of the tannin-containing cells do not develop thick walls and are more or less crushed by the expanding fibers; others develop into fibers, though often with a delayed formation of secondary walls. Usually, in the end, the mature fibers form solid strands of sclerenchyma tissue with uniformly thickened walls (plates 3 and 4). A fiber cell does not become multinucleate, but in mature state it has thin septa that divide the cell into several compartments, each with a separate nucleus. The protoplasts remain alive until the fibers are cut off by the cork.

As was stated in a preceding part of this paper, cortical cells with large starch grains-the starch sheath-occur on the outside of the sclerenchyma strands (plate 4, A). Usually the starch sheath is limited to the vicinity of the fibers, being absent opposite the rays.

The metaphloem that develops centripetally from the protophloem, through tangential divisions in the procambium, consists of sieve tubes, companion cells, and phloem parenchyma. No fibers occur in this tissue. Many of the parenchyma cells contain tannins. Some of the tannin cells are very wide and long (note the large cells in the metap'aloem in plates $2, C$, and 3 ) and are called, by Strasburger (1891, p. 252), "sac-like parenchyma cells, rich in tannins." 
The sieve-tube elements of the primary phloem have transverse or slightly inclined end walls bearing simple sieve plates. The first mature sieve tubes of the protophloem have extremely short elements, the later ones successively longer units. In addition to the sieve plates, the primary sieve tubes, at least those of the metaphloem, have many sieve areas on the longitudinal walls. The usual callus formations occur on these sieve areas and on the sieve plates, and definitive callus is deposited before the sieve tubes are obliterated. Though the walls of the primary sieve tubes are relatively thick, they are less massive than those of the similar elements in many other plant species (Esau, 1939; Schneider, 1945). All primary sieve tubes have slime bodies in their early stages of differentiation and are enucleate at maturity (Esau, 1947).

The first cork cambium is initiated in the primary phloem (metaphloem) just inside of the fibrous strands. The sieve tubes and companion cells are obliterated and the remaining parenchyma cells divide periclinally (plate 3 ). Such divisions extend also into the interfascicular (ray) areas, but there the cells involved in cork formation lie very near or even next to those initiating the interfascicular cambium (plate $3, B$ ). The cork cambium therefore appears to dip in the region of the rays-a feature that is later reflected in the undulate-appearing surface of a mature cane (fig. $1, B$, at $e$; plate $5, B$ ).

The periclinal divisions concerned with the initiation of the cork are repeated in the successive products of the initial cell, so that a radial file of cells is formed, in which the outer and inner faces of the original cell may be recognized. (Compare $A$ and $B$ in plate 3.) The youngest cells in such a file occur one or two cells outside the inner limit of the file (plate $3, B$ ). These young cells could be termed "cork cambium," but their activity is very limited. The fully formed cork consists of only a few layers of cells (plate 15, D). Once these are formed, cell divisions cease, the cork matures and without further change serves as a protective layer until the end of the next growth season. Then a new cork layer appears in the secondary phloem (plate 19, $C$ ). Sometimes, before the new cork arises, the cells immediately beneath the old cork greatly extend radially and divide tangentially (plate 19, $C$, above), but this activity leads to no cork formation since it is interrupted by the development of the deeper-seated cork (plate 19, $C$, below).

The cork cells in the ray region are crowded and compressed and their masses are deeply stained with tannins. These cells give the dark-brown color to the grooves on the surface of a cane (plate $5, B$ ).

Whether the cells lying in the path of the originating cork contain starch alone or starch and tannins, they are equally active in the formation of cork (plate $3, A$ ) and the starch disappears only gradually in the dividing cells. Before the cork matures, the cells outside of it lose starch, but retain the tannins and crystals. According to Strasburger (1891, p. 251), the tannins later impregnate the cell walls and give the dead bark its brown appearance.

As was mentioned in an earlier section of this paper, the primary-phloem fibers, the cortex, and the epidermis are sloughed off through cork formation (plate 5). Sometimes the first cork arises partly in the secondary phloem, and then some secondary-phloem fibers may be cast off together with the primary. (See also Gard, 1900.) Occasionally, in seedlings, cork initiation was observed in the innermost cortex, that is, outside the primary-phloem fibers. 
The metaphloem sieve tubes are obliterated during the first season. The tissue beneath the cork then constitutes the nonconducting (nonfunctioning) phloem, which is composed of intact phloem-parenchyma cells and of crushed sieve tubes and companion cells (plate $15, D)$. Thus a mature cane has no primary phloem in function.

Secondary Phloem. The secondary phloem consists of blocks of tissue of the longitudinal system alternating radially with wide phloem rays, that is, with the blocks of tissue of the transverse system (plate $7, A$ ). The longitudinal system consists of two distinct kinds of cell complexes arranged in tangential bands : the bands of fibers and the bands containing sieve tubes, companion cells, and phloem parenchyma. The transverse system is made up of rays of two orders : the rays of the first order-secondary rays that are continuous with the primary rays; and rays of the second order-secondary rays arising in the fascicular areas as the stem increases in circumference. (See also "Gross Anatomy of the Axis of the Grapevine," page 224.) Both kinds of rays are several cells in width, but the rays of the first order exceed those of the second in height. Their cell structures are similar.

The secondary-phloem fibers have moderately thick secondary walls and are septate. (Penzig, 1882, reported that septate and nonseptate fibers occur in Vitis in about equal amounts.) In Hypericum (Vestal and Vestal, 1940), the septa arise after the secondary thickenings are formed on longitudinal walls and become attached to these thickenings. D'Arbaumont (1881b) found, in his studies of different species of Vitis, that septa may be formed rather early in the pholem fibers, and that the secondary thickening may or may not continue after the septa are formed. In the present study no exhausitve search for stages in septum development was attempted, but evidence of their late origin was encountered in the xylem. The pits of the secondary-phloem fibers are bordered. They have slitlike openings and an enlarged pit cavity at the pit-closing membrane. (See also Hill, 1908.)

The secondary fibers undergo some apical intrusive growth but remain markedly shorter than the primary-phloem fibers. They occur in tangential bands that are several cells thick and reach from ray to ray. The cells are arranged in radial rows (plates $7, A ; 8 ; 9, B ; 11, A ; 14, A$ and $B ; 15, D ; 19, A$, $C$, and $D$ ). Sometimes the band is much narrower on one side than on the other; or it does not reach across the entire block of the longitudinal system and is made up partly of fibers and partly of thick-walled parenchyma cells.

The septate fibers are living cells and have a nucleus in each compartment. They remain alive until they are removed by cork formation; and they store starch at certain times of the year. (See also Wilhelm, 1880, and Strasburger, 1891, p. 247-48.)

The tangential bands containing the sieve tubes and the parenchymatous members of the longitudinal system are here referred to as sieve-tube bands for convenience. In transverse sections the sieve tubes are usually distinguished by their relatively large size (plate $7, A ; 8, A ; 10 ; 11 ; 14, A$ and $B$; $16, A)$. Since, however, the ends of most sieve-tube elements are tapering, some of the small cells in a given section may be sieve-tube elements. The smallest cells, which have dense protoplasts, are companion cells. The phloemparenchyma cells are of intermediate sizes, and some contain tannins (plate $11, A)$. 
The sieve-tube elements vary in shape and size (fig. $2, A-F$ and $L-P$ ). They are derived from fusiform cambial cells (plate 16, $B$ ), which develop into sieve-tube elements (and their companion cells) either directly or after one or two transverse divisions. The resulting sieve-tube elements are, therefore, either fusiform, with both end walls tapering; or they have transverse walls on

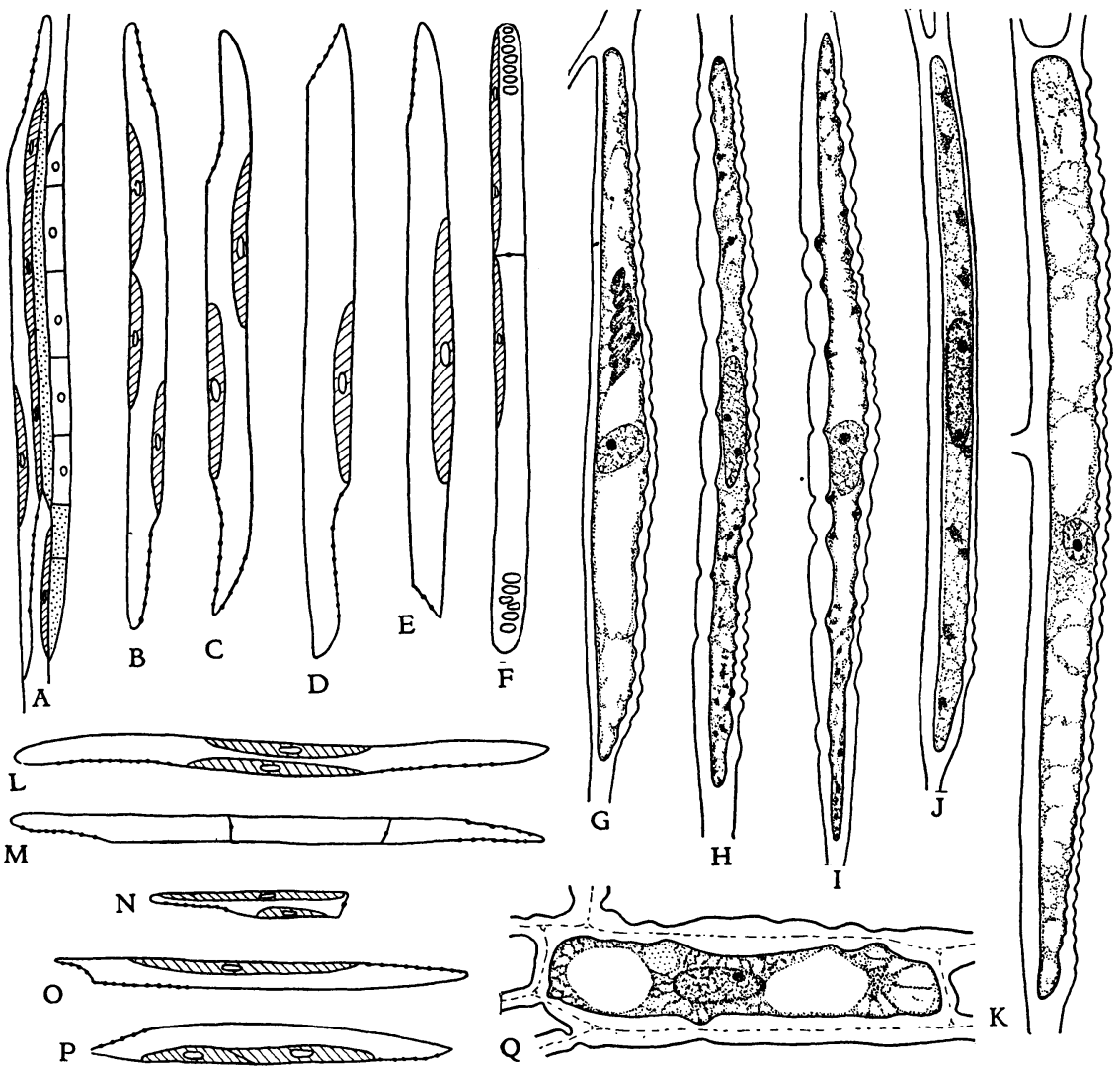

Fig. 2. Longitudinal sections of various phloem cells. $A-F$ and $L-P$, Outlines of sieve-tube elements and companion cells (singly hatched). $A$ shows also some phloem-parenchyma cells. Among these, the cells with tannins are indicated by stippling and the tannin-free cells by outlines of nuclei. $F$ illustrates two sieve-tube elements in radial view with two sieve plates in face view. All the other drawings in this series $(A-E$ and $L-P)$ are from tangential sections and show the sieve plates (beaded parts of walls) in sectional views. $G-K$, Companion cells. Each of these had the associated sieve-tube element to its right. The youngest companion cell, which contains a slime body (above the nucleus), appears in $G$. $H$ and $I$ are from fully differentiated, $J$ from dormant, and $K$ from reactivated phloem. The tannin-free phloem-parenchyma cell in $Q$ is from dormant phloem. ( $A-F$ and $L-P \times 100 ; G-I$ and $K$ $\times 780 ; \bar{J}$ and $Q \times 850$.

one or both ends. The first type predominates in the secondary phloem. Figure 2 gives examples of the two kinds of cells. Each sieve-tube element in figure 2, $A$ to $E, L, O$, and $P$, was derived from one entire fusiform cell. In contrast, one fusiform cell gave rise to two sieve-tube elements in figure $2, F$, and to three elements in figure $2, M$. The short cell in figure $2, N$, is obviously a part 
of a fusiform cell. As is characteristic of cambial cells of woody species, the tapering ends of the fusiform initials in Vitis are wedge-shaped. The narrow side of the wedge is in view in tangential sections (fig. 2, $A-E$, and $L-P$; plate $7, B$ ), the wide side in radial sections (fig. $2, F$; plate $9, A$ ). No apical intrusive growth appears to take place in the formation of sieve-tube elements and the ends of the elements derived from the same part of the cambium occur at nearly the same level (plates $9, A ; 14, A$ and $B$ ).

The companion cells are short cells with pointed ends. Each sieve-tube element has one to several (the maximum is five, according to Wilhelm, 1880). These cells in Vitis have a historic interest since it was for them that the term "companion cell" was coined (Wilhelm, 1880, p. 4). Being much shorter than the sieve-tube elements with which they are associated, the companion cells do not appear in every transverse section of a given sieve-tube element. Their arrangement varies much in individual elements (fig. $2, A-F$, and $L-P$ ). The companion cells of a given sieve-tube element may be either touching, or more or less removed from one another.

Like the primary elements, the secondary sieve-tube members are enucleate when mature and have slime bodies when immature (plate 20,B). Slime bodies also occur in the young companion cells, a feature apparently not yet recorded for any other plant (fig. 2, $G$; see also Esau, 1947).

Most of the phloem-parenchyma cells arise from fusiform cells that are divided several times by transverse walls. Therefore, the parenchyma cells appear as relatively short cells arranged in longitudinal files (plates $7, B$, and $13, A)$. An undivided fusiform cell, or a large part of one, also may differentiate into parenchyma cells (fig. 2, $A$ ). Many phloem-parenchyma cells contain tannins, which cause the darkening of the protoplasts in fixed sections (plates $7,8,9,11, A$, and others). At certain times during the year, abundant starch is present in the phloem-parenchyma cells ; and this starch may occur together with the tannins.

The sieve tubes are arranged in radial rows (plate $14, A$ and $B$ ) or are intermingled with phloem-parenchyma cells (plate $8, A$ ). The companion cells are usually cut off from a sieve-tube element by a wall that occupies a position intermediate between radial and tangential (plates $11, A ; 17, A$ and $D$; and $18, C)$. Occasionally a truly radial wall separates the companion cell from the sieve-tube element.

Parenchyma cells commonly occur between the sieve tubes and the rays (plate $7, B)$. According to Wilhelm $(1880$, p. 5), some of these parenchyma cells are subdivided into small cells containing rhombohedral crystals like those in the marginal ray cells. Occasionally sieve tubes touch the ray cells. Parenchyma cells intervene also between the sieve tubes and the fibers (plate $10, A)$, though sometimes the two latter kinds of elements are in contact with each other (plate 10,B, sieve tube to the left, below).

The secondary-phloem rays consist of parenchyma cells. In radial and transverse sections the latter appear as rectangles, slightly elongated radially (plate $7, A$, to the right), whereas in tangential sections their outlines are rounded (plates $14, C$, and $16, B$ ). If the bark attains considerable thickness, its outer portions undergo dilation-a process that involves only the rays. In this dilation the ray cells stretch tangentially and divide by radial walls. Thus 
their original shape is modified : instead of being radially elongated in transverse sections of the bark, the ray cells now are tangentially elongated or isodiametric in such sections. In plate $7, A$, the ray cells to the right of $a$ (in the functioning part of the phloem) have their original shape; to the left of $a$ (in the nonfunctioning part of the phloem) they have been subjected to dilation. The ray cells contain tannins or starch (at certain times of the year) or both. The tannins appear in the cells very close to the cambium or are present in the cambial cells themselves (plates $16, A$, and $18, B$ ). Starch occurs also in the cambial ray initials, but only during dormancy. The marginal ray cells commonly become subdivided into smaller cells, each of which develops a rhombohedral crystal (plate $7, B$, at $b$ ). The cells containing these crystals do not lose their protoplasts, but the crystal itself becomes imbedded in wall substance that is partly attached to the cell wall (plate $14, D$; see also Wilhelm, 1880 , p. 5). According to Wilhelm (1880), druses may be found occasionally in these cells. When the rest of the ray cells have starch, the crystal-containing cells also form starch. Certain cells within the ray itself develop raphides. These crystals arise in undivided cells near the cambium (plate 18, $B$, at $r$ ). The protoplasts of the raphide-containing cells do not store starch and eventually become disorganized. The crystals then remain imbedded in a mucilagelike substance. The cells with raphides may be rather large and thick-walled. The occurrence of sieve tubes traversing the rays (plate 14, $C$ ) has been mentioned in a preceding part of this paper. The elements of these sieve tubes are very short because they arise from the same kind of cells as the rays, but they have companion cells and in their ontogeny pass through the same stages as the sieve tubes of the longitudinal system.

As stated in the beginning of this section, the sieve tubes are usually the largest cells in a given cross section. Certain parts of the phloem, however, contain sieve tubes that appear very small in transverse sections (plate $8, A$, at $a$ ). These parts are formed at the end of a growth period. The late-season sieve tubes and the associated cells sharply contrast, by their short radial diameters, with the sieve tubes that are formed earlier in the season and also with those that arise in the beginning of the next growth period. If more than one annual increment of phloem occurs in a given sample of the bark, the small-celled bands serve as a demarcation between the increments. Sometimes the ray cells too are somewhat smaller in the late-season phloem. In plate $7, A$, and $8, A$, the small-celled phloem at $a$ divides the 1944 and 1945 phloem increments ; plate 15, $C$, contrasts the small-celled late phloem with the large-celled early phloem in plate $15, A$; and plate $16, A$, shows that though the separation of the annual increments in the phloem (at $a$ ) is quite distinct, it is less sharp than the demarcation between the annual rings in the xylem (at $b$ ).

Walls of Sieve Tubes. Although the structure and development of the sieve plates and related structures in Vitis have been described in the literature (Wilhelm, 1880; Hill, 1908), they were reconsidered in the present study so as to assure a sound basis for recognizing any existing differences between the newly formed and the reactivated phloem.

Most of the sieve plates are borne on the end walls of the sieve-tube elements (fig. $2, A-F$, and $L-P$; plates $7, B ; 9, A$; and $13, A$ ), but some occur on the longitudinal walls. Transverse end walls of short diameters usually bear 
simple ${ }^{\theta}$ sieve plates; others have compound ones. The sieve areas on the end walls (plates 11, $C$, and 12, $C$ ) lie closer to each other than do those of the sieve plates on the longitudinal walls (plates $11, B$, and $12, D$ ). The sieve plates on the inclined end walls appear in sectional views in the tangential sections of the phloem (plates $7, B$, and $13, A$ ), and in face views in the radial sections of the tissue (plate $9, A$ ). The sieve plates of the longitudinal walls are not limited to the radial walls.

Sieve areas less highly differentiated than those of the sieve plates occur on longitudinal walls between sieve-tube elements. In the literature on phloem such sieve areas are often called "sieve fields," in conformity with the terminology introduced by Nägeli (1861). (See also review by Esau, 1939.) Since the two kinds of sieve areas differ only in the degree of specialization and may be connected with each other by transitional structures, designating them by different terms seems unnecessary. Both may be called sieve areas, or, synonymously, sieve fields. (See also Cheadle and Whitford, 1941.) To specify the reference to the two kinds of structures in this paper, the sieve areas of the sieve plates are called sieve areas of type $A$ or sieve areas $A$, and those on the longitudinal walls (excluding the sieve plates on these walls) sieve areas of type $B$ or sieve areas $B$. The two types of sieve areas are not so well separated in Vitis as in some other plants (Esau, 1939). Nevertheless, the sieve areas A have obviously thicker connecting strands and are associated with larger masses of callus than the sieve areas B. (Compare the sieve areas $A$ in figures 3 and 4 and plates $1, B$, and $13, B$, with sieve areas $B$ in figure 4 and plates 1 , $C ; 13, C$ and $D$.) The cytoplasm of the sieve tube is more firmly attached to a sieve area $A$ than to one of the other type. Sometimes a series of sieve areas of a sieve plate merge with a series of sieve areas of type B (fig. $4, G$, and $6, B$, to the left), or the two are intermingled (fig. $4, H$ ).

Hill (1908) stressed the occurrence of "median nodes" (interpreted as swellings of the middle lamella under the influence of ferments) in sieve areas of type B (fig. $4, D$ ) and their absence in sieve plates. He concluded, nevertheless, that this was not a fundamental difference and that a sieve area $B$ might become converted into a sieve area A through subsequent enlargement of connecting strands and the concomitant disappearance of the median nodes. In the present study the median nodes of the sieve areas B were observed in some preparations (fig. $4, D$ ) and not in others (fig. 4, $E$ and $F$ ).

The sieve areas of the sieve plates develop from the primary pit fields of the cambial walls (fig. $3, A$ and $C$ ). Occasionally plasmodesmata survive the handling of material and are seen traversing the pit-closing membranes of the future sieve plate (fig. $3, B$ ). The number of the plasmodesmata in the pit fields corresponds to the.number of connecting strands in the sieve areas of a sieve plate. This relation implies that each plasmodesma becomes one connecting strand of a sieve plate.

As the sieve plate develops, its wall thickens. Though the pit-closing mem-

- The terminology used here with reference to the sieve plates and similar structures agrees with that published by Cheadle and Whitford (1941). According to this terminology, the pores with connecting strands are clustered in the sieve areas on the sieve-tube walls. The highly specialized sieve areas (that is, those having relatively large connecting strands) form the sieve plates. The sieve plate is simple if it consists of one sieve area, compound if it is made up of more than one sieve area. 
branes increase in thickness, the portions between the pit fields thicken even more, so that in older walls the pit fields become more conspicuous (fig. 3, $D-F)$. The thickening of the pit-closing membrane causes the extension of the plasmodesmata (fig. 3, $F$ ) and is associated with the first appearance of callose (fig. $3, D$ and $E$ ). Sometimes an original pit field becomes subdivided into smaller ones by an additional thickening of a part of the pit-closing membrane (fig. $3, \boldsymbol{F}$, second pit field from below).

As has been often described in the literature (Esau, 1939), the callose appears first around each connecting strand on both sides of the pit-closing membrane (fig. 3, $M$ ). Later the two portions of callose on the two sides of the closing membrane become confluent. The callus is now said to form cylinders, each enclosing a connecting strand (fig. $3, P$ ). The cylindrical shape of the calloused portion is soon obscured by the lateral spread of callose near the surface of the wall, but a deeper part of the original wall, between the strands, remains unmodified (fig. $3, \boldsymbol{O}$ ). Though sometimes the limits of the calloused areas are very sharp (fig. 3, $O$ ), they also may appear blurred, and the blue color, imparted to the callose by the aniline blue, may fade out toward the uncalloused portions of the cellulose wall (plate $3, N$ ). This observation indicates that callose partly impregnates the cellulose of the sieve-area wall. A substitution of cellulose by callose probably occurs also: when callus disappears in nonfunctioning sieve tubes, the plate exposes pores of as wide diameters as those of the original callus cylinders. Callose does not remain limited to the callus cylinders but is deposited also on the surface of the sievearea wall, which therefore becomes considerably thickened (fig. 3, $G$ and $H$ ) and eventually the sieve areas cease to be the thin portions of the wall. After the definitive, or dormancy calli develop, the sieve areas are thicker than the intervening portions of the sieve plate (fig. $6, C$; plate $13, B$ ).

While callus appears, the connecting strands of the sieve areas become thicker and their chromaticity increases (fig. 3, $G$ and $H$ ). This change occurs rather abruptly. A comparison of the various parts of the differentiating phloem shows that in the youngest phloem located next to the cambium the connecting strands are hardly visible; outwardly this part of the tissue is succeeded immediately by phloem in which the connecting strands are clearly discernible and are not easily destroyed by various treatments. This change in the appearance of the connecting strands coincides with definite changes in the sieve-tube protoplasts, changes involving the dispersion of slime bodies and the breakdown of nuclei. While the slime bodies and nucleus are intact in a sieve-tube element (plate $20, B$ ), the connecting strands are of the nature of plasmodesmata. These strands remain difficult to demonstrate while the slime bodies are spreading out in the initial stages of their dispersion (fig. 6 , $A)$. Then, after the incorporation of the slime bodies into the vacuolar contents of the sieve tube-and the concomitant breakdown of the nucleus-the connecting strands suddenly become prominent. As has often been recorded in the literature (Esau, 1939), sieve tubes cut after this stage of development have the slime in dense accumulations on the sieve plates, and the connecting strands passing through these plates appear to be made up of slime (plate 12, $A$ and $B ; 20, C)$.

The sieve areas of the sieve plate seem to follow two developmental patterns. 


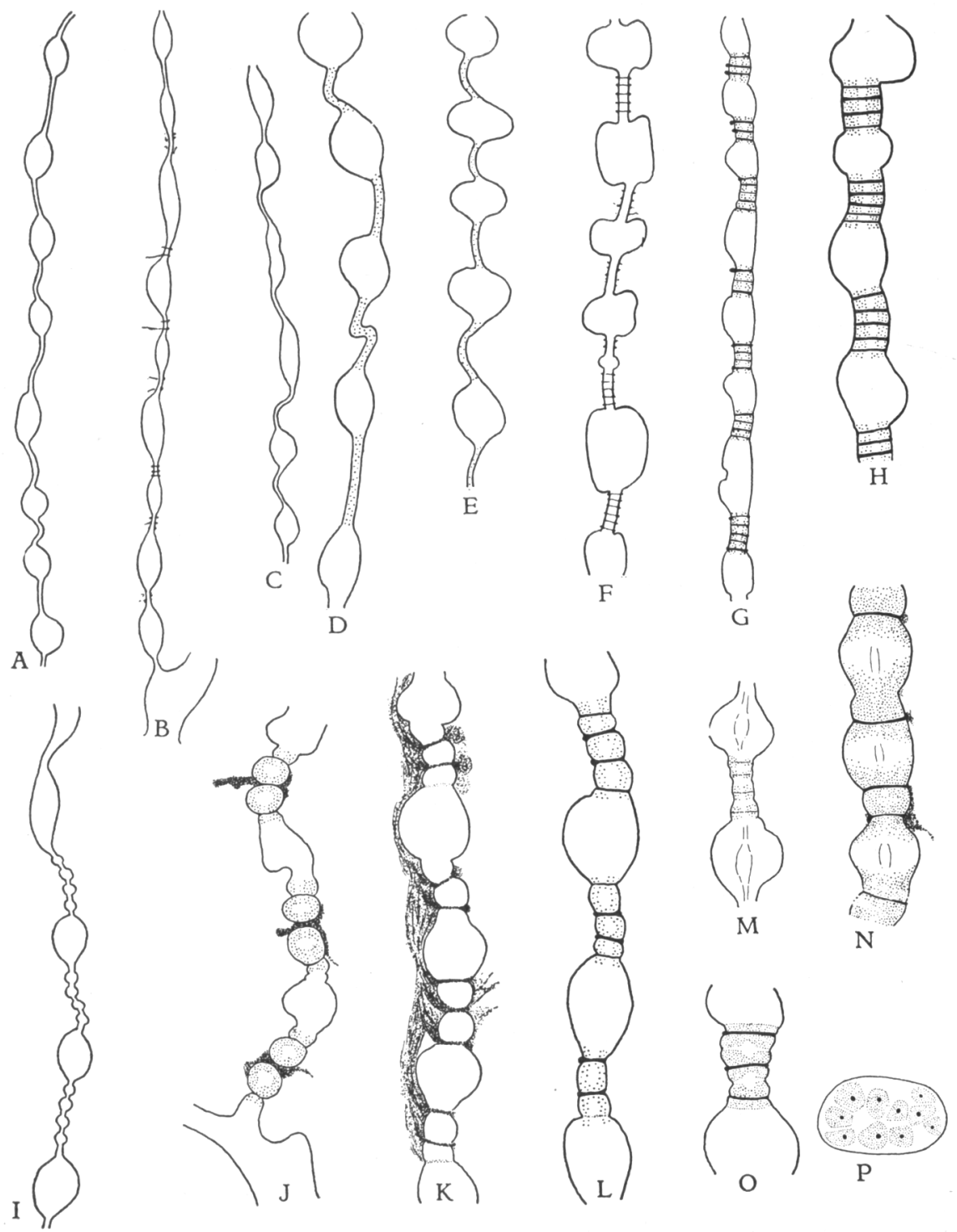

Fig. 3. Longitudinal ( $A-O)$ and transverse $(P)$ sections of sieve-tube walls (sieve plates) bearing sieve areas of type $\mathrm{A}$ in various stages of differentiation. $A-F$ and $I$ are from immature sieve tubes, the others from mature ones. The calloused areas are stippled in $D, E, G$, $H, J$, and $L-P$. $A-C$, Young walls with callus-free pit fields. $D-F$, Sieve plates at the stage when callus is detectable in the pit fields. In $B$ and $F$ plasmodesmata are shown in some pit fields. $G$ and $H$, Sieve plates (with connecting strands and callus) that were apparently derived from the type of walls shown in $A-F$. I, Young sieve plate in which the pit fields of the first order are subdivided into pit fields of second order. $J-L$, Sieve plates that apparently were derived from a type of wall as in $I . M-P$, Sieve areas showing details of the spatial relation between connecting strands and callus. ( $A$ and $G \times 875 ; B-F$ and $H-P \times 1320$.) 
In one the sieve area arises through a transformation of a primary pit field in the manner described above; that is, a pit field becomes converted into a sieve area, with the pit-closing membrane thickening uniformly (fig. $3, C ; D, G$, and $H$ ), except when the sieve area becomes subdivided into smaller units (fig. 3, $F)$. In the other type the primary pit area shows thickenings between every two plasmodesmata, so that, in sectional views, a beaded appearance is noticeable not only in the entire compound sieve plate but in the pit-closing membrane as well. The latter is much more delicately beaded than the former (fig. $3, I)$. The sieve plates derived from such doubly pitted walls have rather widely spaced connecting strands (fig. $3, J-L$ ) and these probably attain greater thickness than the strands formed in singly pitted walls. Hill (1908) must have been referring to the same developmental difference when he said that in some sieve plates, as seen in sectional views, one strand occurs in each sieve area, in the other, four to five. The area between two small thickenings (fig. $3, I$ ) he evidently termed one sieve area.

The existence of the differences, just mentioned, in the development of the sieve plates justifies combining the sieve areas of the longitudinal walls (sieve areas B) and the sieve areas of the sieve plates (sieve areas A) under one term, sieve areas. Though the sieve areas $\mathrm{B}$ are less specialized than the sieve areas A, the latter too vary among themselves in the degree of differentiation.

The sieve areas of type B pass through visible stages of development similar to those of sieve areas A. Each sieve area arises from a primary pit field of a cambial wall (fig. $4, A$ ). If plasmodesmata are distinguishable in the differentiating walls (fig. $4, B$ and $C$ ), their number in the pit areas corresponds to the number of strands in the sieve areas (fig. $4, D, E$, and $F$ ). During its ontogeny, a given sieve area may become subdivided into smaller units by wall thickenings arising later and not attaining the same thickness as the wall parts separating the original primary pit fields (fig. 4 , I, wall to the right). Though at first each connecting strand has its own callus cylinder (fig. $4, D)$, later the callus formations of one sieve area merge and the same material becomes deposited on the surface of the wall also (fig. $4, E$ and $F$ ). In surface views, sieve areas B (fig. $4, I$ and $J$; plate $13, C$ and $D$ ) vary in shape and size much more than sieve areas $\mathrm{A}$ (fig. $3, P$, and plate $12, C$ and $D$ ).

Walls of Cells Associated with the Sieve Tubes. Sieve areas of type B occur, but rather infrequently, on walls that separate the sieve-tube element from a phloem-parenchyma cell. As is well known in the phloem literature (Esau, 1939), such walls show sieve areas only on the sieve-tube side (fig. $5, G-I$ ), whereas an ordinary pit, ${ }^{10}$ at the most, occurs on the parenchyma side. In the sieve-tube wall the connecting strands are associated with callus and are as

\footnotetext{
${ }^{10}$ According to the Committee on Nomenclature (1933), pit designates a recess in a secondary wall only, and primary pit field a thin area of the primary wall and intercellular material. However, in the present paper pit serves to identify a depression either in a primary or a secondary wall, whereas primary pit field is used in reference to walls in the cambium and to the cambium's immediate derivatives. The adoption of a strict distinction between the terms primary pit field and pit would require an equally aceurate differentiation between primary and secondary walls. The precise identification of the nature of walls is often beyond the scope of an anatomical study (or of a classroom exercise). In such a circumstance the investigator (or the teacher) is left without a term for the thin areas in the walls. If pit were to be used for these areas without regard to the nature of the wall (as is done in the present paper), primary pit and secondary pit could be employed whenever a precise distinction between primary and secondary walls is essential.
} 
conspicuous as in the sieve areas B located between sieve-tube elements, whereas in the part of the wall that belongs to the parenchyma cell the connecting strands are like plasmodesmata and are difficult to demonstrate. A sieve area on the sieve-tube side does not necessarily have a clearly defined pit opposing it in the parenchyma-cell wall (fig. 5, $G-I$ ), though, presumably, plasmodesmata occur in the latter. (See Hill, 1908.) On the other hand,
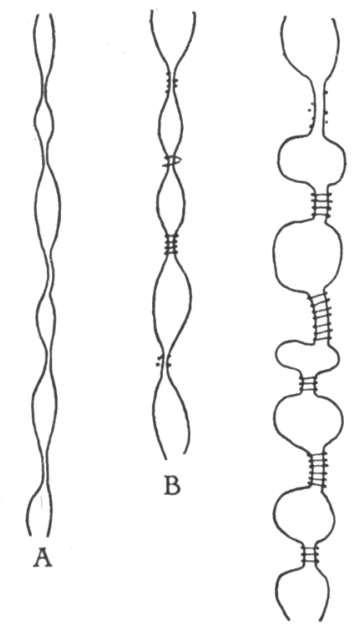

C
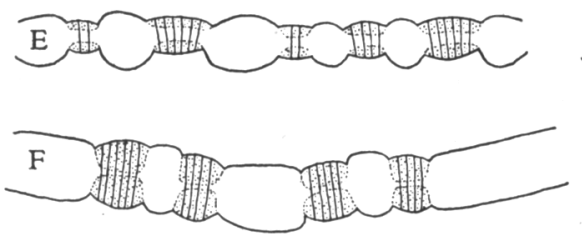
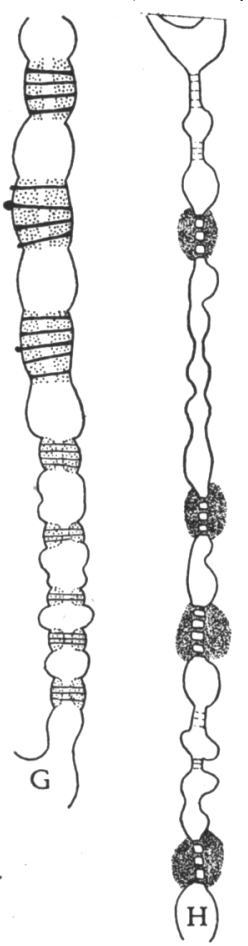
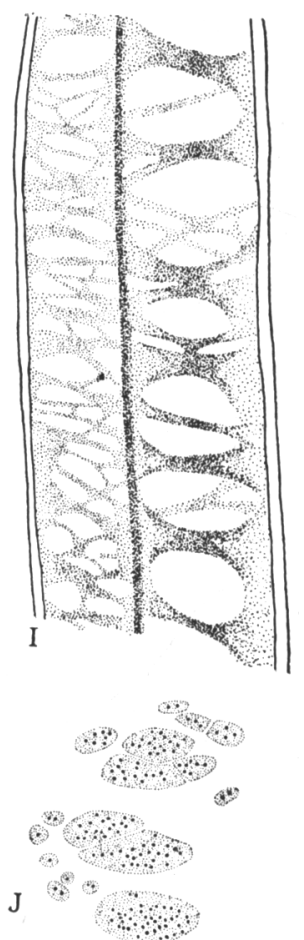

Fig. 4. Sectional $(A-H)$ and face $(I$ and $J)$ views of sieve-tube walls bearing sieve areas of type $B$. Stippling indicates the calloused parts in $G, E, F$, and $J$, the slime accumulations in $H$. $A$ and $B$, Young walls with pit fields. (Plasmodesmata are shown in $B$.) $C$, Partly differentiated sieve areas with conspicuous plasmodesmata. In $D$ the wall is markedly thickened and the connecting strands are associated with callus. (The two are not differentiated from each other in the drawing.) $E$ and $F$, Two advanced stages in the development of sieve areas. $G$ and $H$, Walls bearing two types of sieve areas, A (thick connecting strands) and $B$ (thin connecting strands). I, Sieve-tube wall with pitting between the sieve tube and a companion cell, to the left, and pitting between two sieve tubes (sieve areas $\mathrm{B}$ ), to the right. The stippled areas are the thick portions of the wall, the unstippled are the depressed portions (pits or sieve areas). $J$, Sieve areas B with callus (stippled parts) and connecting strands (large dots in stippled parts). $E$ and $J$ show sieve areas in similar stages of development. ( $A-F$ and $J \times 1245 ; G-I \times 825$.)

parenchyma walls with deep depressions may be associated with perfectly smooth sieve-tube walls (fig. $5, N$, below); or the latter may show only slight indentations without any connecting strands (fig. $5, O$, above). If the sievetube element and a parenchyma cell are connected by a sieve area-pit complex, callus accumulates only on the sieve-tube side (fig. 5, I). These unilateral deposits of callose are particularly striking in dormant phloem and they appear to be formed even in wall parts where no pits or sieve areas can be ex- 


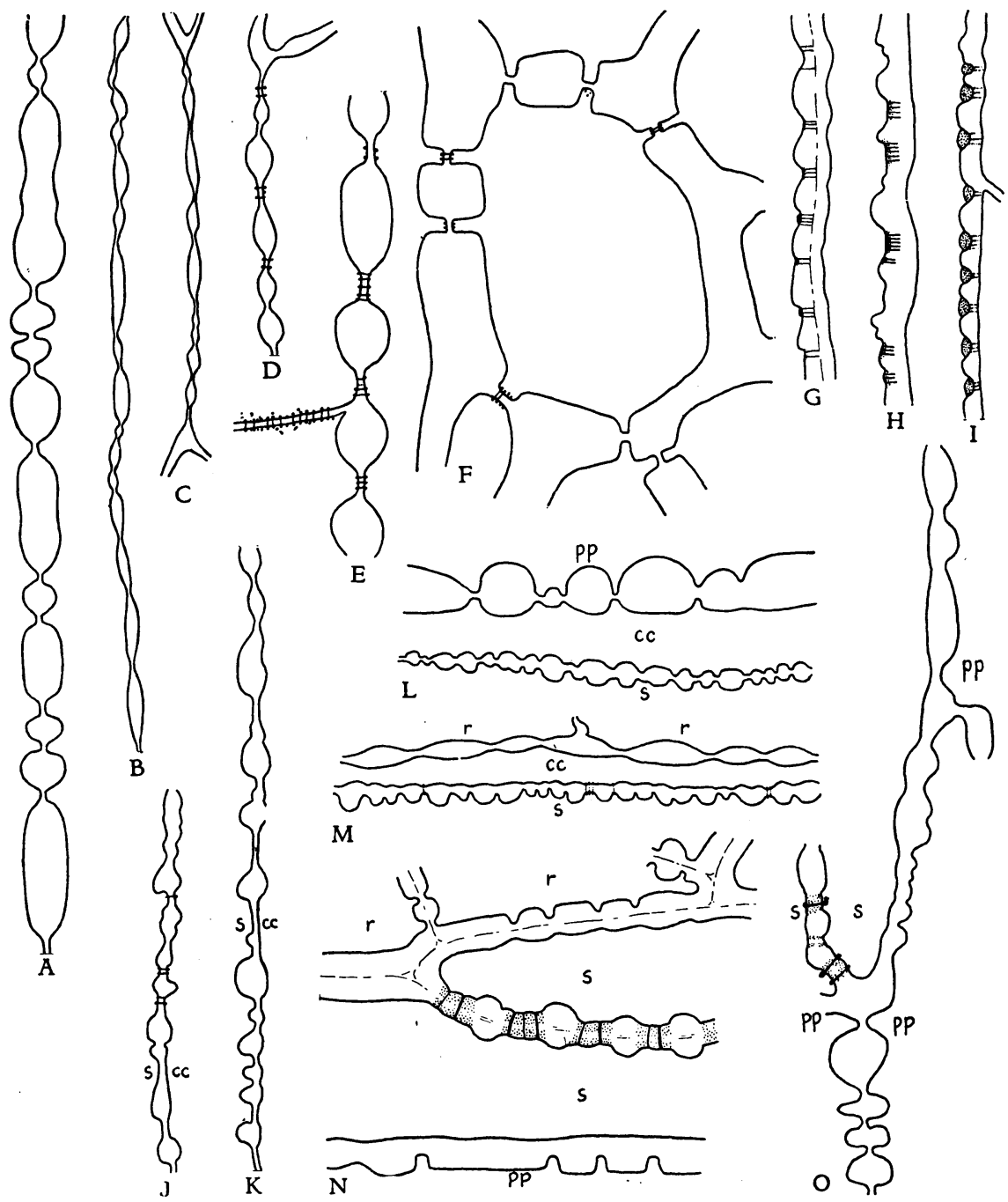

Fig. 5. Sectional views of various cambium and phloem walls. Cambial walls during dormancy $(A)$ and during growth $(B$ and $C)$. Younger $(D)$ and older $(E)$ phloem-parenchyma walls with plasmodesmata in the pits. $F$, Ray cell with plasmodesmata in some pits. $G-I$, Walls between sieve tubes and phloem-parenchyma cells from tangential ( $G$ and $I$ ) and radial $(H)$ sections. The connecting strands in $G$ and $H$, and the callus in $I$ are visible only on the sieve-tube side. $J$ and $K$, Walls between sieve tubes $(s)$ and companion cells $(c c)$, with plasmodesmata in some pits. $L-O$, Walls between different cells whose identity is indicated by the small letters. Details are: $c c$, companion cell; $p p$, phloem-parenchyma cell; $r$, ray cell; $s$, sieve-tube element. $(A-H$ and $J-L \times 1175 ; I$ and $M-O \times 780$.)

pected; namely, opposite the transverse walls separating phloem-parenchmya cells from each other (plate $1, D$ ). Where a sieve tube occasionally touches a ray cell, the latter may show rather deep depressions in its wall, but the associated sieve-tube wall has, at the most, only shallow indentations. In this study, no connecting strands were noted in walls between the sieve tubes and rays. 
The wall between a sieve-tube element and a companion cell is relatively thin but is profusely pitted (figs. $2, G-K$, walls to the right; $5 J-M$ ). Plasmodesmata occasionally remain preserved in these pits when fresh sections treated with iodine and aniline blue are used (fig. $5, J$ ). According to Hill (1908), the connections between the sieve tubes and companion cells are similar to those between the sieve tubes and phloem-parenchyma cells. Because of the thinness of the wall between the companion cell and the sieve tube, this point is difficult to ascertain. After a long search, callus was found on the sieve-tube side of such a wall, but only in dormant phloem. In face view, the pits on this wall resemble the sieve areas B, but are smaller (fig. 4 , $I$, cell to the left). The wall between a companion cell and a phloem-parenchyma cell is usually prominently pitted (fig. $2, H$ and $I$, wall to the left; $5, L$ ). The wall between a companion and a ray cell is either shallowly pitted (fig. $5, M$ ) or is smooth.

The longitudinal walls separating phloem-parenchyma cells from each other are rather thick and have deep pits (fig. 5, $O$, below). The transverse walls are generally thin and without pits. If plasmodesmata are evident in the sections, they are confined, in the longitudinal walls, to the pit-closing membranes; but in the transverse walls are scattered throughout (fig. $5, D$ and $E$ ). The ray-cell walls, as seen in tangential sections (fig. $5, F$ ), are prominently pitted where these cells touch each other or the phloem-parenchyma cells. The plasmodesmata are confined to the pit-closing membranes.

If the presence of sieve areas and pits signifies the existence of interconnections between protoplasts, then one might summarize the relation of the phloem cells to each other as follows. The sieve-tube elements are intimately connected with each other by sieve areas of different degrees of specialization; they are connected with the companion cells by pits that are probably modified into sieve areas on the sieve-tube side. Few or no connections exist between sieve tubes and the other parenchymatous members of the phloem (phloemparenchyma and ray cells). Companion cells, on the other hand, are connected with parenchyma and ray cells by pits. The relation of the companion cells to each other may be disregarded because they rarely touch one another. The common walls of the fibers are pitted, and pits occur also between the fibers and the phloem-parenchyma cells that are in contact with the marginal fibers.

The cambial cells and their immediate derivatives that give rise to the various phloem cells show similar unevenly thickened walls (figs. $3, A-C ; 4, A$; $5, B$ and $C$ ). In other words, they all show primary pit fields. These structures then undergo various modifications, depending on the type of cell in which they occur.

Since each wall is actually composed of two parts-one from each of the two cells that occur side by side-the pit fields, too, are double structures : they are pit-field pairs. In such a pair the two members develop differently when a sieve area differentiates on the sieve-tube side and a pit on the phloemparenchyma side. The pits in parenchyma walls visibly differ from the primary pit fields of the active cambium by the greater thickness of their wall parts. This difference is obviously not fundamental, since, during dormancy, cambial walls may be as thick and have as deep depressions as the parenchyma cells in the fully developed phloem (fig. $5, A$ ). 
As far as could be judged from this study, all phloem cells, except the fibers, have primary walls. The sieve tubes show no transitory thickening (nacré) comparable to that of the sieve tubes of many other plants (Esau, 1939).

Characteristics of the Functioning Phloem. The terms functioning phloem and nonfunctioning (or functionless) phloem are used here to differentiate between the tissues containing functioning sieve tubes and nonfunctioning sieve tubes, respectively. According to this terminology, the functioning phloem is concerned with the principal activity of this tissue (food conduction) as well as with certain other functions, whereas the functionless phloem has ceased to conduct but may still be concerned with starch storage, protection, and other functions. Thus the differences between functioning and nonfunctioning phloem are largely determined by the condition of the sieve tubes and their companion cells. The characteristics, which the sieve tubes assume at the end of their differentiation and which they retain in a more or less constant state during growth, flowering, and fruit ripening of the grapevine, are here interpreted as the characteristics of functioning or mature sieve tubes. Since these features have been considered from various viewpoints earlier in the paper, they may be briefly summarized here. The general appearance of the functioning phloem is shown in plates $7, A$, to the right of $a ; 7, B$; $8, A$, to the right of $a ; 9, A$, and $13, A$.

In a mature sieve tube the enucleate protoplast contains a vacuole in which the slime is dispersed. In cut material this slime accumulates in various amounts on the sieve plate and is continuous through the pores. Because the slime stains well, its presence in the sieve-plate pores makes the connecting strands very conspicuous in sieve tubes of the active phloem (figs. $3, G, H, J$, and $L ; 6, B$; plates $12, A$ and $B ; 20, C)$.

The amount of callose on the sieve areas varies within certain limits. Generally, each connecting strand is imbedded in a callose cylinder, and some callose covers the surface of the sieve area as well. The callose varies in thickness on sieve areas B also, but, in general, the connecting strands of these areas are most prominent during the functioning stage. The longitudinal walls of the sieve tubes are thick, but not noticeably thicker than those of the parenchyma cells (plate $8, A$ ). As was mentioned previously, the peculiar thick wall, which occurs in the differentiating and recently matured sieve tubes of many plants (Esau, 1939), is not evident in the grapevine sieve tubes.

Plastids containing starch, which stains red with iodine, are present in the protoplast (fig. $6, B$; plate $12, A$ ). Since the starch grains often shown Brownian movement, their occurrence in the vacuoles-at least in cut material-may be assumed. (See also Esau, 1939.)

The mature companion cells are nucleate cells without starch. As was described in an earlier paper (Esau, 1947), the companion cell has at first a thin protoplast in which a slime body differentiates (fig. $2, G$ ). The latter disperses, leaving somewhat deeply staining particles in the cytoplasm (fig. 2, $H$ and $I$ ). Though the mature protoplast is vacuolate, it appears denser than that of a younger cell, probably because of the presence of slime.

The phloem parenchyma varies little in active and inactive phloem. The principal variation is in the amount of starch, which is at a minimum during the most active growth of the plant. (See also p. 267-68.) 
Phloem during Dormancy. As was stated in the review of literature, Vitis phloem functions for at least two seasons, but the period of activity is interrupted by one of dormancy during the winter. The most outstanding feature of the dormant phloem is the presence of heavy masses of callose on the sieve plates and sieve areas B (fig. $6, C$; plates $13, B$ and $C ; 14, A, C$, and $E ; 15$, $A-C$ ). This callus is referred to in the literature as provisional (Esau, 1939); dormancy callus seems an appropriate term also.

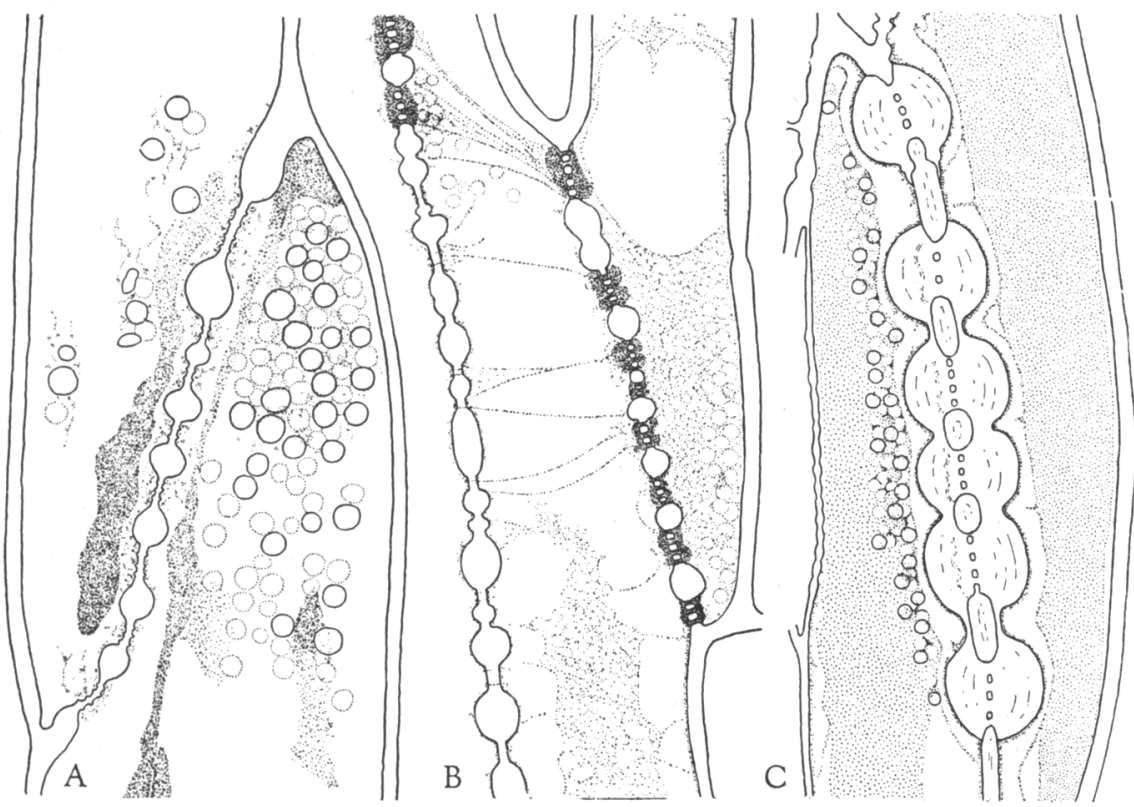

Fig. 6. Longitudinal sections of parts of sieve tubes in different states of activity. An inclined compound sieve plate occurs in the middle of each drawing. $A$, Sieve plate and adjacent structures from an immature sieve tube. The sieve plate shows pitting of two orders like that in figure $3, I$, but no connecting strands. The densely stippled areas indicate the slime. Nuclei were still present in the two sieve-tube elements whose ends appear in $A$. $B$, Sieve plate and adjacent structures from a completely reactivated sieve tube. The dark material that fills the sieve areas and is continuous through their pores is slime. The cytoplasm is lightly stippled. $C$, Heavily calloused sieve plate from a dormant sieve tube. Slime (stippled) appears next to the sieve plate but is not attached to it. The circles in all three drawings indicate starch gains. (All $\times$ 733.)

The dormancy callus is very thick in the large sieve tubes of the earlyseason phloem (plate $15, A$ ) and is moderately thick in the narrow elements of the late phloem (plate 15, C). Using European material, Lecomte (1889) found that the definitive callus was thicker than the transitory. In the California material of the present study, the dormancy callus was generally much thicker than the definitive (compare plates $15, A$, and 19, $B$ ). Very often the masses of dormancy callus of the individual sieve areas fuse and bury the thick cellulose portions that separate the areas from each other (fig. 6, $C$, and plate $20, D)$. The callus shows layering parallel to the surface of the sieve area plate $15, B)$, and sometimes it peels off, in the cut material, along the lines separating the layers. Occasionally most of the callus peels off, leaving the 
plate just slightly thicker than it was during the active period. The cellulose base of the sieve area usually shines through the callus. It is whitish yellow in color and, in material stained with aniline blue, is traversed by blue streaks indicating the callus cylinders in the pores (plate $15, A$ ). In surface view, a sieve area appears blue throughout, but the callus cylinders are of a deeper blue and each has a dot in the center.

Using various techniques, Wilhelm (1880) was unable to recognize connecting strands through the callus in dormant sieve tubes, while Hill's (1908, p. 276) report on this matter was rather vague. Hill said that the "pores of the old strings were seen only with difficulty" in material collected early in April and, supposedly, this material was similar to that sampled during dormancy in February and March. Mühldorf (1937) reported having demonstrated cytoplasmic connecting strands in winter callus in Vitis by subjecting sections to autolysis in a warm oven and a subsequent test for presence of oxydase. The reagents described in "Material and Methods" in the present study revealed no connecting strands in the provisional callus during the height of dormancy. A technique for demonstrating plasmodesmata (Crafts, 1931) was tried also and gave uncertain results: in a sample collected on January 4, 1946, some callus masses showed faint lines crossing them, others did not. Perhaps thin cytoplasmic strands are present in the callus, but the slime of the dormant sieve tubes is usually completely disconnected from the callus masses (fig. $6, C$ ). An exception to this behavior of slime is illustrated by plate $20, D$ : the tough stringy slime is continuous between two elements through one large opening in the otherwise heavily calloused sieve plate. Such connections were found in several samples of dormant phloem. Similar unusually thick connecting strands, one to a sieve plate, were recorded by Nägeli (1861, plate II, fig. 26) in Cucurbita sieve plates covered with definitive callus.

According to Lecomte (1889) and Strasburger (1891), the starch and slime almost disappear from the sieve tubes before dormancy. Wilhelm (1880), however, found no differences in the sieve-tube contents during the summer and winter. In the California material used in the present study, the starch content did not diminish in the dormant sieve tubes, and the slime showed variations in amount not unlike those encountered in the active sieve tubes. Sometimes the slime was almost absent; or it was spread out thinly and uniformly as jellylike, lightly staining mass through an entire element or part of it (fig. $6, C$ ) ; or it was shrunken into a tough, dense, partly coiled strand, very distinct from the parietal cytoplasm of the sieve-tube element. The principal structural difference between the dormant and the active sieve tubes was the previously indicated usual lack of slime continuity through the sieve areas in the inactive state.

In the dormant phloem the sieve-tube starch occurs in the parietal cytoplasm outside the slime. In figure $6, C$, the starch grains were drawn in the same plane as the slime (just to show that starch was abundant in dormant sieve tubes), but in reality they came into view at a different focus than the slime. They obviously were confined to the peripheral portion of the protoplast.

The companion cells, according to Strasburger (1891), have thin protoplasts and are partly collapsed during dormancy. In the material of the present study, the density of the dormant companion-cell contents was equal to or 
even greater than that of companion-cell contents in active phloem. The protoplasts of dormant companion cells often showed no conspicuous vacuoles and the dense substance-probably the remainder of the slime bodies-formed deeply staining flakes, somewhat larger than similar flakes in the active tissue (fig. $2, J$ ). In contrast, the phloem-parenchyma cells, if not filled with starch, commonly appeared much vacuolated (fig. $2, Q$ ). Most phloem-parenchyma cells, all ray cells, and the fibers contain much starch during dormancy.

Phloem during Reactivation. At the break of dormancy the connecting strands again become clearly evident in the callus covering the sieve areas. The slime that during dormancy is not connected to the callus, now appears to adhere closely to it. If no slime was evident before, it now becomes conspicuous, and if its chromaticity was low, the latter is restored in its intensity. At first very thin connecting strands traverse the callus masses-a stage that is not readily detected. Later the connecting strands are much thicker, stain deeply, and are obviously related to the slime accumulations next to the callus. They do not at once appear traversing the whole callus mass, but, as Hill (1908, p. 276) has graphically expressed it, the slime seems "to force its way through the old pores in the callus masses" (plate 20,A). Often a strand single at one end of the callus mass is branched in its interior (plates $10, B$, below ; $20, A$ ) ; or a strand is thick at one side of the callus mass and very thin at the other. These observations suggest that at first only thin cytoplasmic strands traverse the callus (perhaps these strands are present during dormancy but are not very chromatic); then a dissolution of the callus along these strands widens the passages and permits the entry of slime into the latter.

As the reactivation progresses, the callus is gradually dissolved. Its surface, as seen in sections, appears festooned (plate $10, B$, below); then the callus diminishes in thickness until it becomes as thin as it was when the sieve tube first differentiated from cambial derivatives.

The Bismark brown-iodine green-resorcin blue staining combination is very useful for the study of reactivation. The connecting strands are so clearly differentiated from the callose (plates $1, A ; 10$ and 11) that the recognition of the early stages of reactivation in survey work is much facilitated.

Reactivation begins near the cambium, and since the callus masses there are only moderately thick, the youngest sieve tubes quickly assume the appearance of fully active elements. The sieve tubes located farther from the cambium are reactivated somewhat later and more slowly. Plates $10, A$, and $11, A$, may serve to illustrate the progressive reactivation of the phloem from the cambium outward. In the section in plate $11, A$, which occurred next to the cambium, the connecting strands were present in all callus masses and were most prominent closest to the cambium (to the right in the photograph). In the section in plate $10, A$, which was located near the periphery of the cane, one callus mass (below in the photograph) was completely traversed by connecting strands, the other (above in the photograph) showed only a few beginnings of such strands. (See also plate $1, A$.) Plate $11, B$ and $C$, shows longitudinal sections of sieve plates from partly reactivated sieve tubes taken in a part of the phloem similar to the section in plate $11, A$.

The reactivating phloem can be clearly distinguished from the dormant, even in low-power views, by the relative thinness of the callus masses and by 
the conspicuousness of the slime. Plate 14, $A$ and $B$, illustrates these points of difference. In the dormant 1944 phloem in plate 14, $A$, heavy deposits of callose occur on all sieve areas that are evident in the section, but no slime is visible. The reactivating 1944 phloem in plate $14, B$, shows thin callus masses and dense accumulations of slime connected to the sieve areas. A comparison of sections from dormant phloem in plates $13, B$, and $15, A$ to $C$, with those from the partly reactivated tissue in plates 10 and 11 also give a good notion of the morphological distinction between active and inactive phloem.

The companion cells too show some change during reactivation : their protoplasts again become somewhat thinner in appearance, sometimes even thinner than in the preceding season (fig. $2, K$ ). The phloem parenchyma, ray cells, and fibers show a gradual depletion of starch.

Certain characteristics of the dormant phloem seem to be, at least in part, indications of reduced amounts of water in the tissue. Such characteristics are : the rather uniform jellylike appearance of sieve-tube contents (fig. $6, C$ ) or the much contracted condition of the slime (plate $20, D$ ); the comparatively dense protoplasts of the companion cells (fig. $5, J$ ); and the accumulation of starch in the parenchyma and fibers.

Characteristics of the Functionless Phloem. Since the old phloem is periodically sloughed off in the grapevine, comparatively small amounts of nonfunctioning phloem accumulate in the bark. More functionless phloem accumulates in some parts of the plant and in some varieties than in others. Certain environmental conditions and presence of a disease also may be expected to affect the amount of nonfunctioning tissue in the bark.

Normally the grape phloem ceases to function as a conducting tissue in the second year of its existence. It may or it may not become separated from the axis at the same time. Accordingly, the characteristics assumed by the functionless phloem vary in relation to the length of time that such phloem remains attached to the plant in unity with living tissues. If the phloem is cast off soon after its sieve tubes cease to function, all its cells die. If the nonconducting phloem remains attached to the axis, its parenchymatous members (excluding the companion cells) and the fibers remain alive and continue to be concerned with starch metabolism.

As was pointed out previously, phloem ceases to function as a conducting tissue when its sieve tubes become disorganized. The disorganization may occur in three different ways and the variations in this phenomenon are related, at least partially, to the length of time the functionless phloem remains connected with the stem.

The first type of disorganization involves a crushing of the sieve tubes and companion cells by the adjacent parenchyma cells. The crushed cells seem like extremely thick walls, but closer examination reveals the slitlike remnants of the obliterated lumina (plates $10, A$, and 18, $A$ ). Before the sieve tubes are crushed, their contents may become transformed into a homogeneous mass of material that stains very lightly with aniline blue. Since this substance appears to be a remainder of sieve-tube contents (perhaps of the slime), it is here referred to as residual material. No discrete structures, such as plastids or starch, are present in it. Some sieve-tube elements are without the residual material and appear empty, except for the shrunken fragments of the dis- 
integrated protoplasts. The sieve plates lack callose-if definitive callus is formed in advance of the obliteration, it disappears before the sieve tubes are completely crushed-and, of course, have no connecting strands.

The method of sieve-tube obliteration just described is characteristic of primary phloem (plate 2) and of that part of secondary phloem that occurs beneath the cork, particularly in the canes (plate $15, D$ ).

The second type of phloem disorganization involves filling of the sieve tubes with tyloses-a phenomenon that has been recorded in the old literature on phloem (Janczewski, 1881; Strasburger, 1891). The tyloses are outgrowths of phloem-parenchyma cells (fig. 7, $A$ ). Before these outgrowths are formed, the protoplasts of the sieve tubes and companion cells die. Residual material may or may not be present in the sieve tubes but starch grains disappear. Some sieve plates show definitive callus, others are without any callus. If this material is present, it stains very lightly with aniline or resorcin blue.

Since the tyloses develop in great numbers in the phloem, and since pits (and sieve areas) are not too common on the walls between the sieve tubes and parenchyma cells, phloem tyloses may not necessarily arise from the enlargement of pit-closing membranes as do those of the xylem. In fact, the tyloses in the sieve tubes have wide bases where they are connected with the initiating cell, whereas similar connections in the xylem are as narrow as the pits. Probably any part, or at least any thin part (fig. 5, $O$ ), of the common wall between a sieve tube and a phloem-parenchyma cell, is capable of extending into a tylose. If the entire common wall extends, the sieve tube is simply crushed; if parts of such walls extend, tyloses arise. Repeated observations show that tylose formation and partial or entire crushing of the sieve tubes are combined in the same part of the tissue.

Tyloses contain nuclei, starch (fig. $7, A$; plate $8, C$ ), and sometimes tannin. If the tissue remains alive for a relatively long time, tyloses develop thick, profusely pitted walls. If the sieve tube contains residual material, the latter is pushed aside by the tylose (fig. $7, A$; plate $8, C$ ). Tyloses come in contact with the sieve plates that are with or without callus. They may push part way through a sieve plate by stretching the callus-free wall of a sieve area. The typical aspect of phloem with abundant tyloses is illustrated in plates $8, B$ and $9, B$. In the transverse section in plate $8, B$, the sieve tubes with tyloses $(t)$ appear as wide-open cells, those without tyloses $(s)$ as partly crushed structures containing residual material. In the radial section in plate $9, B$, no long cells with wide lumina - the sieve-tube elements (as in plate $9, A$ ) - can be recognized, because these elements are subdivided into small compartments by the tyloses. The companion-cell protoplasts die in the phloem containing tyloses. Occasionally the latter are formed in the companion cells also.

The occlusion of the sieve tubes by tyloses commonly occurs in large branches (arms), main trunk, and roots, where more than one annual increment of phloem may accumulate; but it also occurs in canes.

In the third type of disorganization of the phloem, the sieve tubes are emptied and are rendered functionless without being crushed or closed by tyloses. Remnants of protoplasts occur in such sieve tubes for a time, but residual material is rare. Definitive callus may or may not be deposited on the sieve areas. After it is formed, the connecting strands disappear because of 
the death of protoplasts (plate 19,B). The protoplasts of the companion cells die as the associated sieve tubes cease to function.

The phenomena just described occur in the phloem that functions till the end of the season and then is cut off by the cork in the normal process of bark sloughing. After the sieve tubes become functionless in such phloem (plate 7, $A$, to the left of $a$ ), the latter differs much less from the functioning phloem (plate $7, A$, to the right of $a$ ), than the tissue containing tyloses (plates 8 and 9 ). But soon certain phloem-parenchyma cells enlarge radially, divide tangentially (plate 19, $A$ ), and form several layers of cork (plate 19, $C$, at $c$ ). While this growth occurs, the cells in the nonfunctioning part of the phloem begin to collapse. All living cells die but certain inclusions, such as tannins and crystals, are not removed from them. The tissue that is cut off becomes the dead bark. Quite commonly the empty sieve tubes are very conspicuous in the dead bark because their large lumina stand out among those of the other more thoroughly collapsed cells (plate $19, D$ ). Definitive callus is present occasionally in the dead phloem. The fibers lose their protoplasts also but do not change their shape because of the rigid secondary walls.

\section{SEASONAL CHANGES IN THE PHLOEM}

Histology of Cambial Reactivation. A consideration of phloem activity would be incomplete if it were not related to the activity of the cambium from which new phloem arises. As the review of literature in the present paper shows, many workers have studied cambial reactivation in woody dicotyledons and all have generally concluded that springtime cambial divisions are initiated beneath the buds and then spread downward to the main branches, trunk, and roots. Vitis also shows this common pattern of cambial reactivation and it exhibits the usual histologic details in the resumption of growth by the vascular meristem.

During dormancy the latest xylem elements of the preceding growth season are easily recognized by their thick, lignified walls. The cambium and the nearest phloem cells, however, are indistinguishable on the basis of wall thickness : both have thick, nonlignified walls (plates $15, C$, and 17, $A$ ). Wall thickness alone, therefore, does not indicate the layer (or layers) that should be regarded as cambium proper, nor the initial layer. Since, however, sieve tubes occur sometimes in the second layer from the xylem (fig. 7, $B$ and $D$ ), only one layer of cells could be called "cambium," namely, the layer between the xylem and the nearest sieve tubes. The occurrence of tannin cells in the second row from the xylem (plate 17, $A$ ) suggests the same arrangement, though the presence of tannins does not always prove that the cell is outside the meristem : in the interfascicular area some ray initials contain tannins (plate 18, $B$ ). The ray initials also store starch during dormancy - a feature that is not characteristic of the initials in the fascicular areas. (Lodewick, 1928, also observed starch in the ray initials of dicotyledonous trees.) The cambial cell in the fascicular area always lies next to the xylem and sometimes only one phloemparenchyma cell separates it from the phloem fibers (fig. 7, $C$ ).

The resumption of cambial activity is first expressed in an enlargement of the cambial cells parallel to the radius of the stem (plate 17, $B$, two cells in median part of photograph). This phase is soon followed by that of tangential 
divisions (plate 17, $B$ ). During the initial enlargement of the cambial cells, their radial walls stretch and become thin, particularly in the region where the new tangential wall is to be attached. In sections, this thin part of the wall easily breaks (plate 17, $C$ ). After the cambium has been active for a while, this localized thinning down of the wall is not conspicuous because the walls are rather thin throughout. Furthermore, the tangential divisions follow one another so rapidly that the radial extension of the cell, which precedes a division, becomes very limited. The cambium and its immediate derivatives now
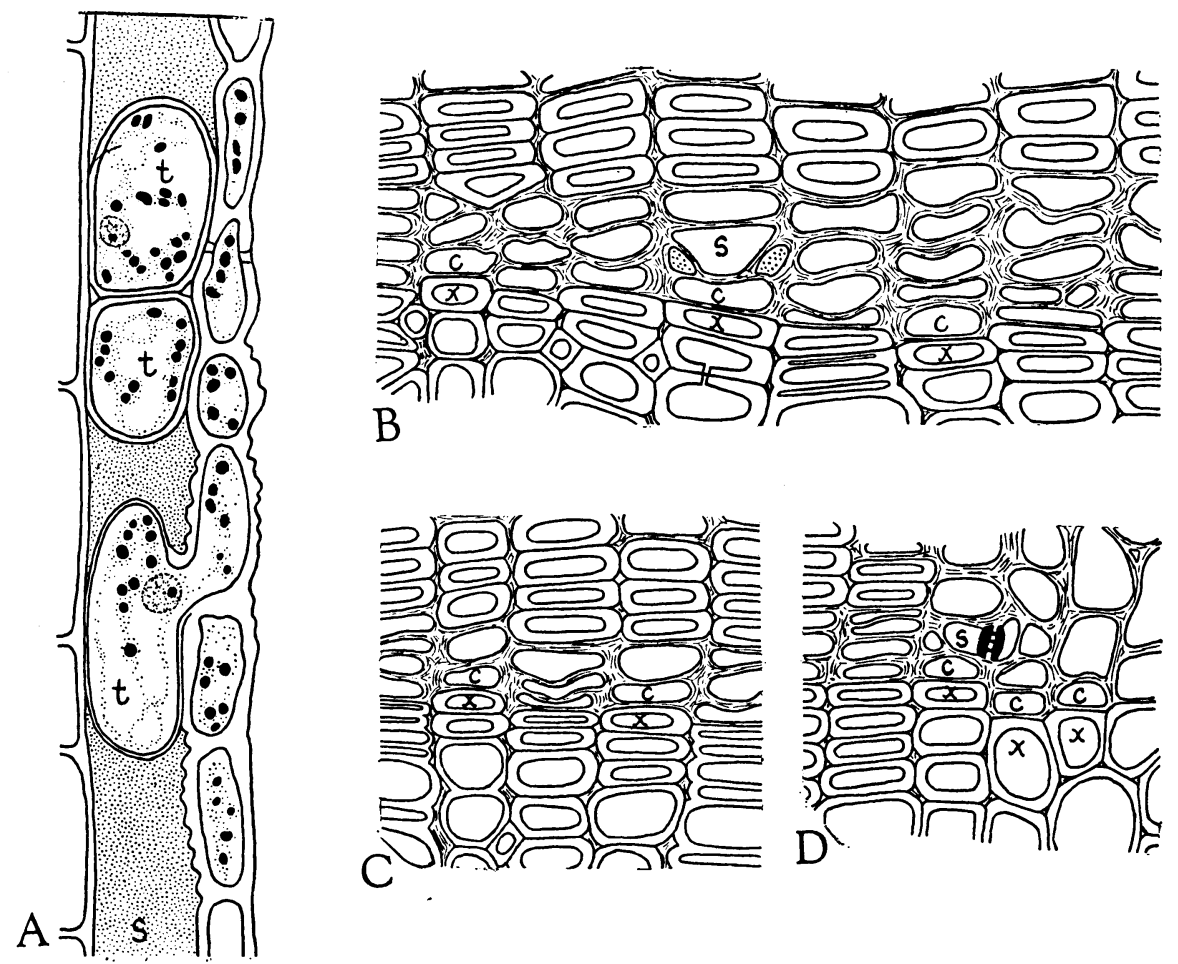

Fig. 7. $A$, Longitudinal section of part of a sieve-tube element $(s)$ containing tyloses $(t)$ and residual material (uniformly stippled). To the right of the sieve-tube element are phloem-parenchyma cells, one of which is continuous with a tylose. The black spots in the parenchyma cells and in the tyloses represent starch grains. $B-D$, Transverse sections of dormant cambium and adjacent cells from a cane. Details are: $c$, cambium; $s$, sieve tube; $t$, tylose; $x$, xylem. $(A \times 360 ; B-D \times 457$. $)$

give the common picture of an active cambial region : they form radial files of cells, which are flattened perpendicularly to their tangential diameters (plate $18, C)$. In this complex the radial walls of the cells engaged in the most active divisions are weak, as are those of the cells that enlarge in the first phase of cambial reactivation, and they too break readily in the sections (plate $17, D$ ). The obvious result of this weakness of the radial walls, during the earlier and later stages of cambial activity, is the slipping of the stem bark that is easily induced by mechanical means when spring growth begins.

While, during dormancy, the cambium can be identified as a single layer 
next to the xylem, the recognition of the initial layer is rather problematical when its undifferentiated products accumulate. In plate $18, C$, the initial layer appears to be at $c$ since this region shows some recently formed tangential walls. Where such walls do not occur, however, the cambial cells and their immediate derivatives are alike. Judging by plates $17, D$, and $18, C$, in the fascicular areas the presence of tannins may be taken as evidence that tissue differentiation has begun : no tannin cells occur in the initial layer and its immediate derivatives. The sieve tubes also begin to differentiate close to the initial layer (plates $17, D$, and $18, C$, at $s$ ), so that, in general, only a relatively narrow band of cells having no obvious characteristics of phloem or xylem elements occurs in the cambial region. The phloem fibers (above the young sieve tubes in plate $18, C$ ) resemble cambial cells until their walls begin to thicken. Plate $16, A$, illustrates particularly well the similiarity between the region where cambial divisions occur (next to the xylem) and that containing the young fibers (separated by tannin cells from the cambial region). The fusiform cambial cells of the fascicular area strikingly contrast with the short ray initials (plate $16, B$ ).

No detailed studies were undertaken on the relative time of appearance of the new xylem and phloem cells. However, evidence obtained thus far indicates that both are formed approximately at the same time. The two tissues have an equally long growth period, but a xylem increment of a given season is much wider than the corresponding phloem increment. These observations agree with the conclusions drawn by Knudson (1916) from his studies on radial growth in Vitis labrusca.

Pattern of Cambial Reactivation in the Axis. To ascertain the spatial pattern of cambial reactivation in the axis, several cane pieces were studied in detail at bud break and the relative appearance of active cambium was also determined in the trunk and roots. Figure 8 shows the canes (really pieces of canes, called "canes" for convenience) that were used in this study. They were collected on the following dates of 1945 : April 12 (fig. 8, A), April 17 (fig. 8, $B$ ), April 23 (fig. 8, $C$ ), and April 26 (fig. 8, $D-G$ ). The cane in figure $8, A$, consisted of two parts : the lower, the main part of the cane (from the joint above $k$ and downward), and the upper, a lateral branch on the main part of the cane. Both parts were one year old. The direct continuation of the main part of the cane was cut off between the levels $j$ and $k$ (in figure $8, A$ ) long before the sample was taken, and the lateral part was trimmed at the cut end (above in the figure) at pruning time. The cane in figure 8, $C$, also has a joint (above $n$ ) but the one in figure $8, B$, is all of one piece. The degree of development of the buds on the canes in figure $8, A$ and $B$, is indicated in the drawings. The bud below the level $d$ in figure $8, A$, and those below the levels $f$ and $w$ in figure $8, B$, showed no signs of growth; all the others had leaves in various stages of unfolding. In the cane in figure $8, C$, the longest lateral shoots were removed before the sketch was made. These were as follows : above level $a$, two shoots, 1.0 and 1.5 inches long, one with flower primordia ; above level $g$, two shoots, 0.5 and 2.0 inches long, both with flower primordia; above level $n$, at the junction of two cane pieces, one shoot 2.0 inches long with flower primordia.

Sections for microscopic study were made from the three canes at the levels 
$[$ Vol. 18, No. 5

indicated by the small letters in figure $8, A$ to $C$. To retain the proper relative orientation of the sections, a shallow longitudinal slit was made along one side of the cane and the exposed cells were dyed with safranine. Thus each section had a red spot on one side.

In the drawings, broken lines indicate the position of the sections that
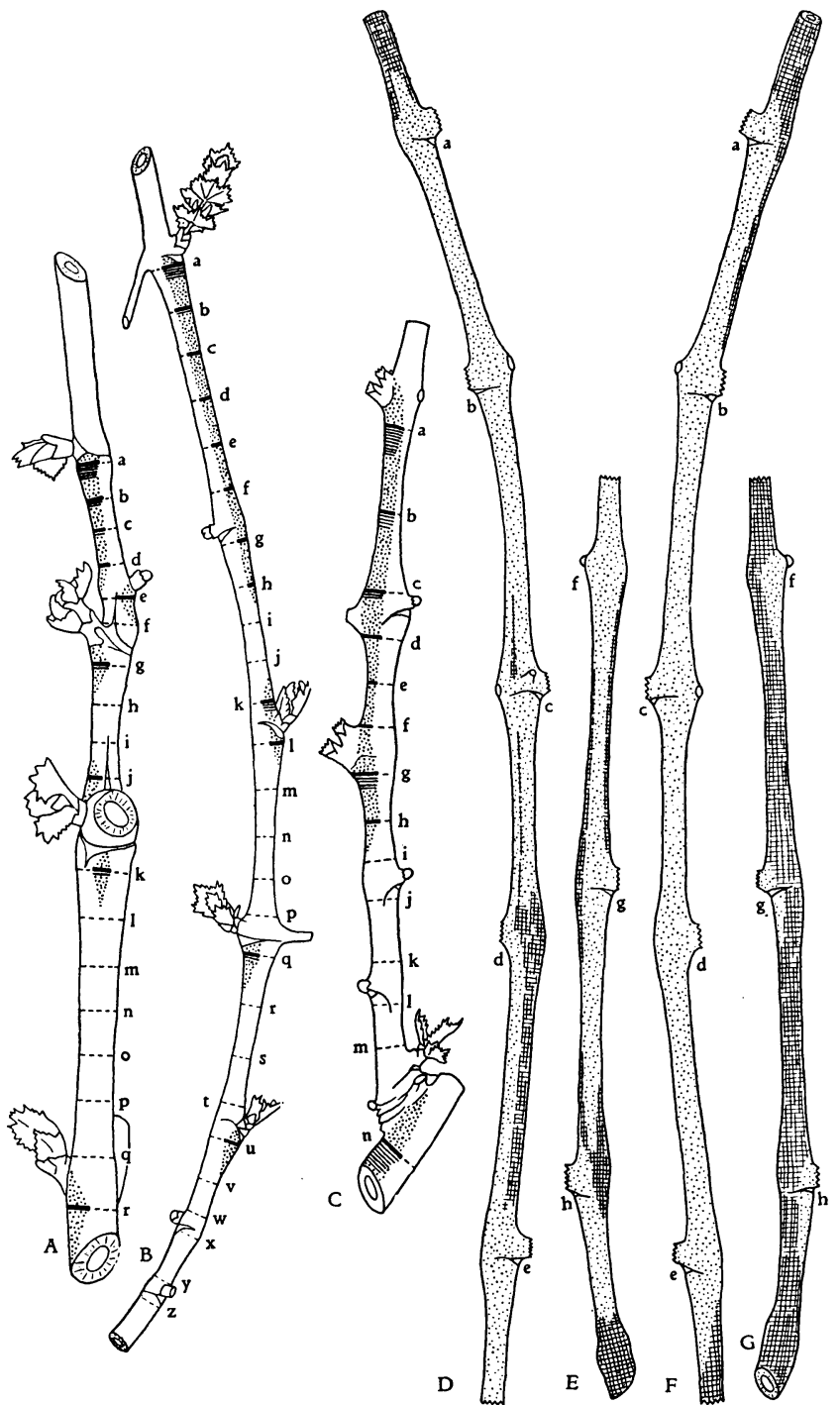

Fig. 8. Pieces of canes used in part of the study of cambial reactivation. The small letters in $A-C$ indicate the levels at which the canes were sectioned. The cambium was active in the stippled parts in $A-C$; the solid lines denote the maximum number of divisions that had occurred at the different levels. $D$ and $E$, Two pieces of the same cane separated from each other between the nodes $e$ and $f$. $F$ and $G$, The same two pieces of cane as in $D$ and $E$, respectively, but turned $180^{\circ}$ about their axes. The stippled areas in $D-G$ show where the bark could be made to slip. In the cross-hatched areas the bark was firmly attached. The lateral shoots are not shown in $C-G$ but are described in the text. $(A \times 2 / 5 ; B-G \times 1 / 5$. 
showed no cambial activity. Where a part of a line has been made solid, cambial activity was present but did not reach around the stem. One solid line at a given level signifies that only one division, at the most, had occurred here. If more than one cell was formed by the cambium, additional lines were drawn beneath the one located at the level of sampling. The total number of these solid lines at a given level corresponds to the maximum number of cells that were produced there by the cambium. The stippling delimits the area where the cambium was active.

Some of the sections made from the cane in figure $8, A$, are outlined in crosssectional views in figure 9. The small letters in the center of each section in figure 9 give the levels in the cane in figure $8, A$, from which these sections were taken. In figure 9 only the xylem and the phloem were outlined. Leaf traces were clearly evident where, in the diagrams, the rays are represented by double lines. The broken line encircling the stem near the periphery gives the position of the inactive cambium; the solid lines that are continuous with the broken lines mark the active parts of this meristem. To emphasize the intermittent distribution of active cambium, the sectors containing such cambium were stippled.

Figure $8, A$ to $C$, shows that the initiation of the cambial activity is spatially related to buds. Usually this activity begins beneath the buds and then progresses downward. Sometimes the cambium becomes reactivated above a bud also, but only for a short distance (levels $j$ in figure 8, $A$, and $k$ in figure $8, B$ ). Cambial activity is commonly absent beneath buds with no signs of growth (fig. $8, B$, levels $g$ and $x ; 8, C$ levels $j$ and $l$ ). Since, as a rule, the uppermost bud on a cane is the first to begin growth, cambial activity also starts at the apex of the cane. Evidence of such apical dominance was present in the canes in figure $8, A$ to $C$ : cambial activity that was induced beneath the uppermost buds had progressed to a greater distance downward than the activity associated with the lower buds.

Because cambial activity starts beneath a bud, the largest number of cells produced by the cambium, in the early stages of growth, occurs beneath a bud and this number decreases in the downward direction. The cross-sectional views in figure $9, A$ to $D$, show also that the lateral spread of cambial reactivation is greatest close beneath the bud and diminishes downward in the internode. In any given area with active cambium, the highest number of new cells occurs in the median portion of the area. Thus at level $a$ in figure $8, A$, six cells were formed in the middle of the arc of active cambium (see also figure $9, A$ ), whereas toward the margins the number diminished to one. Figure 9, $E, G, J$, and $K$ shows that although at the levels represented (fig. 8, $A$, levels $e, g, k$, and $r$ ) cambial reactivation had spread laterally to a considerable distance, it was absent at the nearest levels below (fig. 8, $A$, levels $f, h, l$, and $9, F$ and $H$ ). Thus near the levels $e, g, k$ and $r$, in figure $8, A$, the rather wide patches of active cambium were sharply isolated from each other. Figure $9, I$, shows that at level $j$ (see also fig. $8, A$ ) where the cambium was reactivated in an upward direction from a bud, the lateral spread was very restricted.

Thus in the early stages of growth, active cambium occurs in discontinuous patches spatially related to the position of the buds on the canes. Gradually 

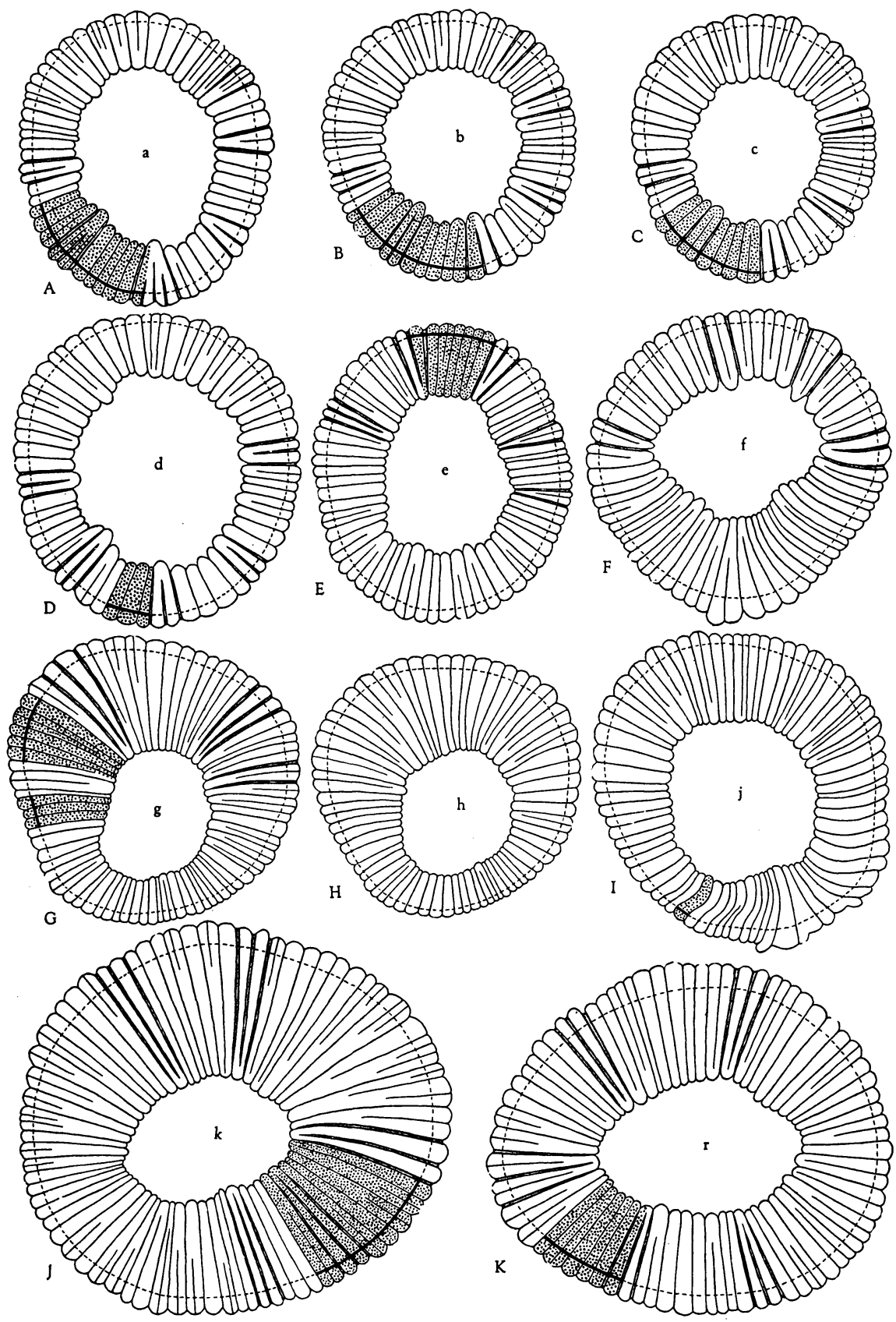

Fig. 9. Transverse sections of the cane illustrated in figure $8, A$. The small letters $a-h, j, k$, and $r$, denote the levels in figure $8, A$, from which these sections were taken. In all drawings the dormant cambium is indicated by a broken line, the active cambium by a solid line continuous with the broken one. The cane sectors containing active cambium are stippled. $($ All $\times 5$. $)$ 
reactivation spreads downward and laterally until the previously isolated patches merge. Figure $8, D$ to $G$, shows the distribution of active cambium during an advanced state of reactivation. The pieces depicted in this figure are all from one cane. Figure $8, D$ and $E$, shows this cane from one side, figure $8, F$ and $G$, from another. The piece in figure $8, E$ and $G$, was attached to the longer piece in figure $8, D$ and $F$, between the nodes $e$ and $f$. The lengths and the developmental features of the lateral shoots that occurred at the various nodes on the cane in figure $8, D$ to $G$, were as follows : $a, 6.0$ inches, with flower buds; $b, 10.5$ inches, with flower primordia ; $c, 4.0$ inches ; $d, 0.5$ inches ; $e, 5.5$ inches, with flower primordia; $f$, no growth; $g, 0.5$ inches $; h, 3.0$ inches.

The cane in figure $8, D$ to $G$, was not sectioned; instead, the position of the active cambium was located by determining the parts of the bark that could be made to slip without the aid of any instruments. These areas were marked by stippling in the drawings. In the cross-hatched portions the bark was firmly attached to the wood.

Most of the upper part of the cane (fig. 8, $D$ and $F$ ) was in an active state. The lower part showed much active cambium on one side (fig. $8, E$ ) but only small patches of it at the nodes on the other side (fig. 8, $G$ ). In the uppermost end of the cane, that is, in the portion located between the pruning cut and node $a$, cambial reactivation had spread upward from $a$ for a short distance. The rest of this end was inactive.

When samples of phloem were taken from the main trunk, the presence or absence of cambial activity in the sampled areas was recorded. On April 17, when the cane shown in figure $8, B$, was collected, a sample from the main trunk, taken 6 inches below the insertion of the main arms, showed no cambial activity. On April 25, the condition of the cambium in four samples taken on the trunk at various distances from the attachment of arms and downward was as follows : 8 inches, several cambial divisions ; 17 inches, about two cambial divisions ; 26 inches, one cambial division; 35 inches ( 5 inches from the ground), no cambial activity.

The dormant cambium of the roots has thinner walls than similar cambium of the aerial parts of the plant. Therefore the root bark can be forced off the root with relative ease during dormancy. The occurrence of cambial activity in the roots was determined by the use of sections only. In roots several years old, collected on May 2, no divisions had occurred in the cambium. On May 9 similar roots had cambial activity but not around the entire circumference.

Thus, according to the data just given, the grapevine shows a basipetal course of cambial reactivation characteristic of woody dicotyledons. The course of cessation of this activity was not considered in the present study.

Reactivation of the Phloem as Compared with that of the Cambium. The canes that were used for the study of cambial reactivation in 1945 were examined also with regard to the resumption of phloem activity. It became obvious at once that phloem reactivation started before any cambial divisions occurred in the same part of the plant. In all three canes shown in figure 8, $A$ to $C$, connecting strands were present at all levels (although the callus was still massive in the peripheral parts of the phloem), whereas the cambial activity was very much localized in certain areas. The connecting strands in the canes in figure 8, $B$ and $C$, had a uniform degree of development in all 
sections, but in the cane in figure $8, A$, sieve plates with connecting strands were more numerous in the upper sections than in the lower; and they were somewhat better developed on the sides of the cane where buds were present than on the opposite sides. This variation in the degree of phloem reactivation in the cane in figure $8, A$, indicated some relation to the position of active buds. The cambial reactivation in the same cane, however, showed an incomparably more definite relation to the inception of growth in the buds.

Comparative studies on reactivation of cambium and phloem were repeated in 1946. Long pieces of canes were sampled at different levels and the condition of the phloem and cambium was recorded at these levels. The canes were taken from five-year-old vines that grew in a small experimental plot where the pruning operation was delayed until late in March. Thus, during dormancy and during the early part of the growth season, long canes were available and the samples could be taken at widely separated levels on the same canes.

The progress of reactivation was studied in two kinds of branches : in canes that were left on the plant until they were sampled for microscopic study, and in canes that were cut off, brought into a heated laboratory room, placed with the cut ends in water, and covered with a bell jar. (The induction of phloem reactivation in dormant canes by exposing them to room temperature was first studied by Wilhelm, 1880.)

Table 1 sums up the results obtained with the canes kept in the laboratory. Thirteen canes (canes 1 to 13 in table 1 ) were collected on January 4 (series 1 to 3 ) and one (cane 14 in table 1) on January 21 (series 4). One of the canes of the January 4 collection was sampled as soon as it was brought into the room, and the other 12 were kept indoors and were sampled on the dates given in the first column of table 1. Till January 16, inclusive (series $1, A$ in table 1), the uppermost nodes of successive canes were sampled. Since the buds in the group of 12 canes showed no signs of growth on January 16, these canes were sampled once more, beginning with the one that was sampled on January 5 (cane 2), and again the samples were taken at the uppermost nodes. The last of this set of samplings was made on January 23 when the buds had begun to grow (table 1 , series $1, B$ ).

Two of the canes of the January 4 collection, that were not sampled for the second time in series $1, B$ (canes 7 and 8 ) were used for comparing the state of reactivation of tissues at the different levels (table 1, series 2 and 3 ). Several nodes and median portions of the internodes below these nodes were sampled. The cane that was brought into the room on January 21 was treated in a similar manner (table 1 , series 4 ).

As stated previously, the first column of table 1 gives the dates of samplings. This column also designates whether the sample consisted of a nodal or internodal piece of the cane. The numbers after the words "node" and "internode" in series 2 to 4 indicate the relative level of these samples on the cane, with the count beginning at the uppermost node. The second column specifies the number of days that the canes were in the room before the given sample was taken from them. (In series 1, certain groups of samples that gave the same results were combined in the table.) The condition of the buds immediately above the sampled node pieces is described in the third column. 
TABLE 1

Reactivation of Phloem and Cambium in Canes Kept in a Warm Room, StrasON OF 1946

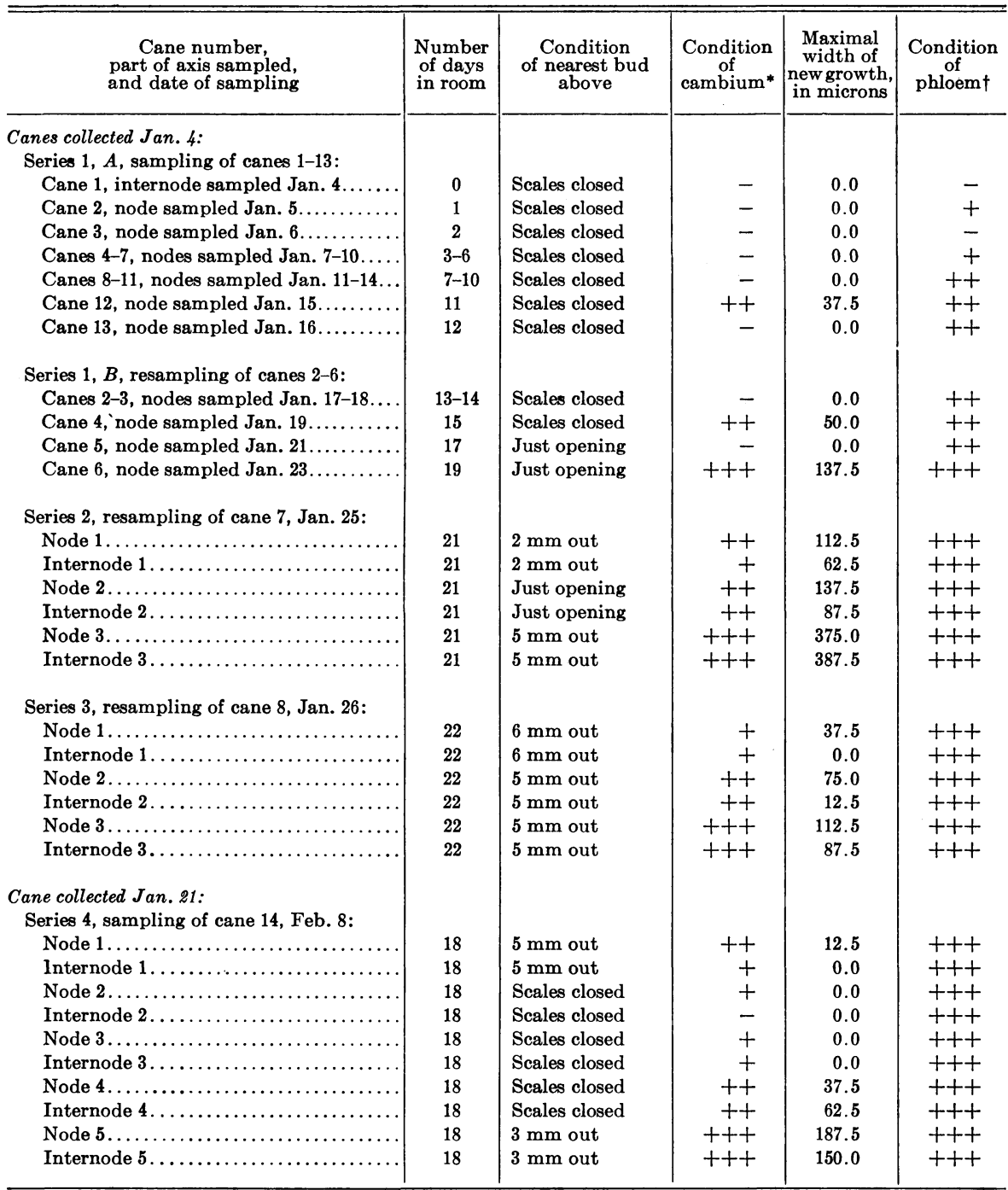

* -, Cambium inactive.

,,++++++ , Cambial cells enlarged or divided over about $1 / 3$ of, over about $2 / 3$ of, or over the entire circumference of the cane, respectively.

$\dagger-$, No visible connecting strands and callus of maximal thickness.

+ , Connecting strands in some callus masses and callus of maximal thickness.

,++ Connecting strands in $1 / 2$ to $2 / 3$ of phloem thickness, callus slightly thinner than before.

+++ , Conspicuously thickened connecting strands present throughout most of the phloem and callus much thinner than during dormancy. 
The method of estimating the degree of reactivation of the cambium and phloem (fourth and sixth columns in table 1 ) is explained in the footnotes to the table. The appearance of the phloem during dormancy and during the progress of reactivation has been described in detail in a foregoing part of this paper. In the material used for table 1, the phloem was not yet completely reactivated in the latest samples, but the process had advanced sufficiently to give a complete picture of its course in the different parts of the canes. The thickness of the new tissue produced by the cambium was measured where it was greatest (fifth column in table 1 ).

As table 1 shows, the first active cambium was observed in the sample taken 11 days after the canes were exposed to the specified laboratory conditions; but the reactivation was not uniform in the successive samples. Series 2 to 4 indicate that the apical dominance in the initiation of bud growth (that is, start of bud growth at the apex of the cane, then at successively lower levels) and the normal pattern of cambial reactivation (that is, its initiation beneath the uppermost buds, then at successively lower levels) was upset by exposure to laboratory conditions. The buds grew out at the bases of the canes soon after or simultaneously with those at the apices, and the cambium was more active at the bases than at the apices of the canes. In the two short pieces of series 2 and 3 , cambial activity increased basipetally from node to node, with no direct relation to the degree of development of the associated buds, and in the lowermost part of the cane in series 2, radial growth was somewhat more advanced away from the bud (internode 3 ) than close to it (node 3 ). In the long cane in series 4 , a region with no increase in radial thickness intervened between the nodes 1 and 4 (see the fifth column in table 1 ) and radial growth was much more advanced at the base of the cane than it was near the apex.

The change in the phloem marking the cessation of dormant state was evident in the cane sampled on January 5 , the day after the canes were brought into the laboratory. In this sample, however, the connecting strands were very faint; they occurred in few sieve areas and these areas were scattered at different depths in the phloem; and the following sample showed no connecting strands. Beginning with cane 4 (sampled January 7 ), phloem reactivation developed consistently and reached its maximum, for this series of collections, after 19 days in the laboratory (cane 6 , series $1, B$ ).

In all the series of table 1 , the distribution of the first visible connecting strands in the node showed no relation to the position of the bud; the nodes and the internodes below them showed no difference in the degree of reactivation; and the condition of the phloem was alike at the different levels of the same canes. Thus the pattern of phloem reactivation in this experiment did not coincide with that of cambial reactivation.

Table 2 gives the results obtained with canes collected at different times from vines growing out of doors. The method of sampling and recording of the data were as for series 2 to 4 in table 1, except that in cane 1 of table 2 no internodes were used. Since canes 2 and 3 were sampled on the same day and were similar with regard to the reactivation of buds, cambium, and phloem, the data pertaining to these canes were combined.

The first signs of cambial reactivation were observed in the cane sampled on March 23 (cane 6). In this cane and in the following one (cane 7), apical 
dominance in bud development and the dependence of cambial reactivation on bud growth were clearly expressed. The first evidence of phloem reactivation preceded that of cambial reactivation. Between March 9 and March 30 the degree of phloem reactivation remained approximately the same; then it was speeded up. Canes 2, 3, 5, 6, and 7 showed a minor decrease in the intensity of reactivation toward their bases, but this decrease was so slight that it was not recorded in the table. In cane 9 , on the contrary, the connecting strands were distinctly more conspicuous at the base than at the top, but here the upper part of the cane showed necrosis in the bark on one side. This abnormality did not seem to affect the reactivation of the cambium, however.

Thus the present studies revealed no close relation between phloem reactivation and bud growth. A basipetal progress of activation was indicated but the evidence of this course quickly disappeared. The reactivation of the phloem definitely preceded that of the cambium. This was true of the canes and also of the older stem parts, whereas the roots showed no complete dormancy in the phloem.

Seasonal Cycle of Phloem Activity. ${ }^{11}$ In the present study the most detailed investigation of seasonal changes in phloem were made on canes of the Sultanina variety. The diagram in figure 10 gives an approximate picture of the yearly cycle in the transformations in the phloem of such canes. Since in its initial stages the activity of the cambium shows a basipetal progression in the axis, different levels of a given cane show the beginning of cambial divisions at different times. The samples used for figure 10 were taken from various parts of the canes but mostly from the median and near basal ones. Naturally, the weather conditions and other environmental factors also affect the dates when the various phenomena occur in the tissues of a plant. Figure 10 is based on data compiled during two years, 1945 and 1946. In 1945, growth began somewhat later than in 1946; and dormancy was reached much later in 1945 than in 1946.

The diagram in figure 10 may be used to follow the changes in a given increment of the phloem through its two years of existence; and it also may serve to illustrate the changes in activity in the phloem as a whole during one season. Cambial activity, lasting about two and a half months, gives rise to a phloem increment. This activity is localized at the start but becomes rather general in a cane toward the end of March, that is, when the leaves of the axillary buds on the canes are unfolding. The first sieve tubes are discernible in the latter part of April. Cambial divisions cease and most of the sieve tubes are mature by the middle of June. The narrow-celled phloem, which is produced at the end of the growth period and constitutes only a small part of the phloem increment as a whole, remains thin-walled and, apparently, immature until late in August. (Figure 10 disregards this late maturation of the last part of a phloem increment.)

The newly formed phloem remains fully active and shows no morphologic changes until after the middle of October. At this time callus-the dormancy callus-begins to develop, usually in the peripheral portions of the phloem

\footnotetext{
"In this discussion the identification of the phloem in the various states (namely, active, inactive, partly active, and fully active) is based solely on such morphologic characteristics as were described in detail in earlier parts of this paper.
} 
TABLE 2

Reactivation of Phloem and Cambium in Ganes on Vines Growing Out of DOORS, SFASON OF 1946

\begin{tabular}{|c|c|c|c|c|}
\hline $\begin{array}{l}\text { Cane no., date of sampling, and } \\
\text { part of axis }\end{array}$ & $\begin{array}{c}\text { Condition of } \\
\text { nearest bud above }\end{array}$ & $\begin{array}{l}\text { Condition } \\
\text { of } \\
\text { cambium* }\end{array}$ & $\begin{array}{c}\text { Maximum } \\
\text { width of } \\
\text { new growth, } \\
\text { in microns }\end{array}$ & $\begin{array}{c}\text { Condition } \\
\text { of phloem } †\end{array}$ \\
\hline 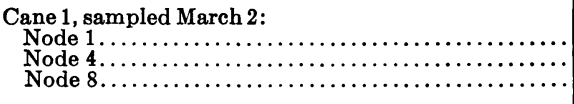 & $\begin{array}{l}\text { Scales closed } \\
\text { Scales closed } \\
\text { Scales closed }\end{array}$ & $\bar{z}$ & $\begin{array}{l}0.0 \\
0.0 \\
0.0\end{array}$ & $\bar{z}$ \\
\hline 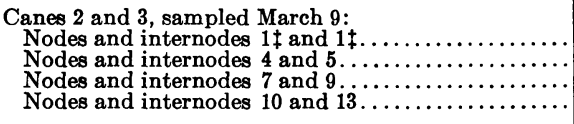 & $\begin{array}{l}\text { Just opening } \\
\text { Scales closed } \\
\text { Just opening } \\
\text { Scales closed }\end{array}$ & $\bar{\Xi}$ & $\begin{array}{l}0.0 \\
0.0 \\
0.0 \\
0.0\end{array}$ & $\stackrel{+}{+}$ \\
\hline $\begin{array}{l}\text { Cane 4, sampled March } 16: \\
\text { Node and internode } 8 \ldots \ldots \ldots \ldots \ldots \ldots \ldots \ldots \ldots \ldots \ldots \ldots \ldots \ldots \ldots \ldots \ldots \ldots \ldots \\
\text { Node and internode } 15 \ldots \ldots \ldots \ldots \ldots \ldots \ldots\end{array}$ & $\begin{array}{l}125 \mathrm{~mm} \text { out } \\
\text { Scales closed }\end{array}$ & $\overline{-}$ & $\begin{array}{l}0.0 \\
0.0\end{array}$ & + \\
\hline $\begin{array}{l}\text { Cane 5, sampled March } 16: \\
\text { Node and internode } 7 \ldots .\end{array}$ & Shoot with active & , & 00 & \\
\hline 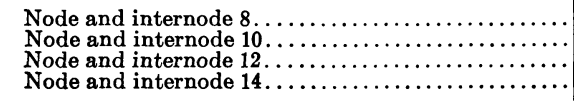 & $\begin{array}{l}\text { Just opening } \\
\text { Just opening } \\
\text { Scales closed } \\
\text { Scales closed }\end{array}$ & $\bar{z}$ & $\begin{array}{l}0.0 \\
0.0 \\
0.0 \\
0.0\end{array}$ & $\stackrel{+}{+}$ \\
\hline 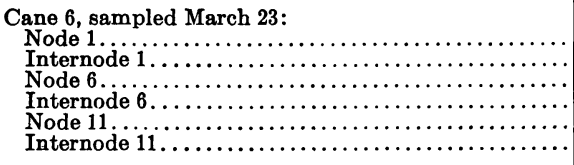 & $\begin{array}{l}60 \mathrm{~mm} \text { out } \\
60 \mathrm{~mm} \text { out } \\
\text { Just opening } \\
\text { Just opening } \\
\text { Scales closed } \\
\text { Scales closed }\end{array}$ & $\begin{array}{l}+ \pm \\
\pm \\
=\end{array}$ & $\begin{array}{r}25.0 \\
0.0 \\
0.0 \\
0.0 \\
0.0 \\
0.0\end{array}$ & $\begin{array}{l}+ \\
\dot{+} \\
+ \\
+\end{array}$ \\
\hline 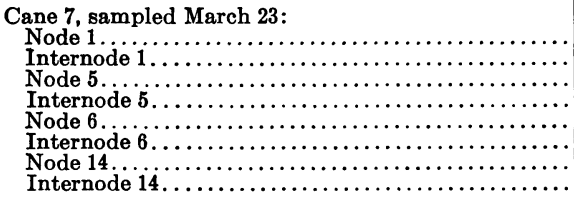 & $\begin{array}{l}140 \mathrm{~mm} \text { out } \\
140 \mathrm{~mm} \text { out } \\
140 \mathrm{~mm} \text { out } \\
140 \mathrm{~mm} \text { out } \\
\text { Just opening } \\
\text { Just opening } \\
\text { Scales closed } \\
\text { Scales closed }\end{array}$ & 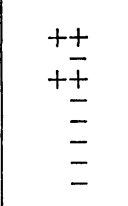 & $\begin{array}{r}37.5 \\
0.0 \\
0.0 \\
0.0 \\
0.0 \\
0.0 \\
0.0 \\
0.0\end{array}$ & $\begin{array}{l}+ \\
+ \\
+ \\
+ \\
+ \\
+\end{array}$ \\
\hline 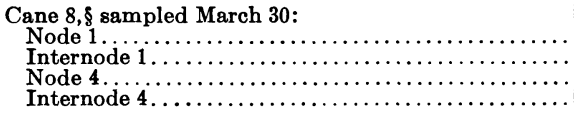 & $\begin{array}{l}1 \text { st leaf } 2 \mathrm{~cm} \text { long } \\
1 \text { st leaf } 2 \mathrm{~cm} \text { long } \\
\text { Scales closed } \\
\text { Scales closed }\end{array}$ & $\underline{ \pm}$ & $\begin{array}{r}12.5 \\
0.0 \\
0.0 \\
0.0\end{array}$ & \\
\hline 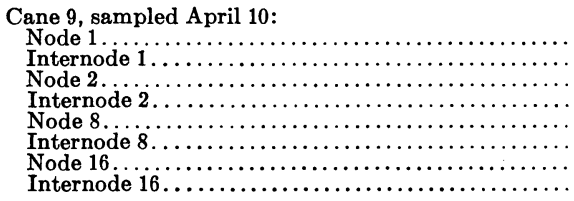 & $\begin{array}{l}2 \mathrm{~cm} \text { out } \\
2 \mathrm{~cm} \text { out } \\
\text { No bud } \\
\text { No bud } \\
1.5 \mathrm{~cm} \text { out } \\
1.5 \mathrm{~cm} \text { out } \\
\text { Just opening } \\
\text { Just opening }\end{array}$ & 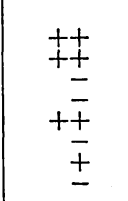 & $\begin{array}{r}137.5 \\
12.5 \\
0.0 \\
0.0 \\
125.0 \\
0.0 \\
0.0 \\
0.0\end{array}$ & $\begin{array}{l}++ \\
+ \\
+ \\
+ \\
+ \\
+ \\
++ \\
+ \\
++\end{array}$ \\
\hline
\end{tabular}

* - Cambium inactive.

,,++++++ , Cambial cells enlarged or divided over about $1 / 3$ of, over about $2 / 3$ of, or over the entire circumference of the stem, respectively.

$\dagger-$, No visible connecting strands and callus of maximal thickness.

+ , Connecting strands in the innermost part of the phloem and callus of maximal thickness.

++ . Connecting strands in $1 / 2$ to $2 / 3$ of phloem thickness, callus slightly thinner than before.

+++ , Conspicuously thickened connecting strands present throughout most of the phloem, and callus much thinner than during dormancy.

$\ddagger$ The first set of figures after the words "node" and "internode" refers to nodes and internodes on cane 2, the second set to those on cane 3 .

\& Between March 23 and March 30 the canes were cut back in a pruning operation and therefore the upper ends of the canes were not available on March 30 and later. 
first, then closer to the cambium as well. This initial development of the dormancy callus is very uneven in different parts of the same section and in different sections sampled successively. After the first frost and the concomitant leaf fall (commonly late in November, but sometimes early in December), the dormancy callus suddenly appears rather generally throughout the phloem. Thus this tissue becomes dormant; and it remains so for approximately three and a half months.

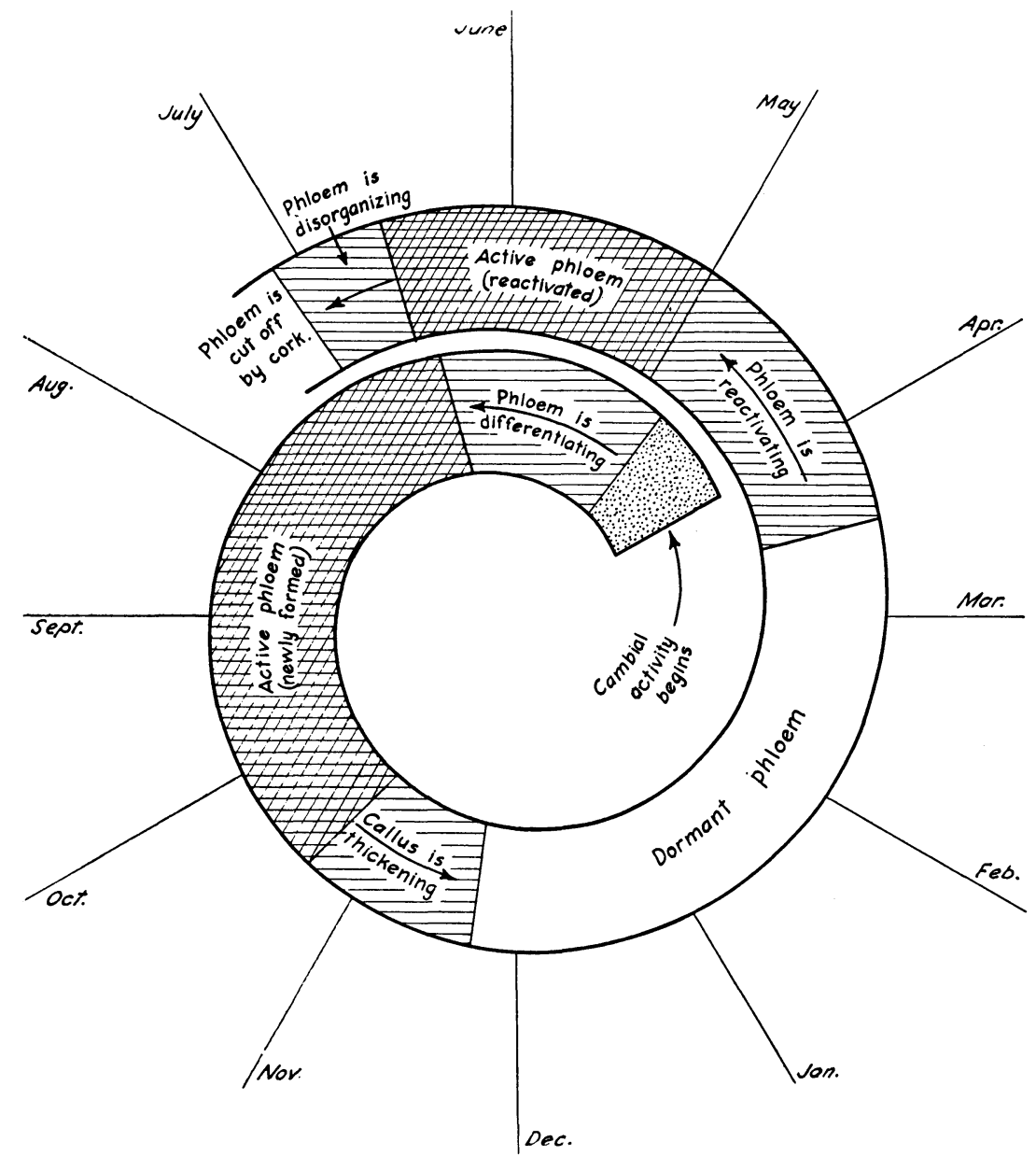

Fig. 10. Diagram illustrating the seasonal changes in one increment of secondary phloem in a cane. (This diagram was designed by Dr. L. K. Mann.)

In the middle of March, connecting strands become visible again and the callus thins down, first near the cambium, then also farther outward. By the end of April or early in May, all the sieve tubes acquire the appearance of active elements, such as they had before the inception of dormancy in the preceding season. Some few sieve tubes near the periphery may fail to return to the active state. Such elements become completely functionless and are 
either crushed or filled with tyloses. The reactivated phloem retains the same morphologic features until the second half of June. At this time the first indications of final disorganization-with or without formation of definitive callus-become perceptible. Like the change preceding dormancy in the fall, this final disorganization (preparatory to the formation of dead bark) does not occur uniformly and may be delayed until very shortly before the cork is formed. The latter arises early in July and causes the death of most of the phloem increment that was formed the year before. Since the cork cambium arises within this increment, some of the old phloem is left connected to the newly formed phloem. The sieve tubes of such a remnant of the old phloem become obliterated.

During one season, the course of transformations in the phloem as a whole has the following notable features. The reactivation of the phloem increment that originated in the preceding season begins while the cambium is still inactive. At this time the upper axillary buds are breaking through the scales, but the leaves are not yet unfolding. Cambial activity starts about two weeks later; but before much of the new phloem has been formed, the old phloem is fully reactivated. The latter tissue constitutes-in partly and in fully active states-the principal portion of the food-conducting tissue while the axillary shoots elongate and their leaves unfold and while the flowers develop from their primordia. (The latter are laid down during the preceding summer, according to Winkler and Shemsettin, 1937.) Of course, the amount of new phloem is constantly increasing in the meantime and early in June, when the berries begin to grow (Winkler and Williams, 1936) and the next-season cluster primordia are initiated (Winkler and Shemsettin, 1937), more than half of the new phloem increment is mature. When the berries are of about one half to two thirds of their mature size, the old phloem begins to show signs of disorganization. In the meantime the formation of the new phloem is completed, and after the cork is formed this phloem remains, during the rest of the season, as the only food-conducting tissue. Its morphology does not change until late in October when occasional signs of approaching dormancy become apparent. Finally, at leaf fall, full dormancy is attained. Thus, fully active phloem is available in the canes from early May till past the middle of October ; partially and fully active phloem together, from the middle of March till late in November.

In the discussion just given, the phloem is presented as becoming functionless after existing for two seasons. Though a given phloem increment usually functions during two seasons, it may function during three and even four seasons. Such longevity is uncommon in canes but is often encountered in trunks; it is more pronounced in some varieties than in others. Judging from the present observations, a phloem increment that is active during severai seasons becomes dormant every winter and is reactivated every spring.

In order that the canes might be compared with other parts of the vines, some samples were collected in 1945 from trunks, roots, and new shoots. The bases of the latter had fully formed primary phloem, with lignified protophloem fibers, early in May. By the middle of June cambial activity had ceased and most of the secondary phloem was mature. In the shoots, as in the cane, the maturation of the narrow-celled phloem that completed the yearly incre- 
ment of secondary phloem was delayed until late in August. When cork appeared in the canes it was also evident in the shoots, although only at their bases. From here this tissue developed acropetally and cut away all the protophloem and sometimes deeper lying phloem parts as well. Complete dormancy was observed in shoot samples collected early in December.

Because of the basipetal course of cambial reactivation in the vine as a whole, the trunks showed a delay (as compared with the canes) in the commencement of cambial divisions. In 1945 the canes exhibited active cambium during the first week of April. The first bark sample from a trunk was taken at the top of the trunk on April 17; it showed no cambial activity. On April 25 cambial divisions reached the middle of the trunk. On May 2 one vine showed active cambium 4 inches above the ground level; another did not. On May 9 cambial activity was observed in the roots. Thus, judging from the few samples examined, some three to four weeks had elapsed between the inception of radial growth in the canes and that in the bases of the trunks.

The samples of April 17 and 25, taken at different levels of trunks and exhibiting different degrees of cambial reactivation, were uniform with regard to the state of phloem reactivation. They were similar also to the cane samples taken at the same time in having partly reactivated phloem, with connecting strands and somewhat thinner callus than during dormancy. Evidently, phloem reactivation in both canes and trunks occurred more uniformly than cambial reactivation.

The disorganization of the phloem that preceded cork formation began irregularly in both canes and trunks, that is, the successive samples showed no uniform progression in the development of this phenomenon. Similarly, the initiation of cork lacked uniformity in the time of appearance and in the spread around the axis. In general, the cane and trunk samples showed new cork at similar times. The samples showed complete dormancy on December 3, but the first evidence of callus thickening was found on October 29 in the canes and on November 19 in the trunks.

As was pointed out previously, the samples of roots showed cambial reactivation some four weeks later than those of canes. Samples collected during the winter had no dormancy callus, but some exhibited thicker callus (with obvious connecting strands, however) at this time than during the summer. The cork was formed more irregularly in the root samples than in the others. Some three- to four-year-old roots still had some pericycle. The presence of the latter and the accumulation of nonfunctioning phloem, previously described in this paper, suggests that cork formation may be omitted in some seasons, at least in parts of roots.

Variations in the Thickness of Phloem. To complete the picture of phloem growth in Vitis vinifera, some data were gathered on the thickness and composition of bark in the varieties Sultanina and Ohanez. These data serve as a basis for tables 3 to 6 and offer comparisons of the following items : the bark of young and old growth on similar vines (table 3 ) ; bark of trunks of different varieties (tables 3 to 5 ) ; and bark of trunks of different ages (table 6 ). The tables consider the thickness of bark, the number of annual increments, and the numbers of sieve-tube and fiber bands.

In the canes the bark was measured in four places around the circumference. 
The bark samples from the trunks were $1 / 2$ to $1 \mathrm{~cm}$ in tangential extent and were measured either in two (data for tables 3 and 4) or four (data for table 6) places. In 1945 (tables 3 to 5) the samples were collected successively through part of the season, beginning in early spring and ending just before the formation of new cork. In 1946 (table 6) all collections were made in February while the vines were still dormant.

Since the samples of 1945 were collected before that season's growth was completed, the 1945 phloem was excluded from the study. The "number of annual increments" in tables 3,4 , and 6 included the outermost (the oldest) increment, which usually was incomplete because a part of it was cut off by cork formation during the preceding season. If the oldest increment was represented by one band of fibers and a narrow band of late phloem, or by the late phloem alone, such partial increment was not counted. If, however, the late phloem was associated with at least a part of a band having wide sieve tubes, the combination was included in the count. The presence of a fragment of an older increment on the outer periphery of the phloem indicated that the younger increments were present in their entirety. Such complete annual increments are analyzed in table 5. Sometimes the remnants of the oldest increments were obscured by changes associated with the loss of function and the initiation of cork cambium. In such instances, the outer limits of the outermost complete increment remained uncertain.

Table 3 gives data on bark thickness in the cane and trunk of Sultanina and in the trunk of Ohanez. The minimal and maximal values in the sixth, seventh, ninth, and tenth columns are not averages of observations on one sample, but represent certain individual observations. For example, among 30 measurements on the trunks of Sultanina vines, 1 gave the minimal value of $0.55 \mathrm{~mm}$ for total bark thickness. The averages in the eighth and eleventh columns are based on all observations on a given set of samples.

Judging from table 3, the one-year-old canes of Sultanina have thinner bark than the trunks. In the more or less elliptical transection of a cane, the vascular tissues are uneven in thickness : they are usually thinner at the extremities of the shorter diameter, thicker at those of the longer diameter. The uneven thickness of the xylem and phloem are visible in plate $5, B$, though the outline of this cane deviates only little from the circular. In less rounded canes the variations in tissue thickness may be even greater. This anatomic feature explains the difference between the minimal and maximal bark thicknesses of canes in table 3 . The trunk samples were more uniform in thickness, with the exception of 1 among 15, which was taken in a deep groove upon a trunk. The bark was very thin at the bottom of the groove. The Ohanez trunk samples in table 3 had thicker bark than those of Sultanina, though the trunks of the latter were older. Ohanez forms in general a thicker trunk than Sultanina.

Table 4 gives information on the relative thickness of bark in different parts of the same trunk. The samples from Sultanina, vine 1, indicate considerable uniformity in bark thickness at different levels of the trunk. The samples taken around the circumference of the trunk of vine 2 of Sultanina are all, except one, rather similar in thickness. The exception was the thin bark at the bottom of a deep groove previously mentioned. The Ohanez vines also showed little variation in bark thickness in the different parts of the trunk. 
Sultanina, vine 2, and Ohanez, vine 2, showed the same average number of annual increments of phloem, though the former had a thinner bark than the latter. Judging from this observation, the total bark thickness depends not only upon the number of annual increments, but also upon the width of each increment. Indeed, a thin bark sample may have more annual increments than a thick one. (Compare, for example, samples 8 and 9 in Sultanina, vine 2, and the various samples in Ohanez, vine 1.) Many observations indicate that the accumulation of several annual increments and the repeated reactivation of the same increment is particularly common in parts of the stem where phloem growth is abnormally weak.

TABLE 3

Comparison of Bark ThICKNess in Certain VARIETIEs of Vitis vinifera, SEASON OF 1945

\begin{tabular}{|c|c|c|c|c|c|c|c|c|c|c|}
\hline \multirow{2}{*}{ Variety } & \multicolumn{2}{|c|}{$\begin{array}{l}\text { Characteristic of } \\
\text { plant part } \\
\text { that was sampled }\end{array}$} & \multirow{2}{*}{$\begin{array}{l}\text { Num- } \\
\text { ber of } \\
\text { vines }\end{array}$} & \multirow{2}{*}{$\begin{array}{c}\text { Num- } \\
\text { ber of } \\
\text { bark } \\
\text { samples }\end{array}$} & \multicolumn{3}{|c|}{$\begin{array}{l}\text { Number of annual incre- } \\
\text { ments of phloem with- } \\
\text { out the current growth }\end{array}$} & \multicolumn{3}{|c|}{$\begin{array}{l}\text { Thickness of bark* } \\
\text { in mm }\end{array}$} \\
\hline & Kind & $\begin{array}{c}\text { Age, in } \\
\text { years }\end{array}$ & & & $\begin{array}{l}\text { Mini- } \\
\text { mum }\end{array}$ & $\begin{array}{l}\text { Maxi- } \\
\text { mum }\end{array}$ & Average & $\begin{array}{l}\text { Mini- } \\
\text { mum }\end{array}$ & $\underset{\text { mum }}{\text { Maxi- }}$ & Average \\
\hline Sultanina.. & $\begin{array}{c}\text { Internode } \\
\text { of cane }\end{array}$ & 1 & 10 & 11 & 1 & 1 & 1.0 & 0.29 & 0.73 & 0.50 \\
\hline Sultanina........... & Trunk & 11 & 4 & 15 & 1 & 3 & 2.2 & 0.55 & 1.40 & 1.03 \\
\hline Ohanez............. & Trunk & 8 & 2 & 17 & 2 & 4 & 2.9 & 1.30 & 2.55 & 1.84 \\
\hline
\end{tabular}

* Includes cork, which is about $0.05 \mathrm{~mm}$ thick.

To obtain detailed information on the width of the individual annual increments and their composition, the trunk bark of the vines used in tables 3 and 4 and of some others was analyzed in table 5 . The 18 bark samples of Sultanina used for table 5 were taken from 7 different vines as the table shows, vines 1 to 4 having eleven-year-old trunks, vines 5 to 7 four-year-old trunks. The 2 Ohanez vines used for sampling had eight-year-old trunks.

In table 5 only the complete annual increments were considered, that is, those increments whose outer limits could be determined by the presence of the late phloem of the next youngest increment. The values for thickness are given for all complete annual increments of each bark sample together and for each increment separately. The numbers of the sieve-tube and fiber bands also were determined for the sum of the complete increments of a given bark sample and for each increment separately. Annual growth always starts and ends with a sieve-tube band (plates $7, A ; 8, A$; and 16, $A$ ). Therefore, the number of fiber bands in a yearly increment is always one less than that of the sieve-tube bands. If the last sieve-tube band was very narrow and was composed of late phloem only (as in figure 7, $B$ to $D$ ), it was not counted as an entire band. In table 5, the presence of such a narrow sieve-tube band was recorded by means of a plus sign following the number for the sieve-tube bands. The distribution of plus signs in table 5 indicates the frequent formation of a narrow band of late phloem after the last fiber band.

Table 5 shows the several features which cause the greater thickness of trunk bark from Ohanez, as compared with similar bark from Sultanina. Each 
TABLE 4

Comparison of Bark Thickness at Difreterent Levels and at Different Positions AROUND THE CIRCUMFERENCE OF TRUNK, SEASON OF 1945

\begin{tabular}{|c|c|c|c|}
\hline $\begin{array}{l}\text { Variety, } \\
\text { vine no., } \\
\text { and } \\
\text { sample no. }\end{array}$ & Location of samples on trunk & $\begin{array}{c}\text { Number of } \\
\text { annual } \\
\text { increments } \\
\text { of phloem } \\
\text { without } \\
\text { the } \\
\text { current } \\
\text { growth }\end{array}$ & $\begin{array}{c}\text { Thickness } \\
\text { of } \\
\text { bark,* } \\
\text { in mm }\end{array}$ \\
\hline \multicolumn{4}{|l|}{ Sultanina: } \\
\hline $\begin{array}{l}\text { Vine 1: } \\
\quad \text { Sample 1 }\end{array}$ & 32 inches from the ground... & 2.0 & 1.15 \\
\hline Sample 2 & 23 inches from the ground... & 2.0 & 1.10 \\
\hline Sample 3 & 14 inches from the ground... & 2.0 & 1.05 \\
\hline Sample 4 & 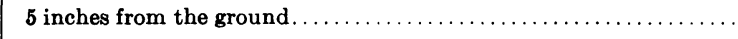 & 2.0 & 1.05 \\
\hline Average. . & & 2.0 & 1.09 \\
\hline \multicolumn{4}{|l|}{ Vine 2: } \\
\hline Sample 5 & 2 feet from the ground........ & 2.0 & 0.93 \\
\hline Sample 6 & $60^{\circ}$ to the right of sample $5 \ldots$ & 3.0 & 1.10 \\
\hline Sample 7 & $120^{\circ}$ to the right of sample 5. & 2.0 & 0.95 \\
\hline Sample 8 & $180^{\circ}$ to the right of sample 5. & 3.0 & 0.65 \\
\hline Sample 9 & $240^{\circ}$ to the right of sample 5. & 2.0 & 1.05 \\
\hline Sample 10 & $300^{\circ}$ to the right of sample 5. & 3.0 & 0.95 \\
\hline Average.... & & 2.5 & 0.94 \\
\hline \multicolumn{4}{|l|}{ Ohanez: } \\
\hline Vine 1: & & & \\
\hline Sample 1 & 4 feet from the ground....... & 3.0 & 2.00 \\
\hline Sample 2 & 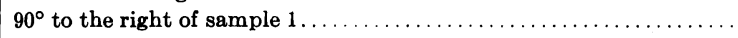 & 2.5 & 1.75 \\
\hline Sample 3 & 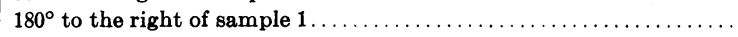 & 2.0 & 1.75 \\
\hline Sample 4 & $270^{\circ}$ to the right of sample $1 \ldots$ & 3.0 & 2.13 \\
\hline Sample 5 & 1 foot from the ground........ & 3.0 & 2.15 \\
\hline Sample 6 & $90^{\circ}$ to the right of sample $5 \ldots$ & 4.0 & 1.83 \\
\hline Sample 7 & $180^{\circ}$ to the right of sample $5 \ldots$ & 3.0 & 1.80 \\
\hline Sample 8 & 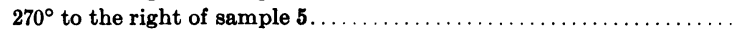 & 4.0 & 1.88 \\
\hline Average... & & 3.1 & 1.91 \\
\hline \multicolumn{4}{|l|}{ Vine 2: } \\
\hline Sample 9 & 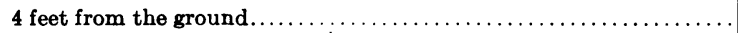 & 2.0 & 1.35 \\
\hline Sample 10 & 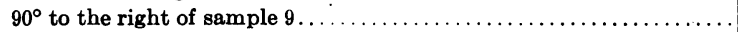 & 3.5 & 1.88 \\
\hline Sample 11 & $180^{\circ}$ to the right of sample $9 \ldots \ldots \ldots \ldots \ldots \ldots \ldots \ldots \ldots \ldots \ldots \ldots$ & 2.5 & 1.30 \\
\hline Sample 12 & 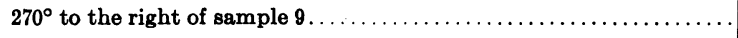 & 2.0 & 1.70 \\
\hline Average.... & & 2.5 & 1.56 \\
\hline
\end{tabular}

* Includes cork, which is about $0.05 \mathrm{~mm}$ thick.

year Ohanez produces a higher number of sieve-tube and fiber bands of a greater total thickness than Sultanina. Furthermore, Ohanez accumulates, on the average, a higher number of annual increments than the other variety.

In the discussion of tables 3 to 5 the condition of the phloem-that is, whether all or only part of it was in functioning state-was not mentioned. However, observations on barks of various thicknesses indicated, firstly, that a trunk with an exceptionally thick bark (table 4, Ohanez, vine 1; see also 


\section{TABLE 5}

Comparison of the Amount of Phlogm Produced during One Year on the Trunks OF CERTaIN VARIETIES of Vitis vinifera, Stason of 1945

\begin{tabular}{|c|c|c|c|c|c|c|c|c|c|c|}
\hline \multirow{2}{*}{$\begin{array}{l}\text { Variety, vine no., } \\
\text { age of vine trunk, } \\
\text { and sample no. }\end{array}$} & \multicolumn{2}{|c|}{$\begin{array}{c}\text { Complete } \\
\text { annual } \\
\text { increments }\end{array}$} & \multicolumn{2}{|c|}{$\begin{array}{l}\text { Total number of } \\
\text { bands with the } \\
\text { different cells }\end{array}$} & \multicolumn{3}{|c|}{$\begin{array}{l}\text { Number of sieve-tube } \\
\text { bands in the } \\
\text { different years }\end{array}$} & \multicolumn{3}{|c|}{$\begin{array}{l}\text { Thickness of phloem in } \\
\text { each annual increment, } \\
\text { in mm }\end{array}$} \\
\hline & $\underset{\text { ber }}{\text { Num- }}$ & $\begin{array}{l}\text { Thick- } \\
\text { ness, } \\
\text { in } \mathrm{mm}\end{array}$ & $\begin{array}{l}\text { Sieve } \\
\text { tubes }\end{array}$ & Fibers & 1942 & 1943 & 1944 & 1942 & 1943 & 1944 \\
\hline 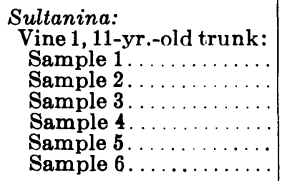 & $\begin{array}{l}3 \\
1 \\
1 \\
1 \\
1 \\
1\end{array}$ & $\begin{array}{l}1.12 \\
0.70 \\
0.73 \\
0.70 \\
0.62 \\
0.88\end{array}$ & $\begin{array}{l}7 \\
4+* \\
5 \\
4+ \\
4+ \\
5\end{array}$ & $\begin{array}{l}6 \\
4 \\
4 \\
4 \\
4 \\
4\end{array}$ & $\begin{array}{l}3 \\
\cdots \\
\cdots \\
. \\
.\end{array}$ & $\begin{array}{l}2 \\
\cdots \\
\cdots \\
\cdots \\
\cdots \\
\therefore\end{array}$ & $\begin{array}{l}3 \\
4+* \\
5 \\
4+ \\
4+ \\
5\end{array}$ & $\begin{array}{l}0.47 \\
\cdots \\
\cdots \\
\cdots \\
\cdots \\
\cdots\end{array}$ & $\begin{array}{l}\mathbf{0 . 3 6} \\
\cdots \\
\cdots \\
\cdots \\
\cdots \\
\cdots\end{array}$ & $\begin{array}{l}0.29 \\
0.70 \\
0.73 \\
0.70 \\
0.62 \\
0.88\end{array}$ \\
\hline 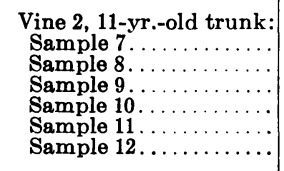 & $\begin{array}{l}2 \\
3 \\
1 \\
3 \\
1 \\
2\end{array}$ & $\begin{array}{l}0.81 \\
1.06 \\
0.60 \\
0.78 \\
0.70 \\
0.58\end{array}$ & $\begin{array}{l}6+ \\
7 \\
4 \\
6+ \\
4+ \\
3+\end{array}$ & $\begin{array}{l}5 \\
5 \\
3 \\
4 \\
4 \\
2 \\
2\end{array}$ & $\begin{array}{l}\ddot{3}+ \\
\ddot{3} \\
\cdots \\
\therefore\end{array}$ & $\begin{array}{l}3 \\
2 \\
. \\
\mathrm{i} \\
\mathrm{i}\end{array}$ & $\begin{array}{l}3+ \\
2 \\
4 \\
2+ \\
4+ \\
2+\end{array}$ & $\begin{array}{l}0.49 \\
0.39\end{array}$ & $\begin{array}{l}0.39 \\
0.34 \\
\dddot{0} .10 \\
\ddot{0} \ddot{10}\end{array}$ & $\begin{array}{l}0.42 \\
0.23 \\
0.60 \\
0.29 \\
0.70 \\
0.42\end{array}$ \\
\hline 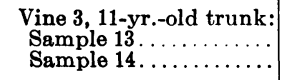 & $\begin{array}{l}1 \\
2\end{array}$ & $\begin{array}{l}0.60 \\
0.81\end{array}$ & ${ }_{5}^{3+}$ & $\begin{array}{l}3 \\
4\end{array}$ & .. & $\ddot{2}+$ & ${ }_{3}^{3+}$ & $\ldots$ & 0.42 & $\begin{array}{l}0.60 \\
0.39\end{array}$ \\
\hline $\begin{array}{c}\text { Vine 4, 11-yr.-old trunk: } \\
\text { Sample } 15 \ldots \ldots \ldots \ldots \ldots \ldots\end{array}$ & 2 & 0.78 & 5 & 4 & .. & $2+$ & 3 & $\ldots$ & 0.31 & 0.47 \\
\hline $\begin{array}{r}\text { Vine 5, 4-yr.-old trunk: } \\
\text { Sample } 16 \ldots \ldots \ldots \ldots \ldots \ldots\end{array}$ & 1 & 0.45 & 3 & 2 & .. & .. & 3 & $\ldots$ & $\ldots$ & 0.45 \\
\hline $\begin{array}{c}\text { Vine 6, 4-yr.-old trunk: } \\
\text { Sample } 17 . \ldots \ldots \ldots \ldots \ldots . . .\end{array}$ & 1 & 0.65 & 4 & 3 & .. & .. & 4 & $\ldots$ & $\ldots$ & 0.65 \\
\hline $\begin{array}{r}\text { Vine 7, 4-vr.-old trunk: } \\
\text { Sample is................ }\end{array}$ & 1 & 0.65 & $3+$ & 3 & .. & .. & $3+$ & $\ldots$ & $\ldots$ & 0.65 \\
\hline Average per increment & .. & 0.47 & 2.9 & 2.4 & .. & 1.9 & 3.4 & 0.45 & 0.30 & 0.54 \\
\hline 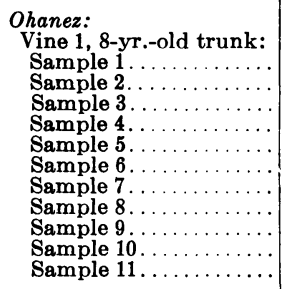 & $\begin{array}{l}3 \\
3 \\
3 \\
2 \\
3 \\
3 \\
3 \\
2 \\
3 \\
2 \\
2\end{array}$ & $\begin{array}{l}2.40 \\
1.89 \\
1.81 \\
1.54 \\
2.13 \\
2.15 \\
1.46 \\
1.25 \\
1.61 \\
1.56 \\
1.25\end{array}$ & $\begin{array}{c}12+ \\
11+ \\
10 \\
9+ \\
12+ \\
12+ \\
9+ \\
9+ \\
9+ \\
9+ \\
7+\end{array}$ & $\begin{array}{r}12 \\
11 \\
9 \\
8 \\
11 \\
11 \\
9 \\
8 \\
9 \\
8 \\
7\end{array}$ & $\begin{array}{c}4+ \\
3+ \\
3+ \\
\because 4+ \\
4+ \\
3+ \\
3+ \\
3+ \\
.\end{array}$ & $\begin{array}{l}4+ \\
4+ \\
3+ \\
3+ \\
4+ \\
4+ \\
3+ \\
4+ \\
3+ \\
4+ \\
3+\end{array}$ & $\begin{array}{l}4+ \\
4+ \\
4 \\
6+ \\
4+ \\
4+ \\
3+ \\
5 \\
3+ \\
5 \\
4+\end{array}$ & $\begin{array}{l}0.73 \\
0.57 \\
0.49 \\
0.73 \\
0.65 \\
0.47 \\
0.57\end{array}$ & $\begin{array}{l}0.86 \\
0.75 \\
0.62 \\
0.60 \\
0.65 \\
0.75 \\
0.47 \\
0.55 \\
0.55 \\
0.78 \\
0.60\end{array}$ & $\begin{array}{l}0.81 \\
0.57 \\
0.70 \\
0.94 \\
0.75 \\
0.75 \\
0.52 \\
0.70 \\
0.49 \\
0.78 \\
0.65\end{array}$ \\
\hline 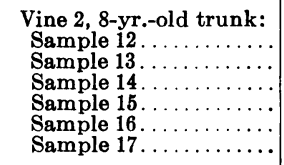 & $\begin{array}{l}2 \\
2 \\
3 \\
2 \\
2 \\
2 \\
2\end{array}$ & $\begin{array}{l}1.30 \\
1.04 \\
1.63 \\
1.17 \\
1.41 \\
1.41\end{array}$ & $\begin{array}{l}8+ \\
7+ \\
9+ \\
6+ \\
8+ \\
8+\end{array}$ & $\begin{array}{l}7 \\
7 \\
8 \\
5 \\
8 \\
7\end{array}$ & $\begin{array}{l}\ddot{y} \\
\ddot{3}+ \\
\ddot{y} \\
\therefore\end{array}$ & $\begin{array}{l}4 \\
3 \\
3+ \\
2+ \\
4+ \\
3+\end{array}$ & $\begin{array}{l}4+ \\
4+ \\
3 \\
4+ \\
4+ \\
5\end{array}$ & $\begin{array}{l}\ldots \\
\ldots .99 \\
\ldots \ldots \\
\cdots\end{array}$ & $\begin{array}{l}0.55 \\
0.47 \\
0.65 \\
0.44 \\
0.68 \\
0.60\end{array}$ & $\begin{array}{l}0.75 \\
0.57 \\
0.49 \\
0.73 \\
0.73 \\
0.81\end{array}$ \\
\hline Average per increment & .. & 0.64 & 3.7 & 3.5 & 3.4 & 3.4 & 4.1 & 0.59 & 0.62 & 0.69 \\
\hline
\end{tabular}

* + , Only a thin layer of late phloem occurring on the inside of the latest fiber band.

plates 8 and 9) may have a larger amount of nonfunctioning phloem than a similar trunk with thinner bark (table 4, Ohanez, vine 2); and, secondly, that thicker, older bark may have a wider layer of functionless phloem than the thinner, younger bark. To check these observations in some detail, the data for table 6 were assembled. The variety Ohanez was chosen for this study because, 


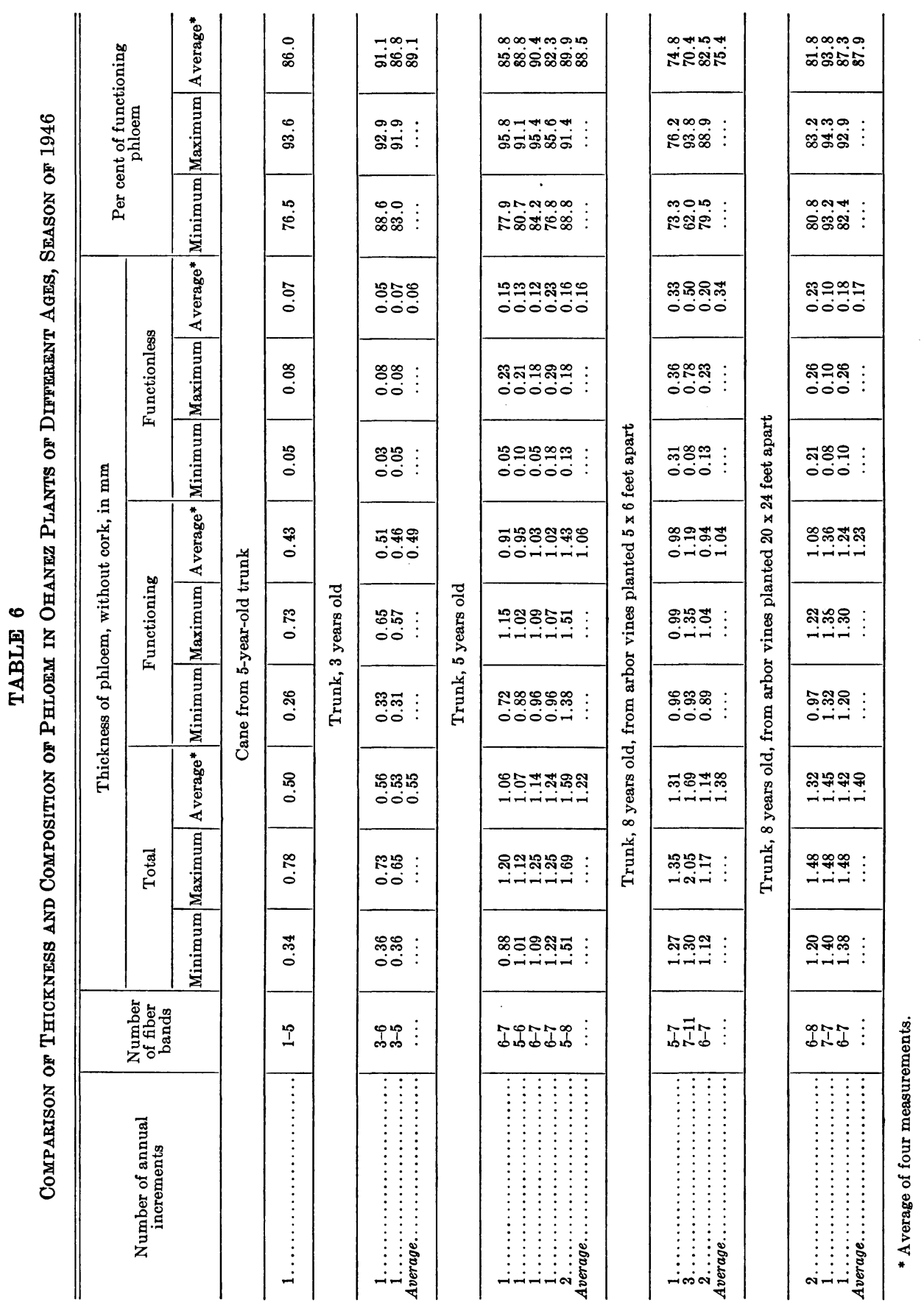


in addition to the plants with the eight-year-old trunks, a few vines with younger trunks were available for sampling. Each trunk-bark sample in table 6 was obtained from a different plant. The cane sample, which was taken from a plant with a five-year-old trunk, was included in table 6 to represent a oneyear-old axis.

Table 6 shows that older axes have thicker phloem than the younger ones, with a higher number of sieve-tube and fiber bands. (Only the latter are recorded in this table; usually, the number of sieve-tube bands may be calculated by adding one, or a plus sign to the number of fiber bands.) Furthermore, as the trunk ages, it tends to accumulate more than one annual increment of phloem in the bark. The cane and the three-year-old trunks showed much less nonfunctioning phloem than the older trunks. The functioning phloem of the younger axes was, however, also considerably thinner than that of the older ones. In other words, the greater thickness of the functionless phloem in the older trunks was compensated for by the greater total thickness of the bark. As a result of these relations, the per cent of functioning phloem was comparable in most axes. Two trunks from the arbor vines in a close planting had a lower per cent of functioning phloem, but the number of samples was not high enough to permit the conclusion that the close spacing had anything to do with the increase in the relative amount of functionless phloem.

Seasonal Variations of Starch Content in Canes. This study was made in a qualitative way, by the use of iodine, on samples collected in 1945. Early in March, before the break of dormancy, the canes showed large amounts of starch in the parenchyma, the septate fibers, and the rays of xylem and phloem. The starch grains in the phloem cells were markedly smaller than those in the xylem. The cambial cells in the fascicular region contained no starch (nor tannin), but those within the ray resembled mature ray cells with regard to starch and tannin content. The first obvious signs of starch removal appeared when the cambium became active ; they were limited to the immediate vicinity of the active cambium on the phloem side. In sections stained with iodine, the zone of active cambium now appeared as a light line dividing the xylem and phloem, both of which were still rich in starch. As the cambial activity spread around the circumference of the cane, starch progressively disappeared in the same direction. In the meantime, where cambial activity started first, the starch became depleted in successively more peripheral regions of the phloem. Early in May, at the time when the old phloem completed its reactivation (fig. 10), all bark appeared to be free of starch. A conspicuous depletion of starch now began in the xylem. In this tissue the starch content reached its lowest level (although not disappearing completely in the samples used) by the middle of June, at the time when the new phloem and xylem were fully formed.

After the middle of June the starch content of the xylem began to rise again, and by the end of this month it became evident in the new xylem. Soon after, the starch appeared in the phloem, but not in the parts that were partially disorganized and were to be cut off by the cork somewhat later (fig. 10). During the second week of July, starch accumulation almost reached the cambium on the xylem side. The youngest cells near the cambium developed large amounts of starch in early September, that is, shortly after the narrow layer of the 
phloem, formed at the very last, became mature. (See "Seasonal Cycle of Phloem Activity," p. 257.)

The observations just reported agree rather well with the data on carbohydrate metabolism in Vitis vinifera obtained by Winkler and Williams (1945, fig. 1). These writers found a rapid drop in starch content when growth began, with the lowest level occurring in June or July, depending on the part of the plant tested. After this final drop, the starch content rose till it reached a peak early in October. Winkler and Williams (1945) observed a second drop in starch content during dormancy, with a difference of some 4 to 6 per cent (based on residual dry weight) between the fall maximum and the winter minimum. The method of testing for starch used in the present study was not delicate enough to detect the winter fluctuation in the starch content.

Regarding the relative time and degree of starch depletion in the bark and wood, Winkler and Williams (1945) also found an indication of primary utilization of bark reserves and observed relatively large amounts of carbohydrates in the wood even at the summer minimum.

\section{DISCUSSION}

The present study confirms the observations of early workers (Wilhelm, 1880 ; Lecomte, 1889 ; Strasburger, 1891; Hill, 1908) that the phloem of grapevine functions more than one season, becoming dormant during the winter and being reactivated in the spring. The present investigation proves in addition that the reactivation of phloem begins before the division of cells is resumed in the cambium.

Considering the plant as a whole, the occurrence of dormancy is not necessarily a constant character of Vitis phloem. In the present study complete dormancy was observed in the aerial parts of the vine, but the roots had nondormant sieve tubes during the winter. Furthermore, the dormant state was attained in the stem parts only after the first frost. It is conceivable that in a milder climate than that of California, or in certain seasons, even the aerial plant parts could show incomplete dormancy or none at all.

The initial cambial activity in Vitis is closely related (as in other dicotyledons) to bud growth, depending on the reactivation of the buds (and the concomitant production of growth hormones); it begins beneath the earliest apical buds and progresses in a basipetal direction from the branch apices toward the main trunk and roots. No comparable localization and dependence on bud growth was observed, in the present study, with regard to the initiation of phloem activity. Some data suggested a basipetal progression of phloem reactivation, at least in the canes. More definite information regarding the progress of this phenomenon, especially in the plant as a whole, is not yet available.

The peculiar changes that occur in the sieve tubes as they become dormant and as they are reactivated, bear upon the present concept of the functioning sieve tube. According to this concept, the protoplast of a mature (functioning) sieve tube is in a denatured or premortal state. (See review by Esau, 1939.) In Vitis the "denatured protoplasts" of the sieve tubes show a considerable longevity and, during this long life, remain capable of performing vital functions, at least such as are involved in the repeated deposition and removal of 
callose. The occurrence of prolonged activity in an enucleate protoplast of a highly evolved plant is a singular phenomenon, indeed, and a speculative assumption seems relevant that the normal nucleate protoplasts of the companion cells have some relation to the sieve-tube protoplasts (Esau, 1947).

The occurrence of phloem reactivation gives a unique opportunity for testing with reasonable exactness the anatomist's notion of a functioning sieve tube. According to the morphologic concept (Esau, 1939, p. 403), one which has emerged mainly from studies of plants showing no phloem reactivation, an active sieve-tube element is enucleate; it contains parietal cytoplasm and a vacuole having the dispersed slime-usually accumulated on the sieve plates in cut material-as one of its components ; it has only small amounts of callose on the sieve plate and has very prominent connecting strands in the sieveplate pores ; it has starch grains, if their presence is characteristic for a given species; and it is associated with active companion cells. The appearance of the reactivated phloem of Vitis supports this concept: the reactivated sieve tubes have the features just described. These features are exhibited by the sieve tubes (the reactivated and the newly formed elements combined) throughout the period of active growth of the plant (fig. 10). The interpretation seems well justified that the sieve-tube elements which have such characeristics are functioning elements.

The presence of prominent connecting strands in the functioning sieve tubes deserves special emphasis. Though the large callus masses may offer no obstruction to the flow of materials through the sieve-plate walls, and though the connecting strands may play no direct role in the translocation of materials through the sieve tubes (Crafts, 1939b), Vitis phloem shows particularly clearly that the large callus accumulations indicate the passive state of a sieve tube, whereas the conspicuous connecting strands occur during the active state.

The present study raises once more the question of the relation of slime to the pores of the sieve areas. According to Crafts $(1939 a, 1939 b)$ and others (see review by Esau, 1939), the connecting strands are homogeneous structures and consist of cytoplasm only ; if slime is present in the pores, it is forced into them merely by changes (induced by cutting) in the pressure gradient in the sieve tubes. The presence of slime in the large callus masses of those Vitis sieve tubes that are just being reactivated (plate 20,A) and the occasional continuity of slime through the sieve plates of the dormant and, consequently, inactive sieve tubes (plate 20,D), do not seem to be related to changes in the pressure gradient and suggest that the slime of two sievetube elements is normally continuous across the sieve areas. Moreover, the deep staining of the connecting strands appears to depend on the presence of slime in the pores and not upon the unusual chromaticity of cytoplasm. During dormancy, the thick densely staining slime, within the lumen of the sieve-tube element, is clearly distinguishable from the lightly-staining cytoplasm, and there is no evidence that the chromaticity of the latter is increased because of "premortal" changes (Esau, 1939, p. 389).

Vitis is a good example of a plant in whose aerial parts "pericycle" does not exist as a distinct tissue of independent origin. The fibrous caps that appear on the periphery of the primary vascular bundles are primary-phloem fibers, 
or, more specifically, protophloem fibers. Many other dicotyledonous plants were previously shown to have fibers of phloic ${ }^{12}$ origin on the outer periphery of the vascular region (see review by Esau, 1943a, p. 195-96); recently Cannabis (Kundu, 1942), Linum (Esau, 1943b), Prunus (Schneider, 1945), and Cryptostegia (Artschwager, 1946) have been added to this group of plants. The ontogenetic relation of the primary fibers to the phloem in Cryptostegia is particularly notable because, in a mature stem, these fibers are isolated from the rest of the phloem by parenchyma and appear to be quite independent of the vascular tissues. During stem ontogeny, of course, the sieve tubes associated with the primary fibers "disappear so quickly" that they can be characterized as "evanescent" (Blaser, 1945, p. 140); nevertheless, these sieve tubes and the cells associated with them form an integral part of the phloem system of the plant. Indeed, the protophloem is the phloem of the growing region, and in its time and place would seem to be no less essential than the less evanescent phloem in the older parts of the plant. The evanescent nature of certain tissues and structures does not imply a lack of morphologic or physiologic significance. To cite only a few examples : the root hairs; the root-cap cells; the primary endodermis with Casparian strips; many floral parts ; cells and tissues involved in sporogenesis and gametogenesis; and, of course, the counterpart of the protophloem in the water-conducting region, the protoxylem - all these have a short existence but are generally regarded as being concerned with some vital part of the life cycle of a plant. The phloem as a whole could be regarded as a transitory tissue, at least in comparison with the xylem, yet all morphologists and physiologists agree that it merits a name of its own. There is accumulating evidence on the phloic origin (in dicotyledons) of the fibers on the outer periphery of the vascular region, and a general adoption of simplified terminology-referring to these fibers as primary phloem fibers-seems timely. If the distinction between the primary and secondary tissues is not essential, phloem fibers is an adequate term.

The behavior of the secondary phloem fibers in Vitis calls attention to still another aspect of the problem of defining fibers. Since De Bary (1884, Chapter II), the loss of protoplasts by fibers has been stressed as a distinguishing characteristic of these elements. In contrast, the "sclerotic cells," that is, the thick-walled forms of parenchyma, are said to remain alive for a long time and partake in the vital function of the plant. De Bary admits that a clear distinction cannot be drawn between the two kinds of cells : in some fibers-and the septate fibers of $V$ itis are given as an example (De Bary, 1884, p. 134) - the functions of the cell cease slowly. Obviously, the septate fibers of $V$ itis (those of the xylem and phloem alike) are concerned with starch storage after they develop their thick lignified walls. In other words, they combine the functions of fibers and parenchyma cells. In certain other plants-for example, the cherry (Schneider, 1945) and guayule (Artschwager, 1943) - the sclerifications of the secondary phloem fibers is delayed until the sieve tubes cease to function. Artschwager (1943, p. 23) specifically mentions that in guayule no difference exists between the phloem-parenchyma cells and the "sclerenchyma initials,

12 The word phloic is adopted here as an adjective derived from the word phloem. A precedent in the use of the adjectival form of phloem occurs in the well known terms ectophloic and amphiphloic. 
since most of these cells are pointed and eventually thicken and lignify." Similarly, the protophloem fibers are living cells as long as the sieve tubes are intact, becoming mechanical elements only after these sieve tubes are obliterated. Judging from the compactness of the fibrous masses formed in the protophloem, all the cells remaining in the latter after the obliteration of the sieve tubes and companion cells become fibers. In other words, the protophloem may contain no phloem parenchyma as such. (See also Esau, 1943b.) Perhaps fibers sometimes replace phloem parenchyma, either by retaining parenchymatous characteristics until after the sieve tubes lose their function (protophloem fibers of many plants ; secondary fibers of cherry and guayule), or by combining the characteristics of parenchyma and fibers (secondary fibers of the grapevine). Recently Kundu $(1942,1944)$ has reported that even such typical phloem fibers as those of Cannabis and Corchorus remain alive throughout the life of the plant; and Foster (1944) has called attention to the probable longevity of the protoplasts in sclereids of Camellia. Obviously the concepts of fibers, and of sclerenchyma in general, cannot be conceived too narrowly with regard to cell shape and cell-wall structure (phloem fibers are not always lignified), and with respect to cell contents and function.

The absence of the so-called nacré walls in the sieve tubes of Vitis is worthy of special mention. Transitory thickenings in the differentiating and recently matured sieve tubes are characteristic of many plants (Esau, 1939). Sometimes these thickenings are so prominent that the sieve tube resembles a xylem element in wall thickness (see, for example, Schneider, 1945). In Vitis, however, the sieve tubes attain moderate thickness-similar to that of the phloemparenchyma cells-and retain it till they are cast off by cork development.

\section{SUMMARY}

The phloem of Vitis vinifera was studied through axis samples collected in a California vineyard at regular intervals during two years. The phloem of the canes (one-year-old branches) was investigated in particular detail, but that of the trunks and roots also was examined.

In addition to the usual iodine-aniline blue technique for studying phloem, a stain combination of Bismark brown, iodine green, and resorcin blue was employed, the staining being followed by the mounting of sections in Karo sirup. The latter stain combination differentiated very clearly between the callose and the sieve-tube slime and produced semipermanent mounts useful for survey work and for detailed studies of the sieve tubes.

The primary phloem of the shoots can be divided into protophloem and metaphloem. In the former, the sieve tubes are obliterated during shoot development and the remaining cells differentiate into septate fibers. The metaphloem has no fibers. The protophloem is cut off by cork at the end of the season and the metaphloem becomes functionless.

The secondary phloem is divided into blocks by broad parenchyma rays. Within each block tangential bands of fibers alternate with bands containing sieve tubes, companion cells, and phloem parenchyma. Each season several fiber bands and several sieve-tube bands are produced by the cambium. Each seasonal increment begins and ends with a sieve-tube band. The phloem formed at the end of the season is composed of very narrow cells and contrasts rather 
sharply with the wide-celled phloem that follows it the next season. Hence it is possible to distinguish between the annual increments.

Each annual increment of secondary phloem is retained on the plant for at least two seasons ; then most of it is cut off by the cork. At the end of the season, younger axes usually have one increment of phloem and a small part of another, older increment; older axes may accumulate two, three, and even four increments.

In the aerial plant parts a given phloem increment functions during the season when it is formed; it is dormant during the winter, is reactivated in the spring, and functions for another season. If it is not cut off by the cork at the end of the second season, it may become reactivated two or even more times. Root phloem does not appear to become dormant.

Since the phloem is sloughed off rather regularly after it ceases to function, only a relatively small amount of functionless (nonconducting) phloem accumulates on the stems just beneath the cork. This amount is usually very small in young stems but may be larger in trunks. Roots appear to have irregular formation of cork and a consequent accumulation of considerable amounts of functionless phloem.

The reactivation of the phloem precedes that of the cambium and appears to show no comparable initial localization in relation to bud growth.

The phloem activity during a given season may be summed up as follows. The reactivation of the phloem that was formed during the preceding season begins about two weeks before the cambial divisions start. This phloem is in full function before much of the new phloem has been produced. When the latter is fully formed, the old phloem disorganizes and is cut off by the cork. The new phloem functions until dormancy sets in after leaf fall.

In addition to the topics just summed up, this paper considers in some detail : the comparative structure of the active, dormant, and functionless phloem ; the ontogeny and histology of the phloem ; the activity of the vascular cambium; and the formation of cork. 


\section{LITERATURE CITED}

ARBAUmont, J. D'.

1881a. Sur la disposition des faisceaux dans la tige, la feuille et les bourgeons de quelques plants de la famille des Ampélidées. Soc. Bot. de France Bul. 28:278-86.

1881b. La tige des Ampélidées. Ann. des Sci. Nat., Bot. Ser. 6. 11:186-255.

ARtschwager, ERNSt.

1943. Contribution to the morphology and anatomy of guayule (Parthenium argentatum). U. S. Dept. Agr. Tech. Bul. 842:1-33.

1946. Contribution to the morphology and anatomy of Cryptostegia (Cryptostegia grandiflora). U. S. Dept. Agr. Tech. Bul. 915:1-40.

Avery, G. S., P. R. BURKHOLDER, and HARRIET B. CRETGHTON.

1937. Production and distribution of growth hormone in shoots of Aesculus and Malus, and its probable role in stimulating cambial activity. Amer. Jour. Bot. 24:51-58.

BARGHOORN, E. S., JR.

1940. The ontogenetic development and phylogenetic specialization of rays in the xylem of dicotyledons. I. The primitive ray structure. Amer. Jour. Bot. 27:918-28.

BenNeTT, C. W.

1940. The relation of viruses to plant tissues. Bot. Rev. 6:427-73.

BLASER, H. W.

1945. Anatomy of Cryptostegia grandiflora with special reference to the latex system. Amer. Jour. Bot. 32:135-41.

Brown, H. P.

1915. Growth studies in forest trees. 2. Pinus strobus L. Bot. Gaz. 59:197-241.

BUTLER, ORMOND.

1910. Observations on the California vine disease. Torrey Bot. Club Mem. 14:111-53.

CHEAdLe, V. I., and N. B. WHITTORD.

1941. Observations on the phloem in the Monocotyledoneae. I. The occurrence and phylogenetic specialization in structure of the sieve tubes in the metaphloem. Amer. Jour. Bot. 28:623-27.

Cockerham, G.

1930. Some observations on cambial activity and seasonal starch content in sycamore (Acer pseudo platanus). Leeds Phil. and Lit. Soc. Proc. 2:64-80.

Committee on Nomenclature, Intprenational Assoctation of Wood ANatomists.

1933. Glossary of terms used in describing woods. Yale Univ., School Forestry. Trop. Woods $1933(36): 1-12$.

CrafrTs, A. S.

1931. Technic for demonstrating plasmodesmata. Stain Technol. 6:127-29.

1939a. The relation between structure and function of the phloem. Amer. Jour. Bot. 26: $172-77$.

$1939 b$. The protoplasmic properties of sieve tubes. Protoplasma $33: 389-98$.

DE BARY, A.

1884. Comparative anatomy of the vegetative organs of the phanerogams and ferns. (English translation by F. O. Bower and D. H. Scott.) 659 p. Clarendon Press, Oxford.

ESAU, KATHERINE.

1938. Ontogeny and structure of the phloem of tobacco. Hilgardia 11 (8):343-424.

1939. Development and structure of the phloem tissue. Bot. Rev. 5:373-432.

1943a. Origin and development of primary vascular tissues in seed plants. Bot. Rev. 9: 125-206.

1943b. Vascular differentiation in the vegative shoot of Linum. III. The origin of the bast fibers. Amer. Jour. Bot. 30:579-86.

1947. A study of some sieve-tube inclusions. Amer. Jour. Bot. 34:224-33.

Foster, A. S.

1942. Practical plant anatomy. 155 p. D. Van Nostrand Company, Inc., New York, N.Y.

1944. Structure and development of sclereids in the petiole of Camellia japonica L.

GARD. Torrey Bot. Club Bul. 71:302-26.

1900. Sur l'origine variable du premier périderme chez le Vitis. Soc. Linn. de Bordeaux, Procè-Verbaux 55 : ccii-cciii. 
Grossenbacher, J. G.

1915. The periodicity and distribution of radial growth in trees, and their relation to the development of annual rings. Wisconsin Acad. Sci., Arts, Letters, Trans. 18: $1-77$.

HILL, A. W.

1908. The histology of the sieve-tubes of angiosperms. Ann. Bot. [London] 22:245-90.

Houston, B. R., KATHERINe EsAu, and WM. B. HEWITT.

1947. The mode of vector feeding and the tissues involved in the transmission of Pierce's

HUBER, BRUNO.

disease virus in grape and alfalfa. Phytopathology 37:247-53.

1939. Das Siebröhrensystem unserer Bäume und seine jahreszeitlichen Veränderungen. Jahrb. f. Wiss. Bot. 88:176-242.

JANCZEWSKI, E. DE.

1881. Etudes comparées sur les tubes cribreux. Soc. Natl. des Sci. Nat. et Math. de Cherbourg, Mém. 23:209-350.

JoHANSEN, D. A.

1940. Plant microtechnique. 523 p. McGraw-Hill Book Company, New York, N.Y.

KNUDSON, L.

1913. Observations on the inception, season and duration of the cambium development in the American larch (Larix laricina [du Roi] Koch). Torrey Bot. Club Bul. 40: 271-93.

1916. Cambial activity in certain horticultural plants. Torrey Bot. Club Bul. 43:533-37.

KROEMER, K.

1906. Ueber die Anatomie der Rebenwurzel. K. Lehranst. f. Wein-, Obst- u. Gartenbau zu Geisenheim a. Rhein, Ber. 1905:207-10.

KUNDU, B. C.

1942. The anatomy of two Indian fibre plants, Cannabis and Corchorus with special reference to fibre distribution and development. Indian Bot. Soc. Jour. 21:93-128.

1944. Anatomy of jute stem with special reference to cambial activity and distribution of fibres in relation to leaf-trace system. Asiatic Soc. Bengal, Jour. and Proc. $10: 27-52$.

LECOMTE, H.

1889. Contribution à l' étude du liber des Angiospermes. Ann. des Sci. Nat., Bot. 10: 193-324.

LODEWICK, J. E.

1928. Seasonal activity of the cambium in some north-eastern trees. New York State Col. Forestry, Syracuse Univ., Bul. 1 (2a) (Tech. Pub. 23) : 1-87.

MÜHLDORF, A.

1937. Das plasmatische Wesen der pflanzlichen Zellbrücken. Bot. Centbl., Beihefte. Abt. A 56:171-364.

NÄGELI, C.

1861. Ueber die Siebröhren von Cucurbita. Bayer. Akad. der Wiss., Math.-Phys. Kl. Sitzber. 1:212-38.

Penzig, Otto.

1882. Anatomia e morfologia della vite ( $V$ itis vinifera L.). Lab. Crittogamico Garovaglio, Univ. Pavia. Arch. 4:145-76.

PRIESTLEY, J. H.

1930. Studies in the physiology of cambial activity. III. The seasonal activity of the cambium. New Phytol. 29:316-54.

Priestley, J. H., L. I. Scotr, and M. E. Mauins.

1933. A new method of studying cambial activity. Leeds Phil. and Lit. Soc. Proc. 2: 365-74.

RAWLINS, T. E.

1933. Phytopathological and botanical research methods. 156 p. John Wiley and Sons, Inc., New York, N.Y.

SASS, J. E.

1940. Elements of botanical microtechnique. 222 p. McGraw-Hill Book Company, New York, N.Y.

SCHNEIDER, HENRY.

1945. The anatomy of peach and cherry phloem. Torrey Bot. Club Bul. 72:137-56. 
SOLEREDER, HANS.

1908. Systematic anatomy of the dicotyledons. Vol. 1. 644 p. Clarendon Press, Oxford.

StrasburGer, EdUARD.

1891. Ueber den Bau und die Verrichtungen der Leitungsbahnen in den Pflanzen. Histologische Beiträge, Vol. 3, 1000 p. Gustav Fischer, Jena.

SZIGETHI-GYULA, A.

1905. Adatok a szölögyökerek anatómiájahoz, különös tekintettel a Phylloxera bántalmára. Növén. Közlemén. (Title changed in 1909 to Bot. Közlemén.) 4(2):45-62. Abstracted in French in: Beiblatt zu den Növen. Közlemén., Organ Botan. Sektion der Königl. Ungar. Naturwiss. Gesell. 4(2):9-11.

VARRELMAN, F. A.

1931. Paper apron to prevent curling of microtome sections. Science 74:20.

Vestal, P. A., and M. R. Vestal.

1940. The formation of septa in the fiber tracheids of Hypericum Androesemum L. Harvard Univ. Bot. Mus. Leaflet 8:169-88.

WIGHT, W.

1933. Radial growth of the xylem and the starch reserves of Pinus sylvestris: a preliminary survey. New Phytol. 32: 77-96.

WILHELM, KARL.

1880. Beiträge zur Kenntnis des Siebröhrenapparates dicotyler Pflanzen. 90 p. Wilhelm Engelmann, Leipzig.

WiNKLER, A. J., and E. M. SHEMSETTIN.

1937. Fruit-bud and flower formation in the Sultanina grape. Hilgardia 10(15):589611.

WinkLeR, A. J., and W. O. WILLIAMs.

1936. Effect of seed development on the growth of grapes. Amer. Hort. Soc. Proc. 33 : 430-34.

1945. Starch and sugars of Vitis vinifera. Plant Physiol. 20:412-32. 
Plate 1. Illustration of the results of staining of phloem with the following combination: Bismark brown, iodine green, and resorcin blue. The callose is stained blue. (The callose in $C$ and $D$ appears more green than it usually does in the slides.) $A$, Transverse section through partly reactivated phloem collected April 7, 1945. Connecting strands are visible in the lower eallus mass. (Compare with plate $10, A$.) $B$, Longitudinal section through the 1944 phloem that has just ceased to function. Collected July 3,1945. Definitive callus occurs on all sieve areas. $C$ and $D$, Longitudinal sections through dormant phloem collected December 3, 1946. The most prominent masses of callus in $C$ are on a wall between two sieve-tube elements. In $D$ the callus occurs on the walls between sieve tubes and phloem-parenchyma cells; it has been formed only on the sieve-tube sides of the walls. $(A \times 320 ; B \times 200 ; C$ and $D \times 800$. $)$ 


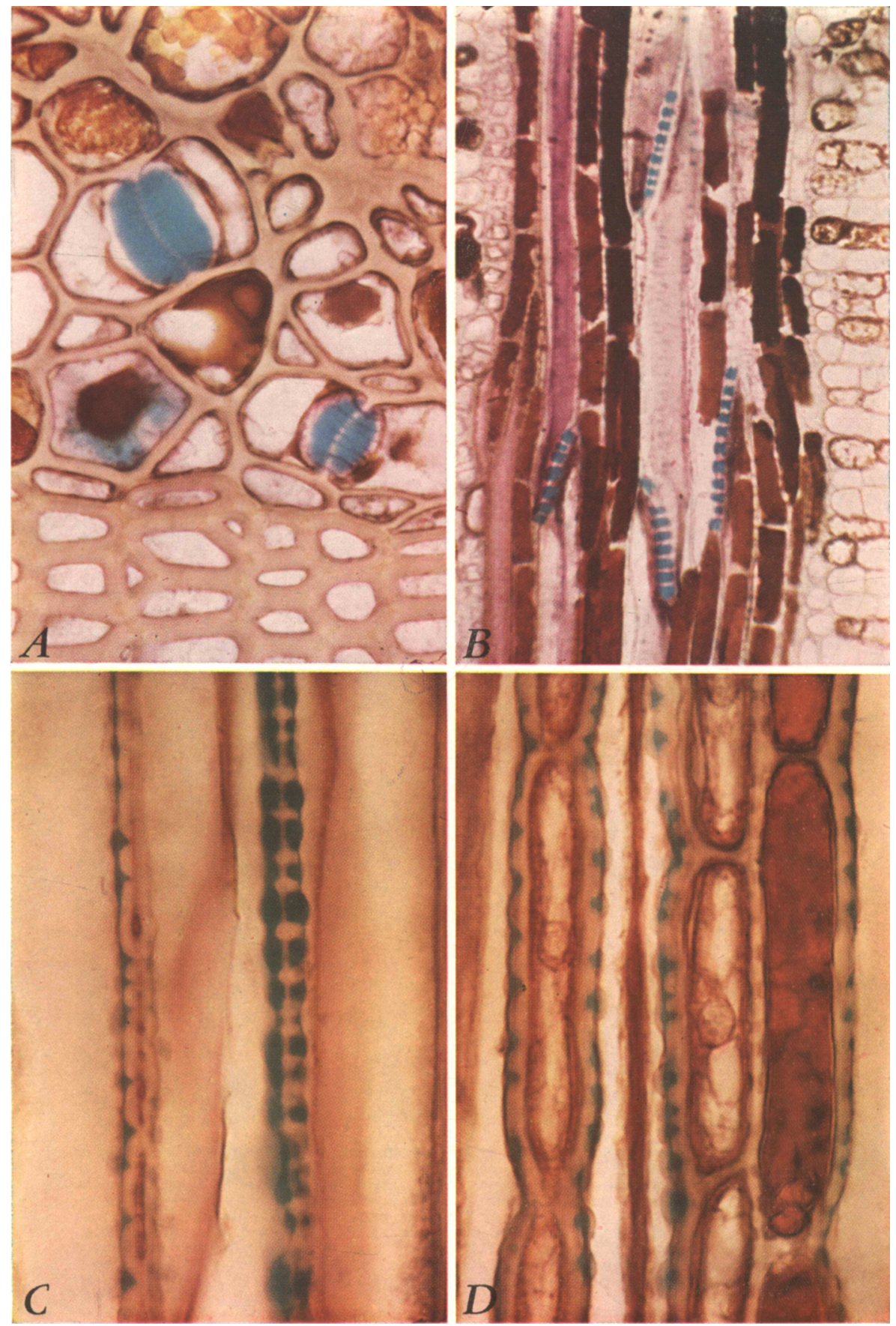




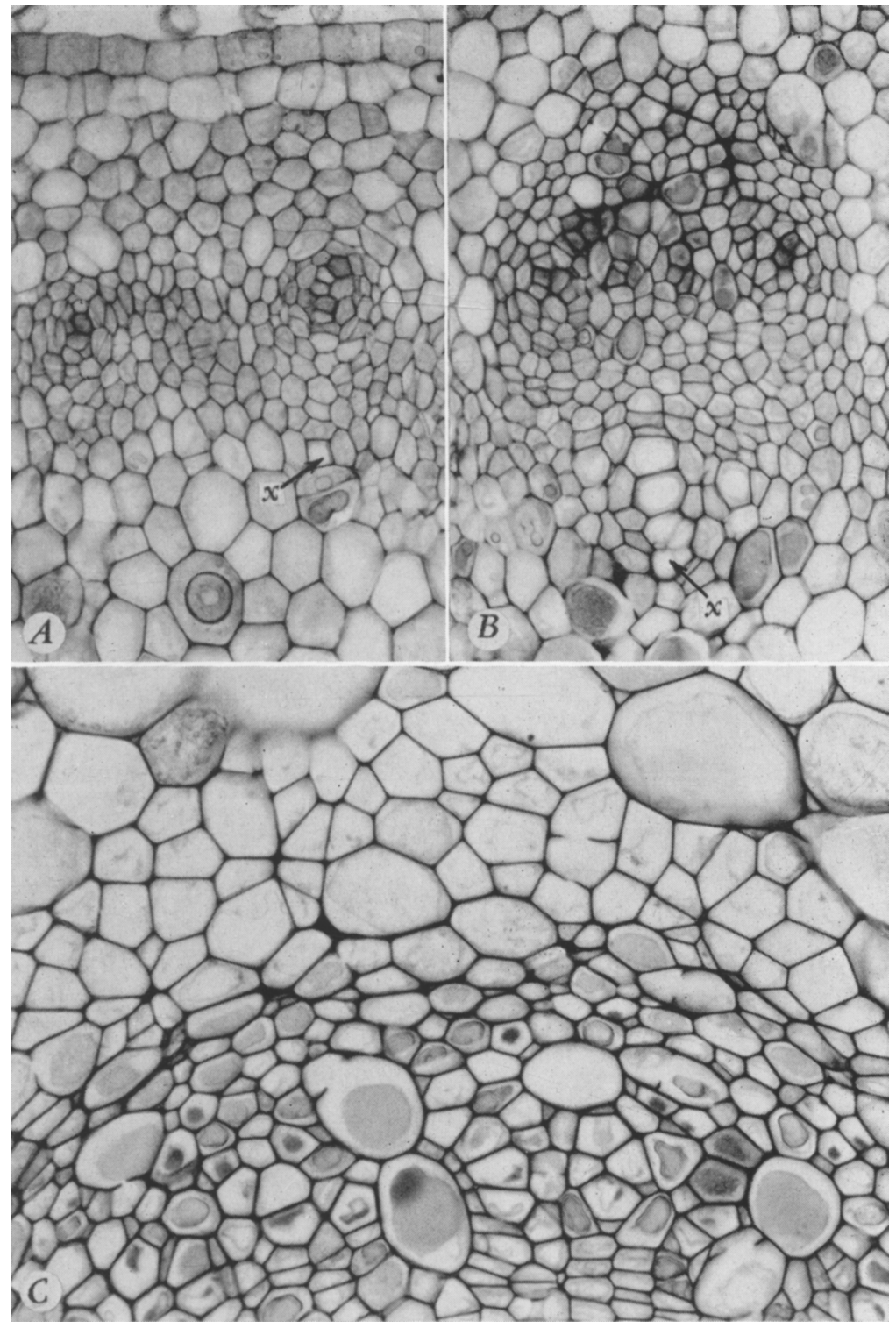

Plate 2. Transverse sections through a shoot illustrating stages in the differentiation of the primary phloem. A, Two procambial bundles: one, to the left, with the first sieve-tube (thick-walled cell); the other, to the right, with several sieve tubes and one xylem element $(x)$. B, Young vascular bundle still lacking cambium. Many sieve tubes have been obliterated in the outermost part of the bundle; their remnants look like darkly stained wall thickenings. A radial row of xylem elements occurs at $x$. $C$, Phloem of a bundle in which primary growth was nearing its end. The regions from the top downward are: cortex (largest cells); nonfunctioning phloem (protophloem) in which the sieve tubes are crushed and the future fibers enlarged; functioning phloem (metaphloem). (All $\times 500$.) 


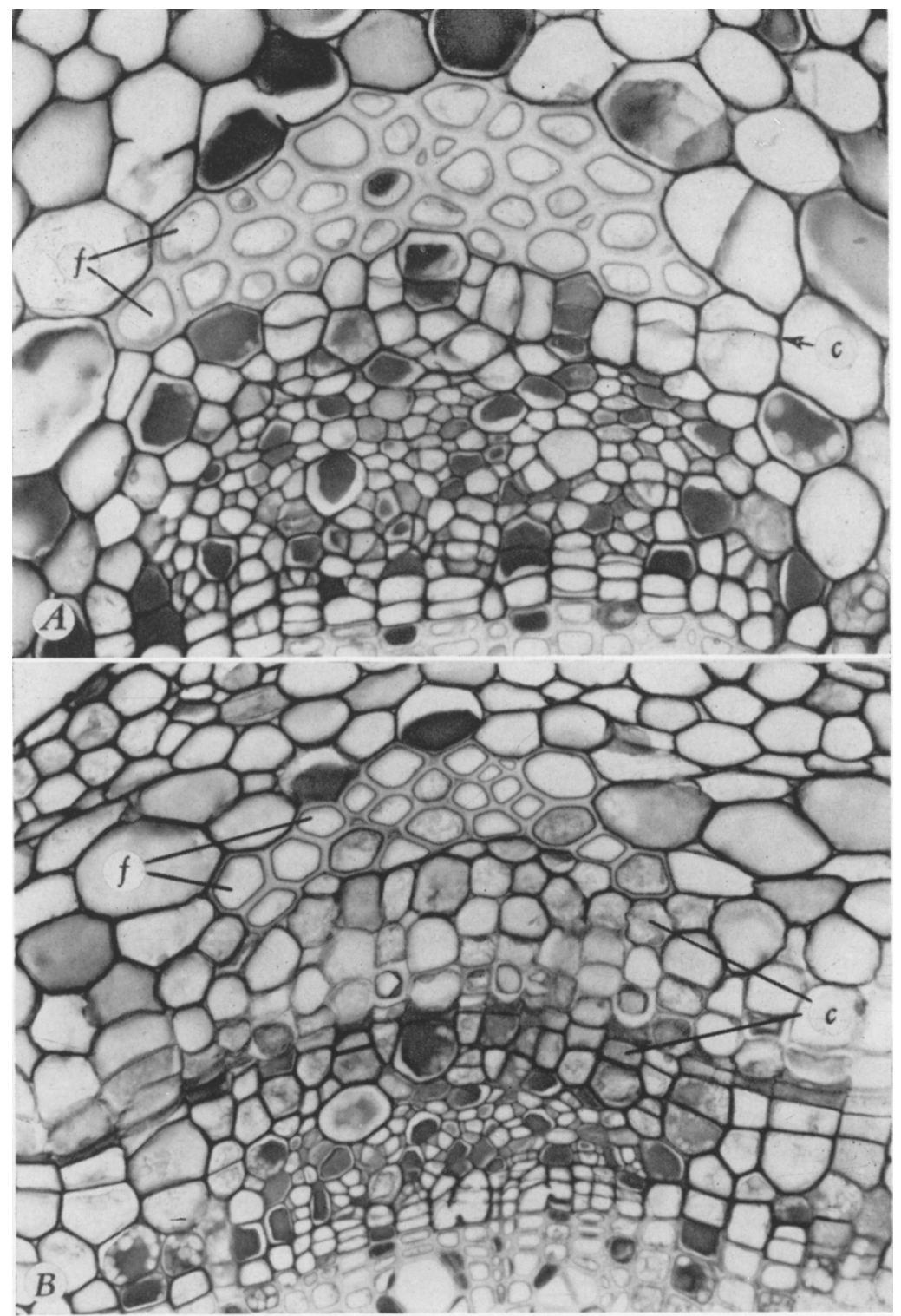

Plate 3. Transverse sections through a seedling stem showing an earlier $(A)$ and a later $(B)$ stage in the initiation of cork. In both sections from the top downward are: cortex primary-phloem fibers $(f)$; phloem-parenchyma cells dividing to form cork $(c)$; functioning phloem (mostly metaphloem); cambium; xylem. (Both $\times 290$.) 

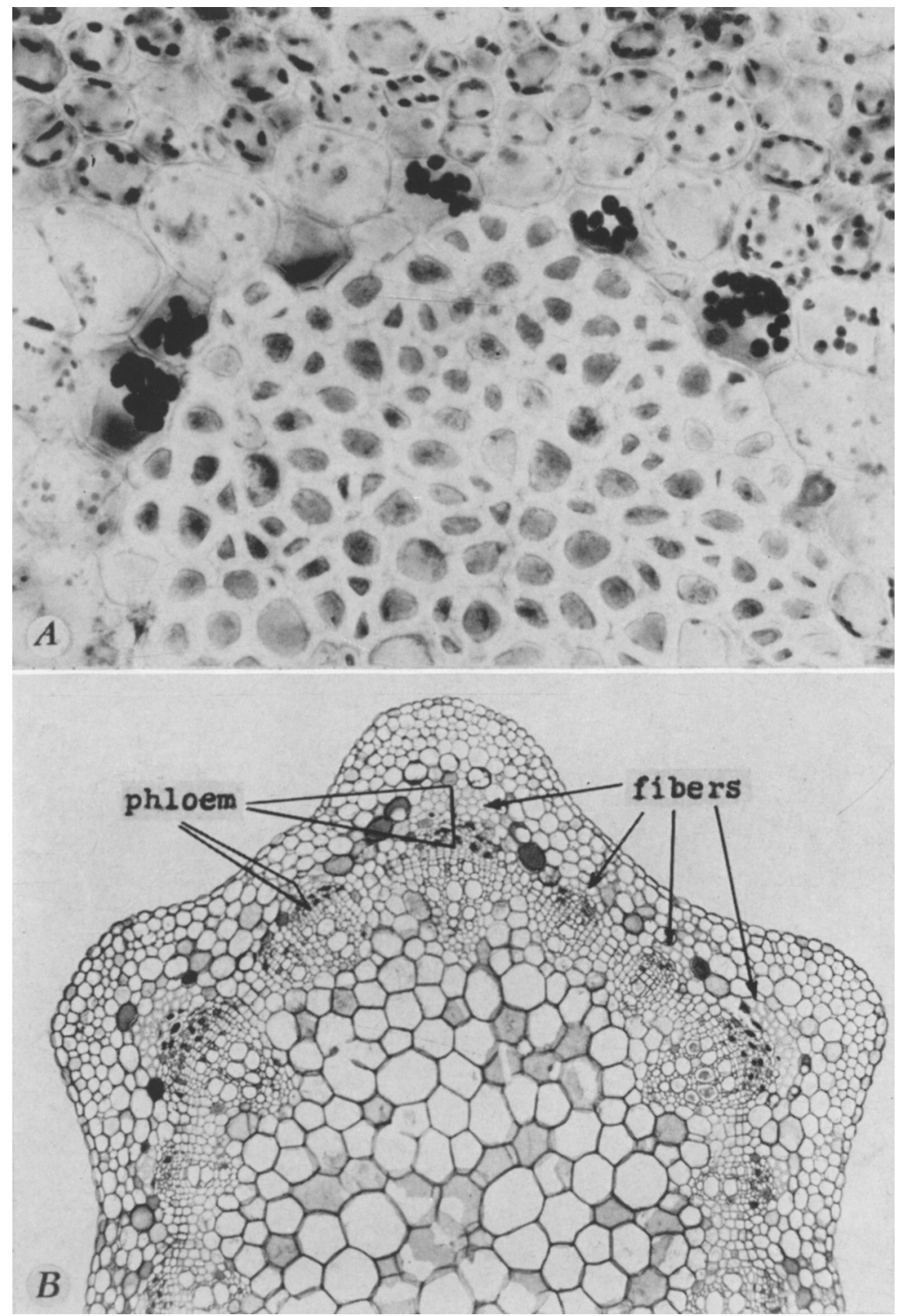

Plate 4. A Transverse section through primary-phloem fibers (below) and cortical cells (above) from a new shoot. The black bodies in the cortical cells are starch grains stained with iodine. The cortical cells with the large starch grains next to the fibers constitute the starch sheath. $B$, Transverse section through a seedling stem in which primary growth was completed. From outside in the tissues are: epidermis; cortex; primary phloem, including the fibers; cambium; xylem; and pith. $(A \times 290 ; B \times 90$. $)$ 


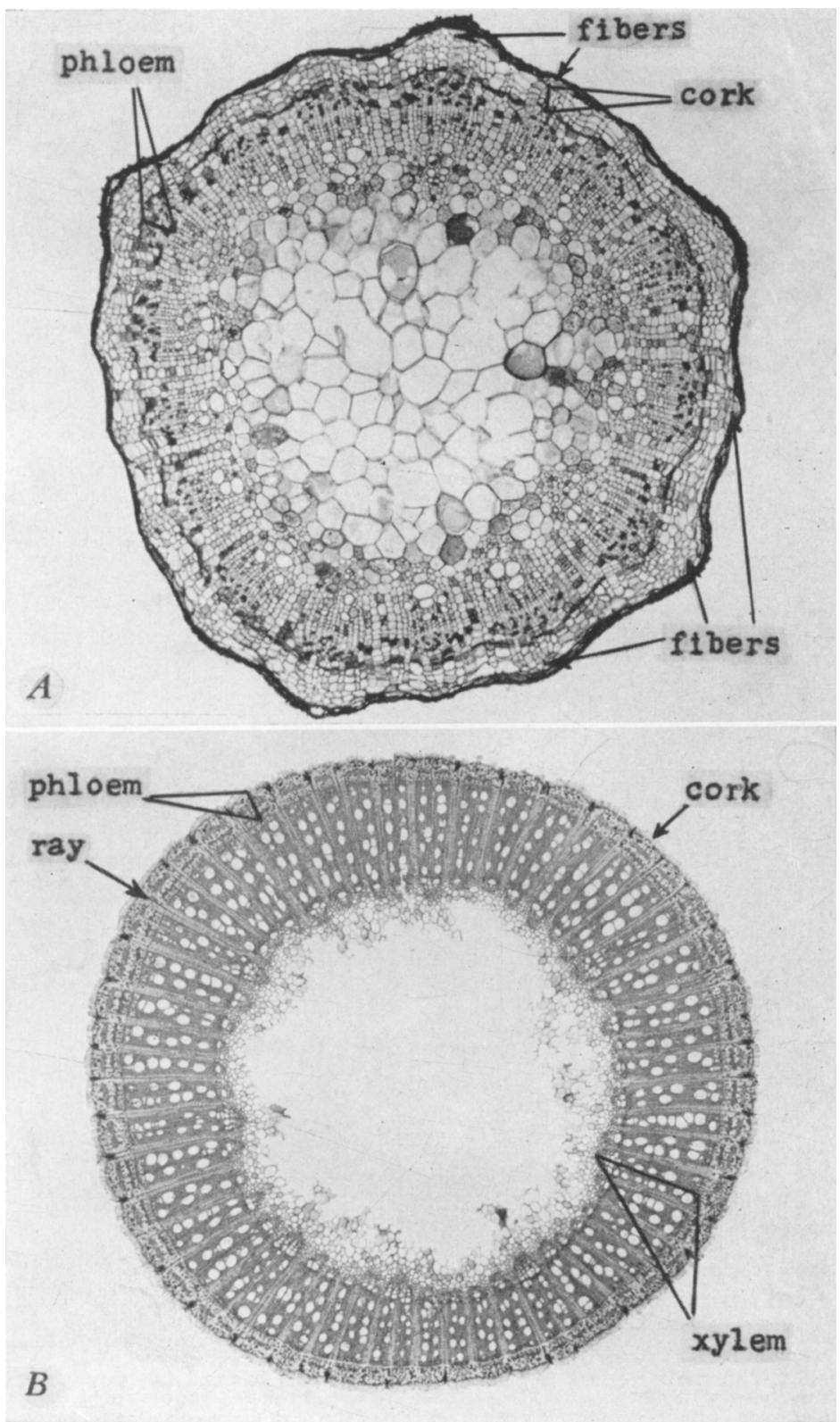

Plate 5. Transverse sections through a seedling stem $(A)$ and a mature cane (a one-year-old branch) $(B)$. The stem in $A$ shows early secondary growth: some secondary xylem and phloem are present and cork occurs beneath the primaryphloem fibers. The latter are still intact, but the cortex (on the outside of the cork) is collapsed. In $B$ the epidermis, the cortex and the primary-phloem fibers have been sloughed off. Only a small part of the xylem (next to the remnants of the pith) is primary; the rest is secondary. $(A \times 50 ; B \times 10$. 


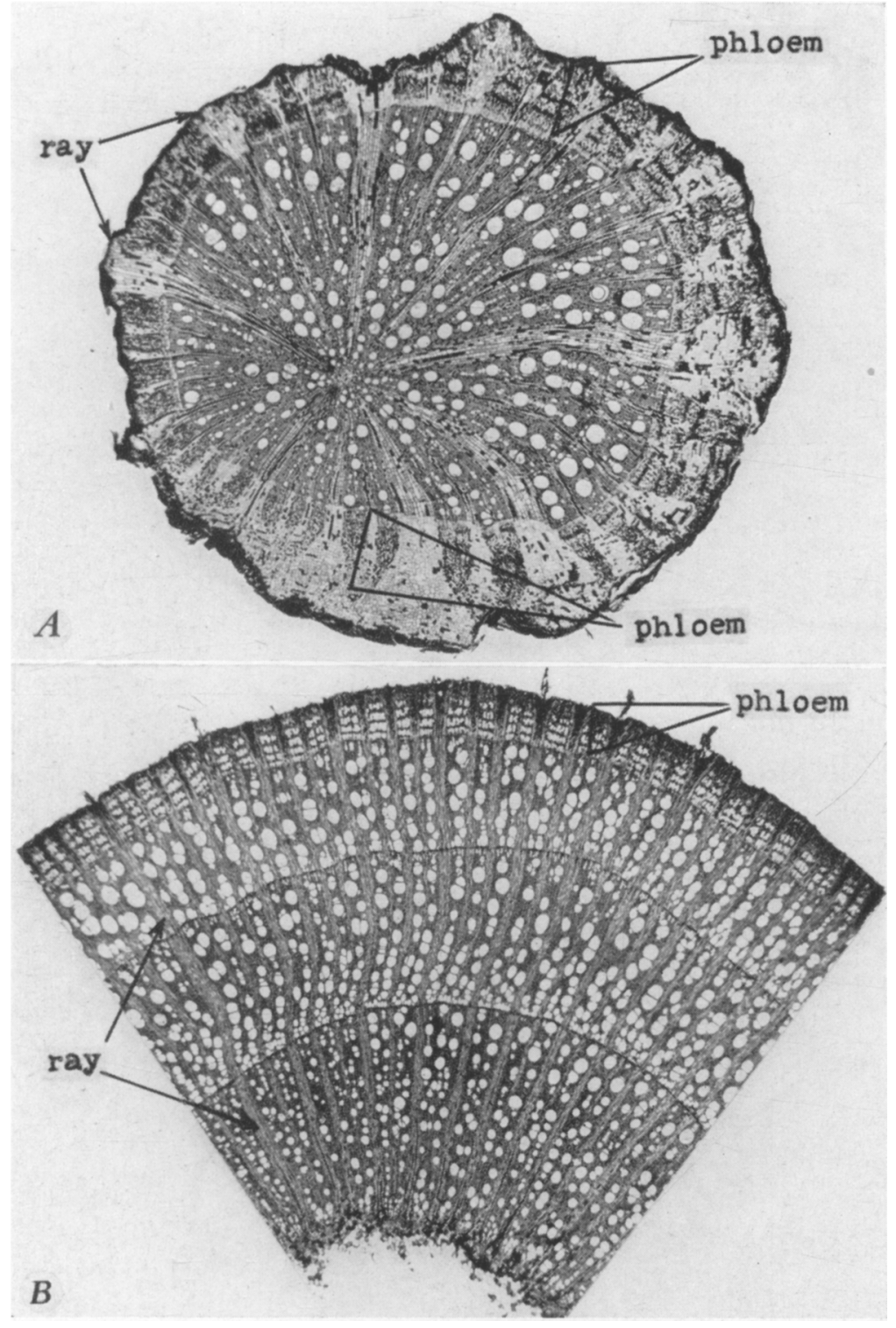

Plate 6. Transverse sections $(A)$ through a four-year-old root and $(B)$ through a part of a three-year-old branch (arm). The lack of distinctness of the annual rings, the great width of some of the rays, and the great thickness of the bark distinguish the root from the branch. $(A \times 9 ; B \times 8$. $)$ 


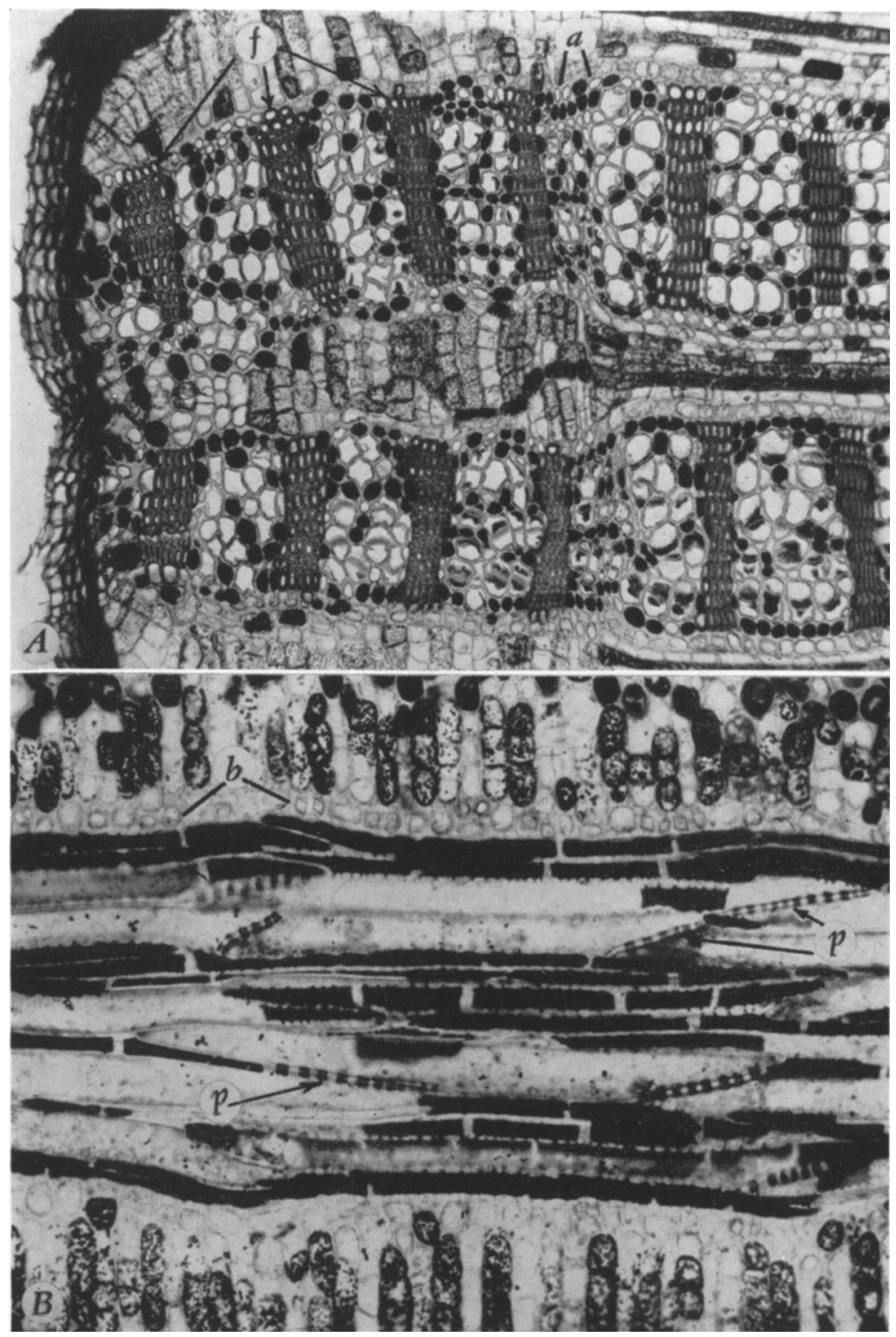

Plate 7. Transverse $(A)$ and tangential longitudinal $(B)$ sections of secondary phloem from a cane in second year of growth. The cane was collected July 3,1945 , just before cork was to be formed. In $A$ the regions from left to right are: 1944 cork; 1944 phloem ending with the late phloem at $a \cdot 1945$ phloem. All phloem to the left of $a$ is functionless. The section in $B$ was taken from the functioning phloem. Ray cells occur above and below in the photograph. Between these are several complete sieve-tube elements, with sieve plates $(p)$ in sectional views, and many phloem-parenchyma cells. (The material stained black in the phloem-parenchyma and ray cells is tannin.) Details are: $a$, late phloem of $1944 ; b$, crystal-containing layer; $f$, secondary-phloem fibers; $p$, sieve plate. $(A \times 90$; $B \times 150$.) 

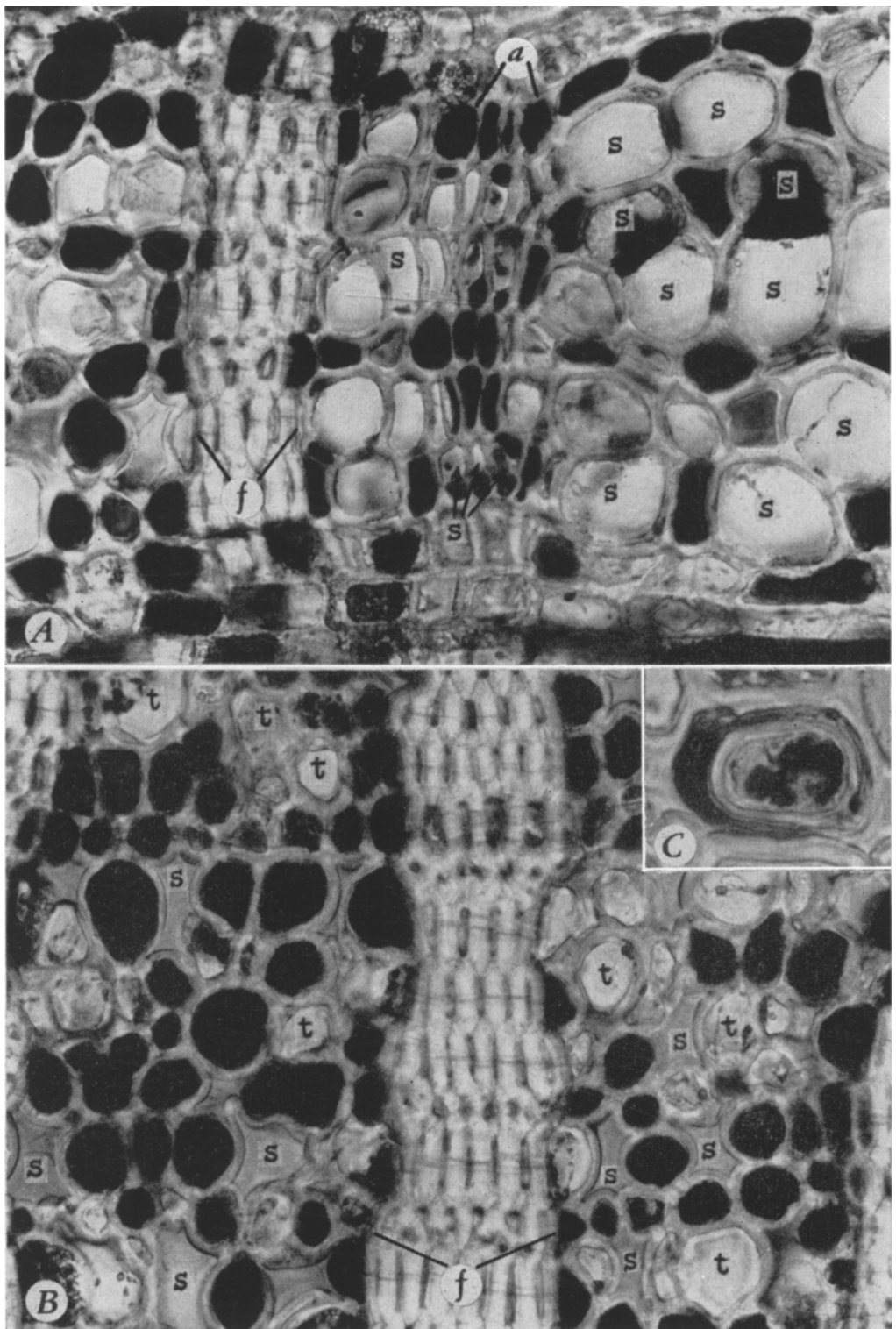

Plate 8. Transverse sections of functioning $(A)$ and nonfunctioning $(B)$ phloem from the trunk of Ohanez variety, collected June 25, 1945. To the right in $A$ is the 1945 phloem. At $a$ is the small-celled late phloem of 1944. The sieve tubes of the 1944 phloem in $B$ either contain tyloses $(t)$ or are partly crushed $(s)$. At $C$ is a single sieve tube with a tylose in transverse section. The black bodies within the tylose are starch grains; the black substance between the tylose and the sieve-tube wall is the residue of sieve-tube contents. Details are: $f$, secondary-phloem fibers; $s$, sieve tube; $t$, tylose. ( $A$ and $B \times 290 ; C, \times 750$.) 


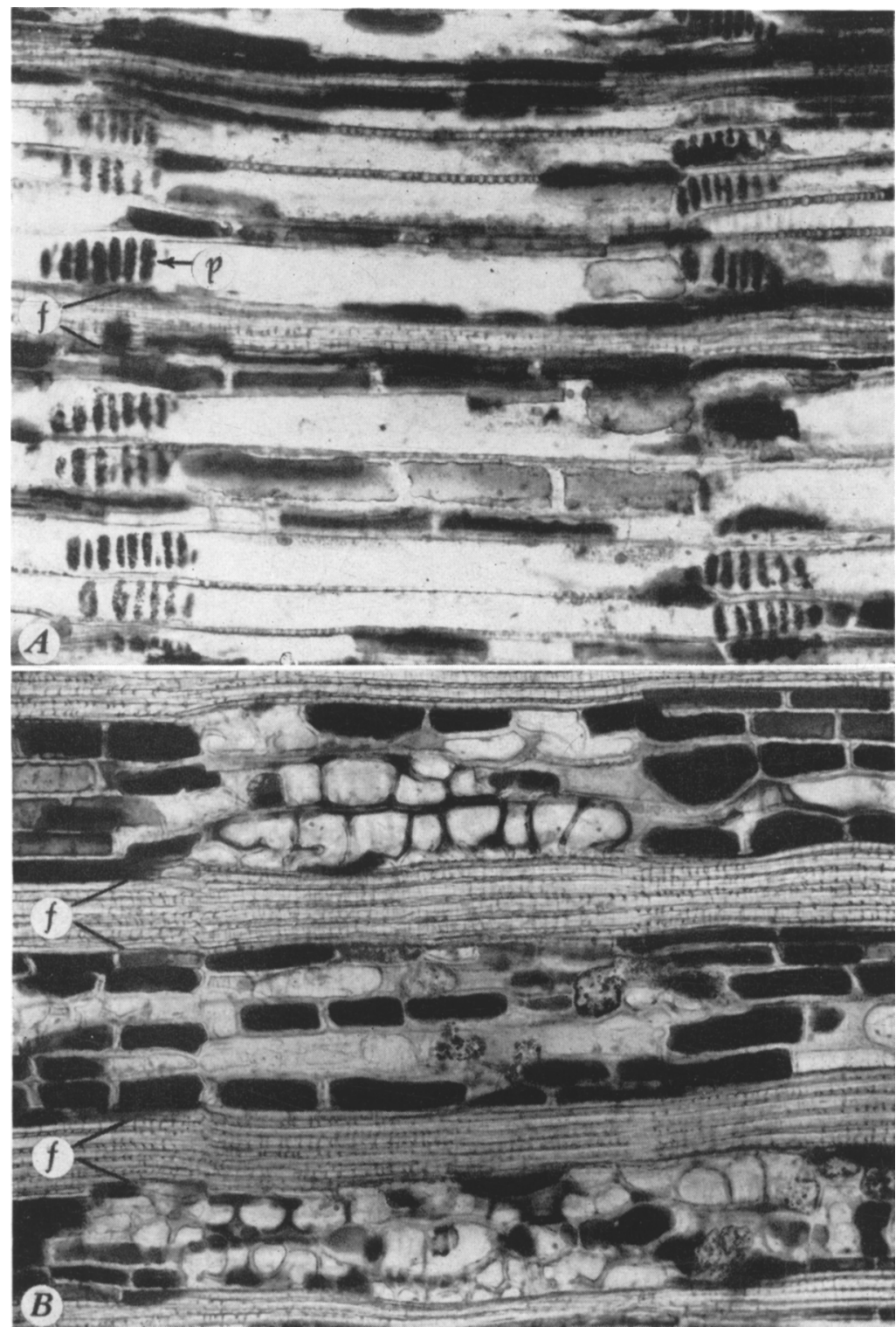

Plate 9. Radial longitudinal sections of the functioning $(A)$ and nonfunctioning $(B)$ phloem from the trunk of Ohanez variety, collected June 25, 1945. The youngest phloem in $A$ is at the top of the photograph. Several complete sieve-tube elements with the sieve plates $(p)$ in face view occur in $A$. In $B$ the sieve-tube elements are indistinguishable because they are filled with tyloses. Details are: $f$, secondary-phloem fibers; $p$, sieve plate. (Both $\times$ 150.) 


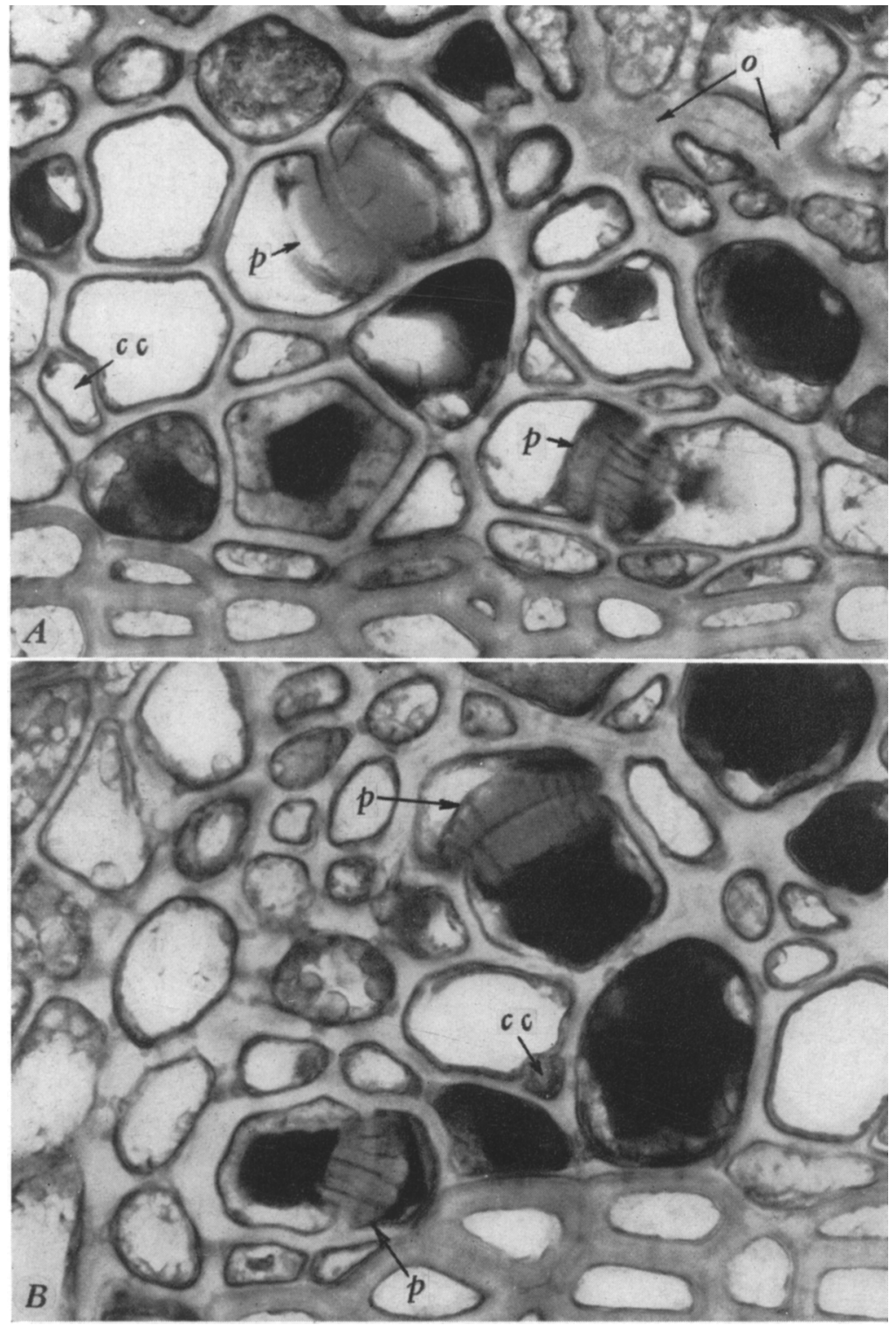

Plate 10. Transverse sections through the peripheral portion of reactivating phloem from a cane collected April 7, 1945. Two calloused sieve plates $(p)$ occur in each photograph. The connecting strands are barely perceptible in the upper callus mass in $A$; they are conspicuous in the lower plate in $A$ and in both plates in $B$. Slime accumulations are associated with the callus in $B$. Details are: $c c$, companion cell; $o$, obliterated sieve tubes; $p$, sieve plate. (Both $\times 750$.) 

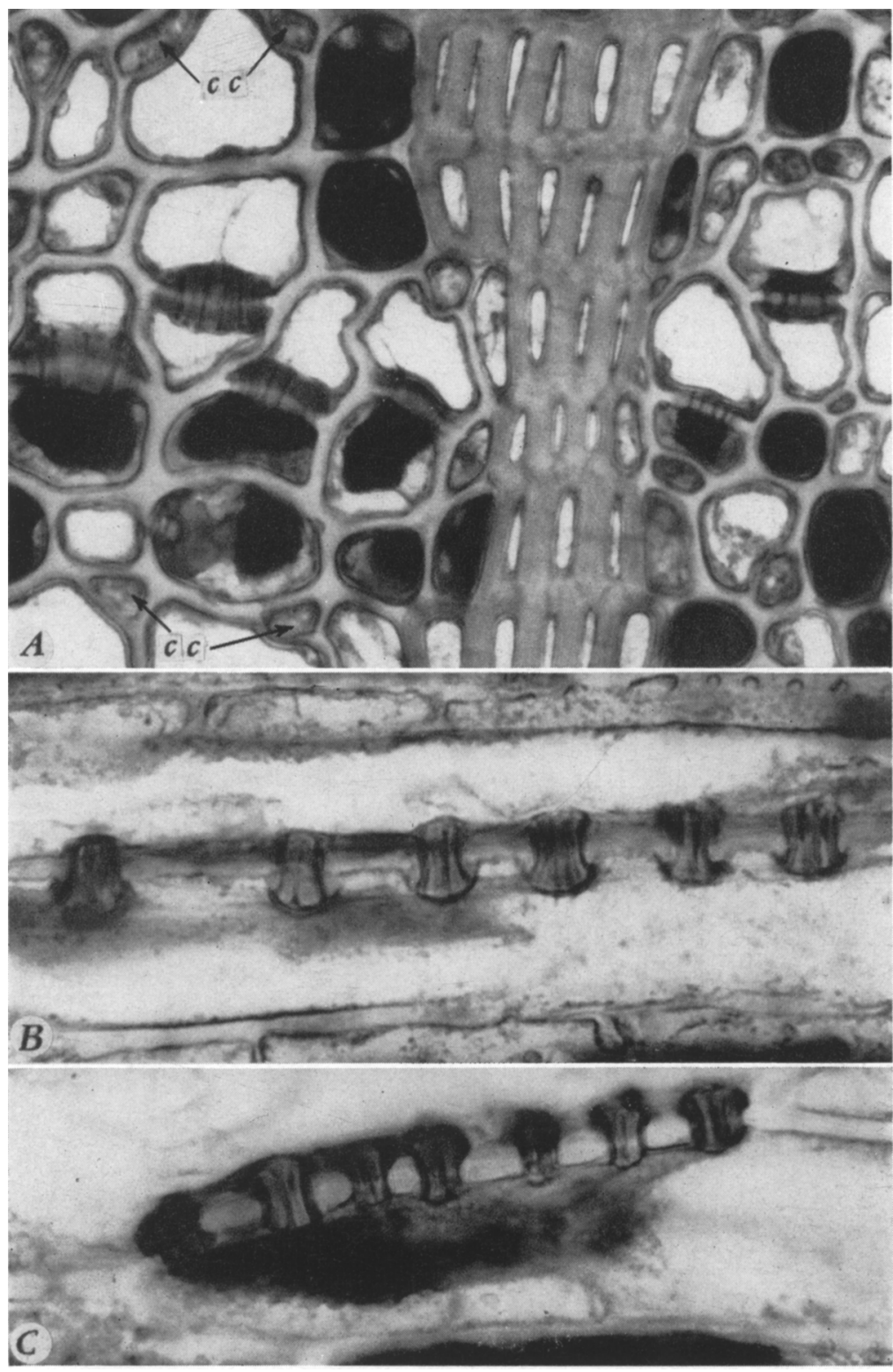

Plate 11. Transverse $(A)$ and tangential longitudinal ( $B$ and $C$ ) sections through the reactivating phloem of a cane collected April 7, 1945. The section in $A$ occurred closer to the cambium than the ones in plate 10 . Six sieve plates, with prominent connecting strands, occur in $A$. Companion cells are at $c c$. The compound sieve plates in the longitudinal $(B)$ and end $(C)$ walls show a callus mass with connecting strands in each sieve area. The darkly stained material near the sieve areas in all photographs is slime. (All $\times 750$.) 


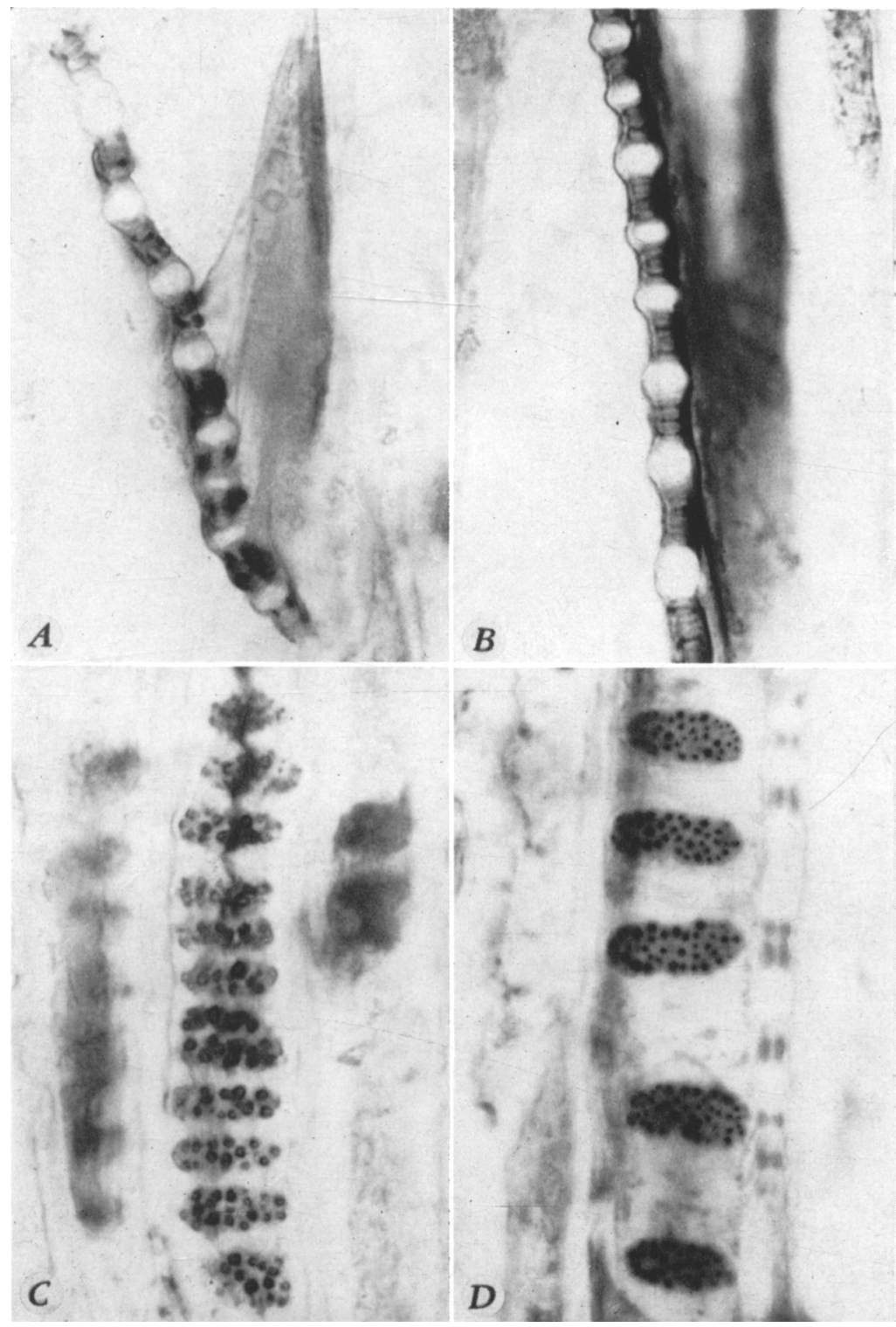

Plate 12. Sectional ( $A$ and $B$ ) and face $(C$ and $D$ ) views of sieve plates of newly differentiated phloem. Some of the connecting strands in $A$ and $B$ show knobs at the surface of the sieve areas. The darkly stained material in $A$ and $B$ is slime; the lightly stained material in $A$, cytoplasm. The latter is connected to the sieve plate and contains starch grains, circular in outline. $C$, Sieve plate on an end wall with sharply outlined callus cylinders in the sieve areas. In $D$, showing a sieve plate in a longitudinal wall, the callus cylinders and the connecting strands together appear as black dots. The entire sieve areas are rather dark because they are completely covered with callus. (All $\times 750$.) 


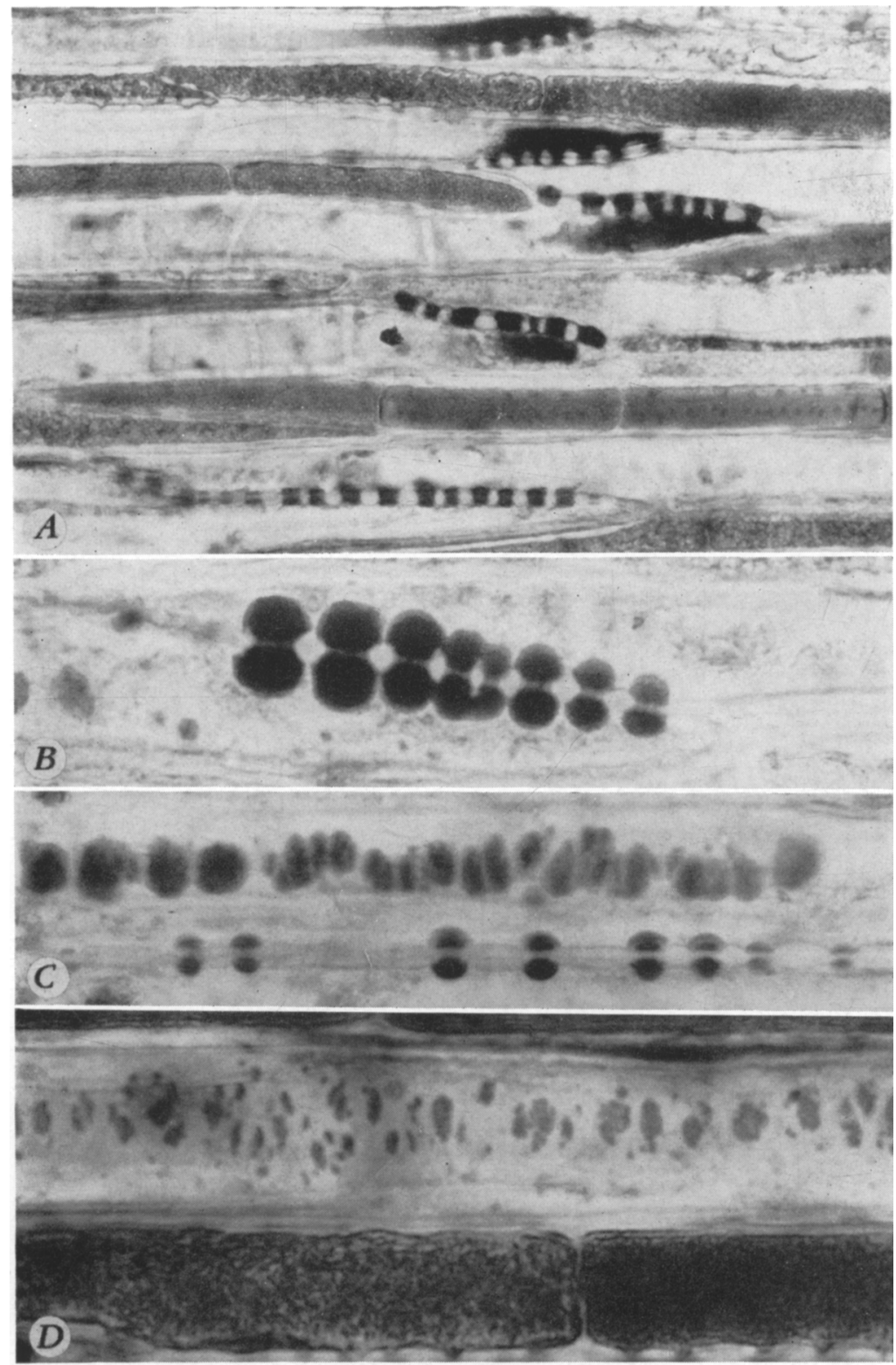

Plate 13. Tangential longitudinal sections from active ( $A$ and $D$ ) and dormant ( $B$ and $C$ ) phloem. $A$ and $D$ were collected May 30,$1945 ; B$ and $C$, March 10,1945 . $A$ shows several sieve plates with the associated slime in sectional view; $B$, a compound sieve plate in section; $C$, sieve areas of type B in face view (above) and sectional view (below); $D$, above, sieve areas of type $B$ in face view $(A \times 290 ; B-D \times 750$. $)$ 


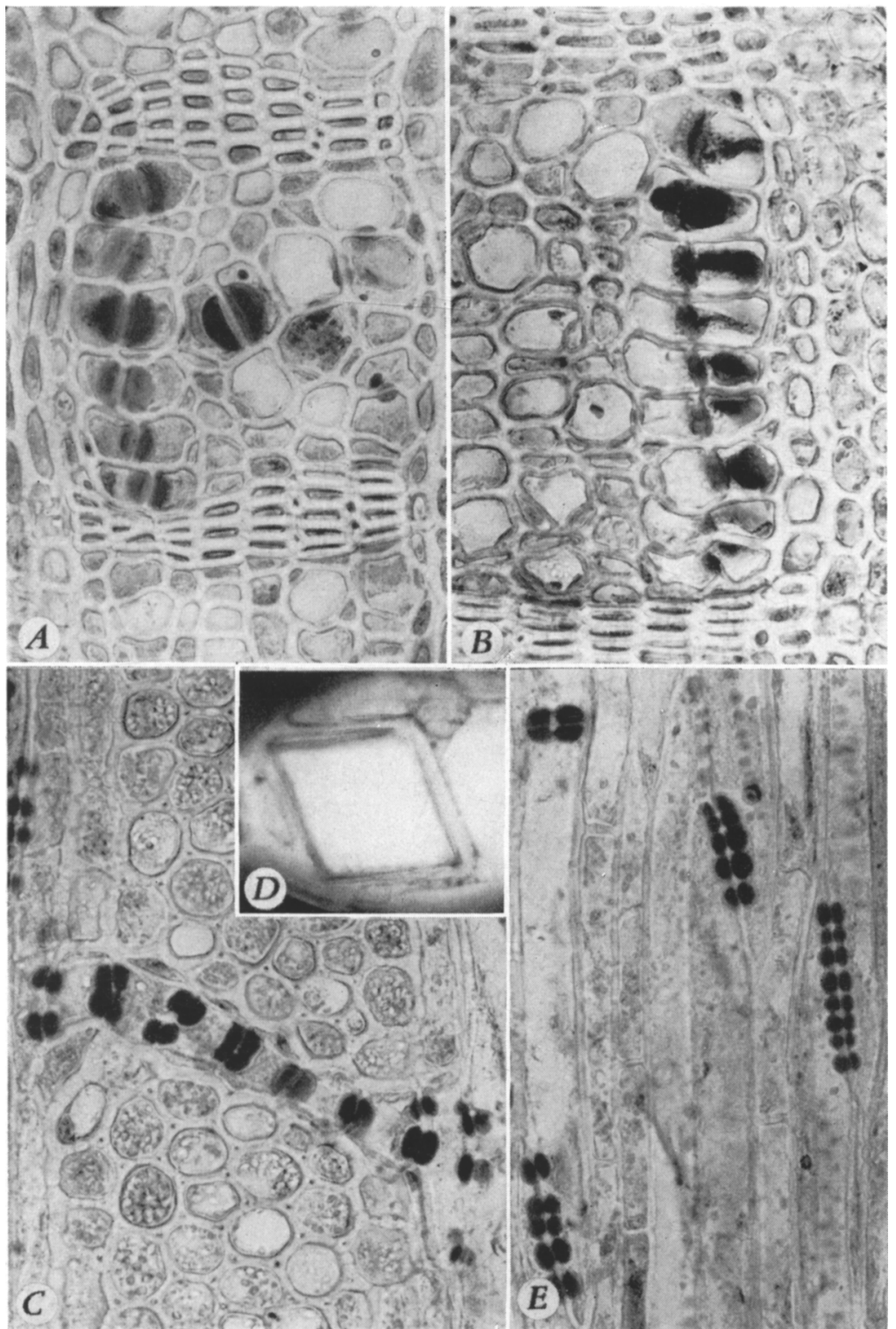

Plate 14. Transverse ( $A$ and $B$ ) and tangential longitudinal ( $C$ and $E$ ) sections of 1944 phloem collected March $10,1945(A, C$, and $E)$ and April $23,1945(B) . A, C$, and $E$, Dormant phloem with massive callus on the sieve plates. In $C$ a series of small sieve-tube elements traverse a ray. $B$ shows signs of resumption of active state: the callus masses are thin, and slime is visible near the sieve plates. $D$, Part of a single ray cell with a crystal imbedded in wall material. ( $A-C$ and $E \times 290 ; D \times 1200$.) 


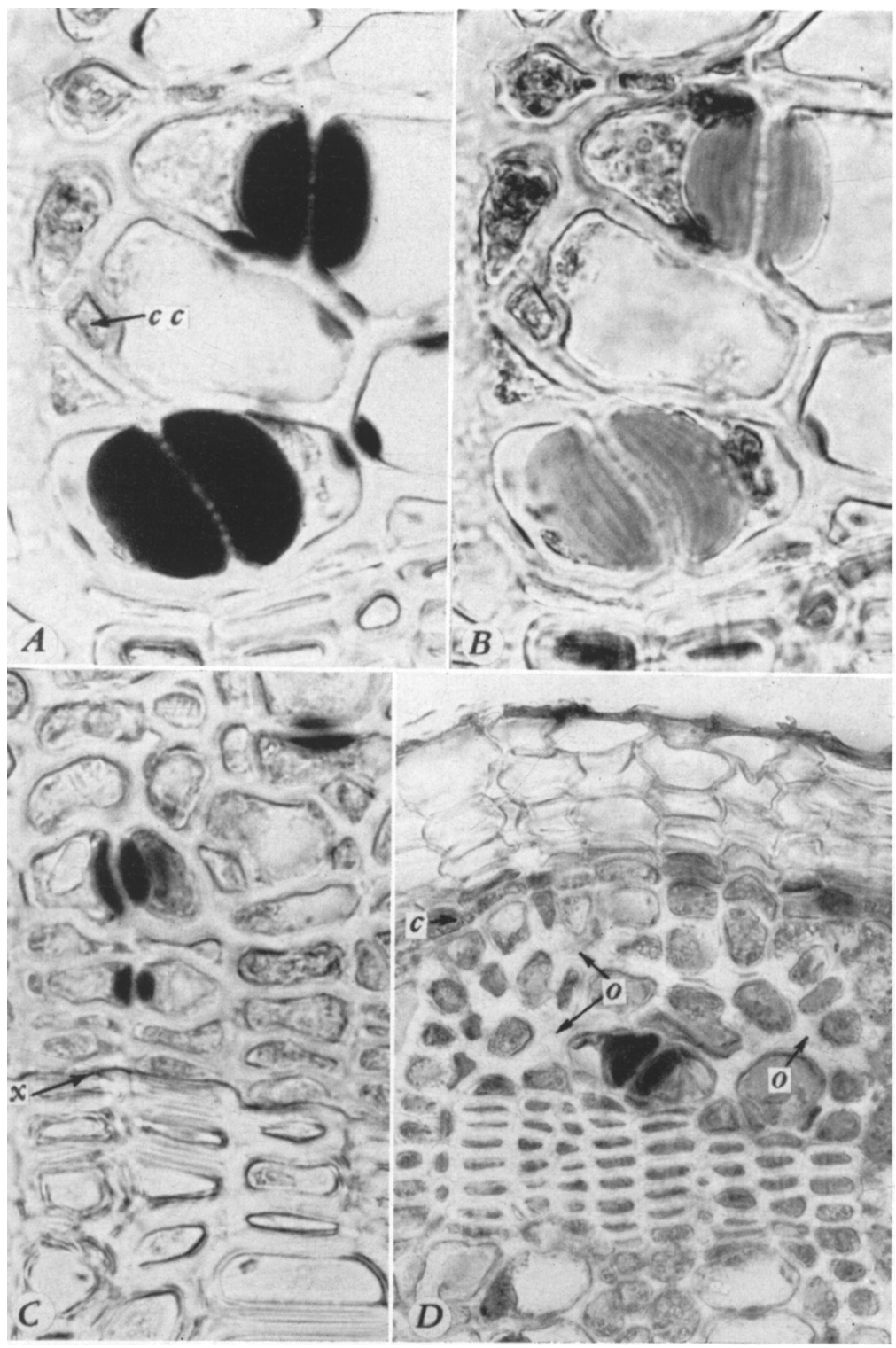

Plate 15. Transverse sections through dormant $(A-C)$ and nonfunctioning $(D) \mathbf{1 9 4 4}$ phloem collected March 10, $1945(A-C)$ and April 23, $1945(D) . A$ and $B$ are photographs of the same section, one taken with Wratten filter $F$ (red), the other with Wratten filter B (green) and a much reduced opening in the substage-condenser diaphragm. In both sections the callus was stained blue. $A$ shows callus cylinders traversing the cellulose wall of the sieve plate. $B$ illustrates the layering in the callus. $C$ shows the late 1944 phloem, cambium, and xylem. The latter is sharply delimited from the cambium at $x$. In $D$, the four to five cells on the upper surface are cork cells (above $c$ ). Beneath the cork most of the sieve tubes have been obliterated $(o) .(A-C \times 750 ; D \times 290$.) 

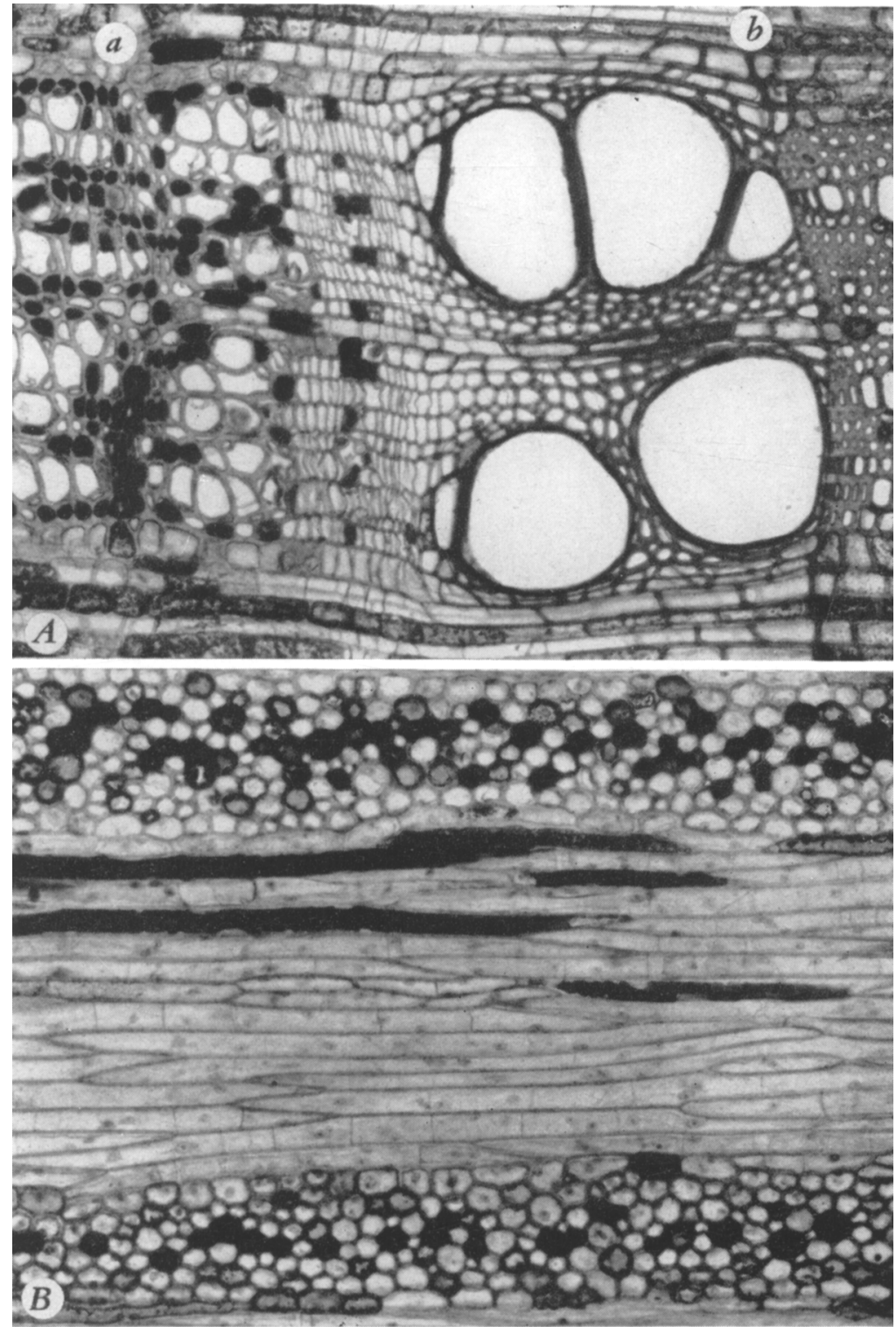

Plate 16. Transverse $(A)$ and tangential longitudinal $(B)$ sections through the cambium and adjacent tissues of a cane in second year of growth, collected May 30,1945 . $A$ shows at $a$ the late 1944 phloem, at $b$ the end of 1944 xylem. Between the 1945 phloem (to the right from $a$ ) and the 1945 xylem (to the left from $b$ ) lies the fascicular-cambium region. $B$ shows rays above and below, and cambial initials and partly differentiated phloem (with tannin-containing cells) between the rays. (Both $\times 140$.) 

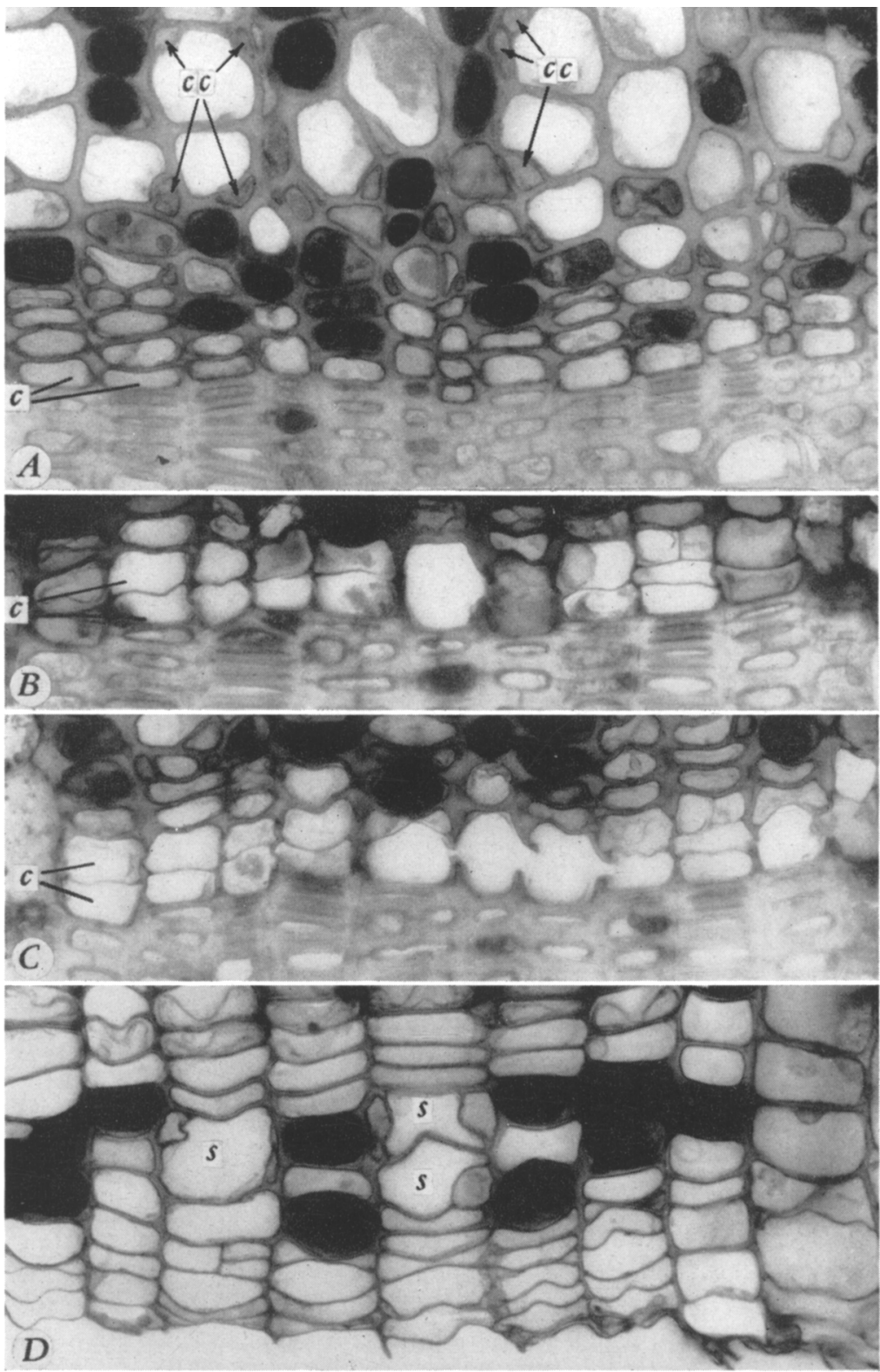

Plate 17. Transverse sections through the cambial region during dormancy $(A)$, at the beginning of cambial activity $(B$ and $C$ ), and at the end of this activity $(D)$. Sections are from canes in second year of growth collected April 7, $1945(A-C)$ and July $3,1945(D)$ In $A-C$ the cambium is at $c$ and the xylem below it. Companion cells are at $c c$ in $A$. In $D$ the cambium occurs at the lower edge of the section (the bark separated from the wood along this edge) and above it are some partly differentiated sieve tubes $(s)$. ( All $\times 450$. 


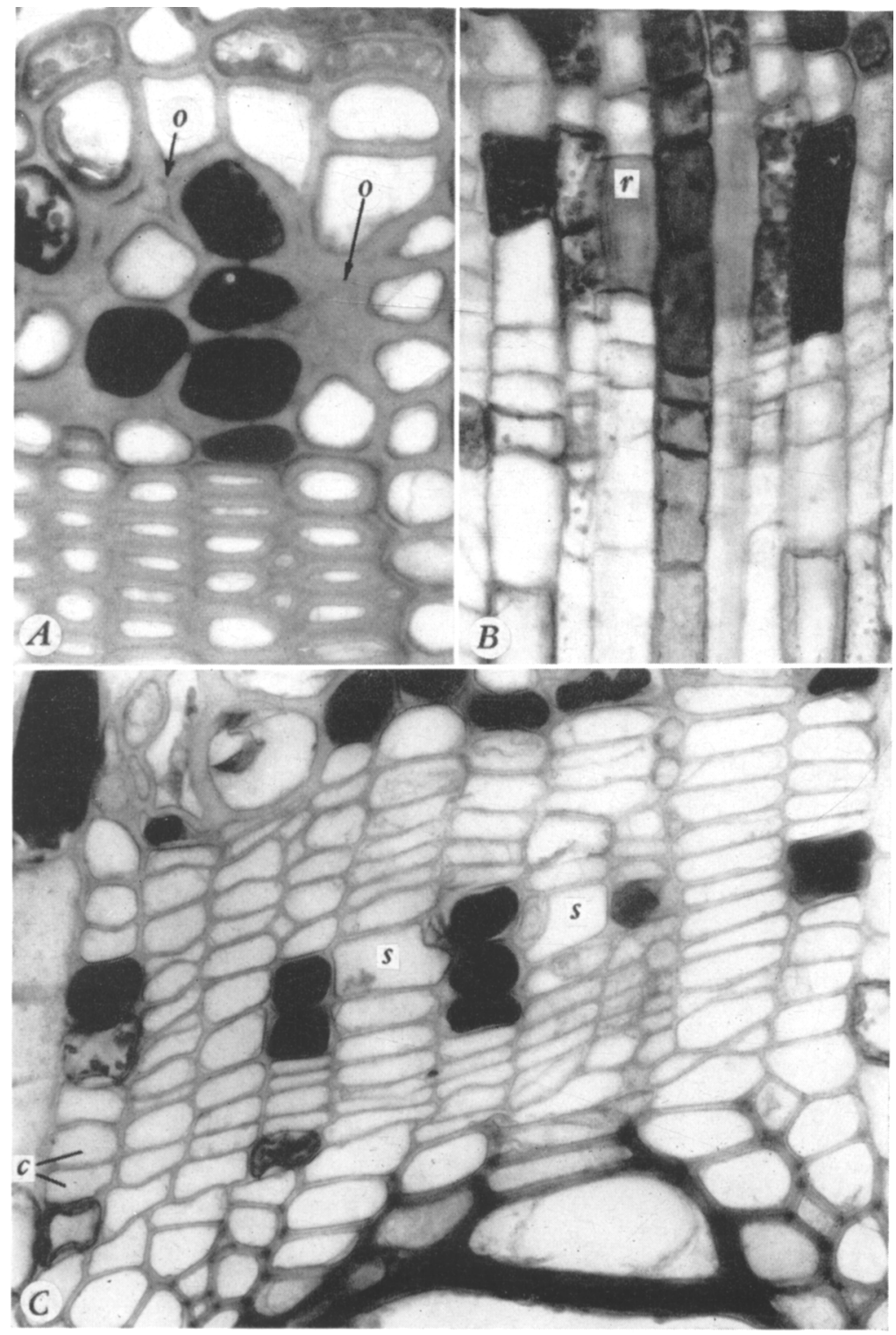

Plate 18. Transverse sections through the regions of: $A$, sieve-tube obliteration; $B$, interfascicular cambium; and $C$, fascicular cambium. All from a cane in the second year of growth collected May 30,1945. (The same cane was used for plate 16.) In $A$ the crushed sieve tubes appear at $o$. In $B$ the cells functioning as ray initials in the median column of cells contain tannins; raphides $(r)$ appear in cells that lie very close to the dividing ones. In $C$ the cambium proper is at $c$. Tannin-containing cells occur on both sides of the cambium; some differentiating sieve tubes $(s)$ are above it. ( $A$ and $C \times 450 ; B \times 290$.) 

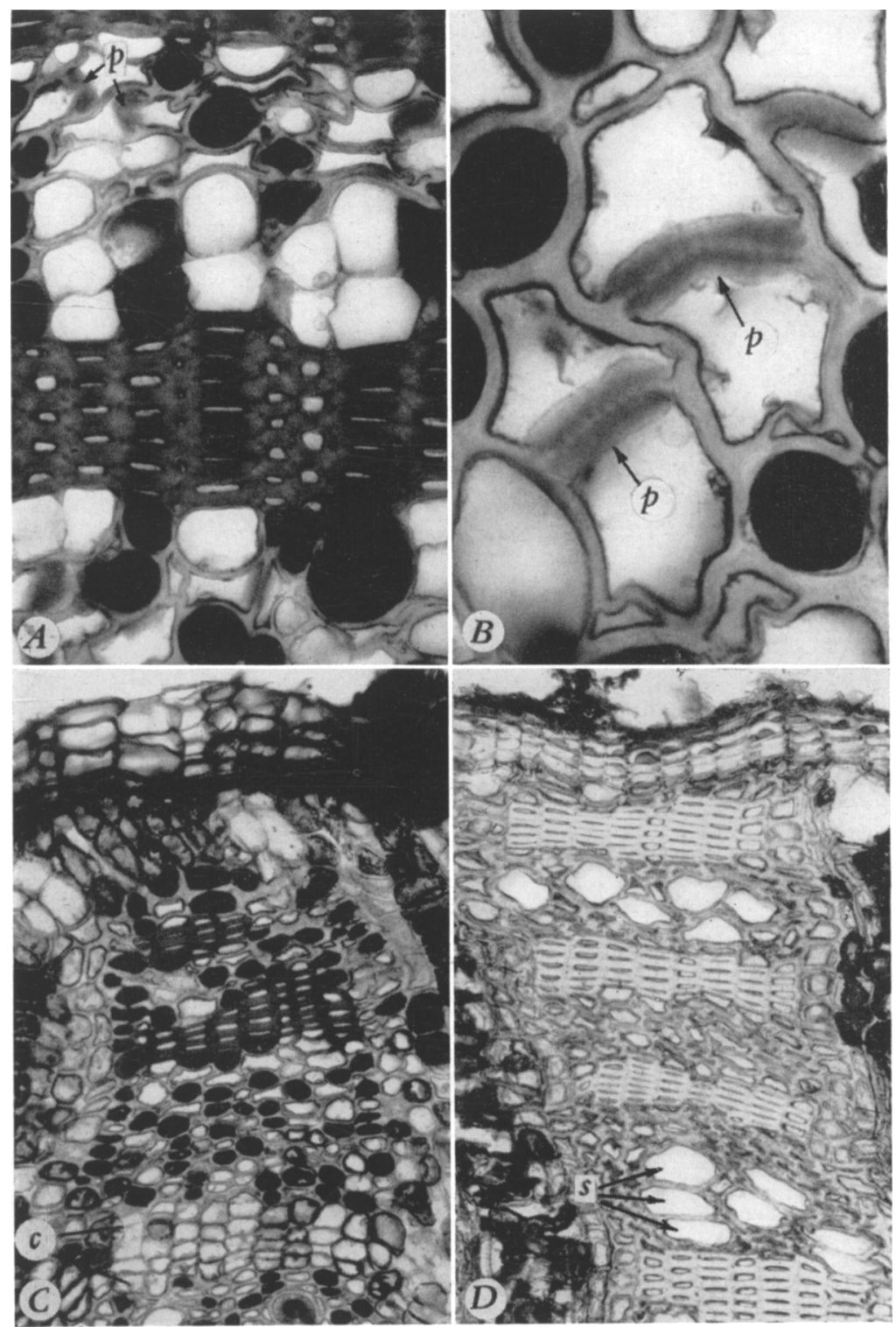

Plate 19. Transverse sections of phloem from trunks ( $A$ and $D$ ) and canes ( $B$ and $C$ ) collected July $3,1945(A-C)$ and April $17,1945(D)$. A, Initiation of cork cambium. Parenchyma cells above the fibers have enlarged and divided. The sieve tubes are partly crushed above the divided cells. Sieve plates with definitive callus at $p . B$, Functionless 1944 phloem with definitive callus on the sieve plates $(p)$. In $C$ the 1944 functionless phloem (above) has been separated from the functioning 1945 phloem (below) by cork $(c)$. The 1944 cork occurs along the upper edge of the section. $D$, Dead phloem of 1943 that was cut off by cork formation in 1944 . Empty sieve tubes appear at $s$. $(A \times 290 ; B \times 750 ;$ $C$ and $D \times 150$.) 


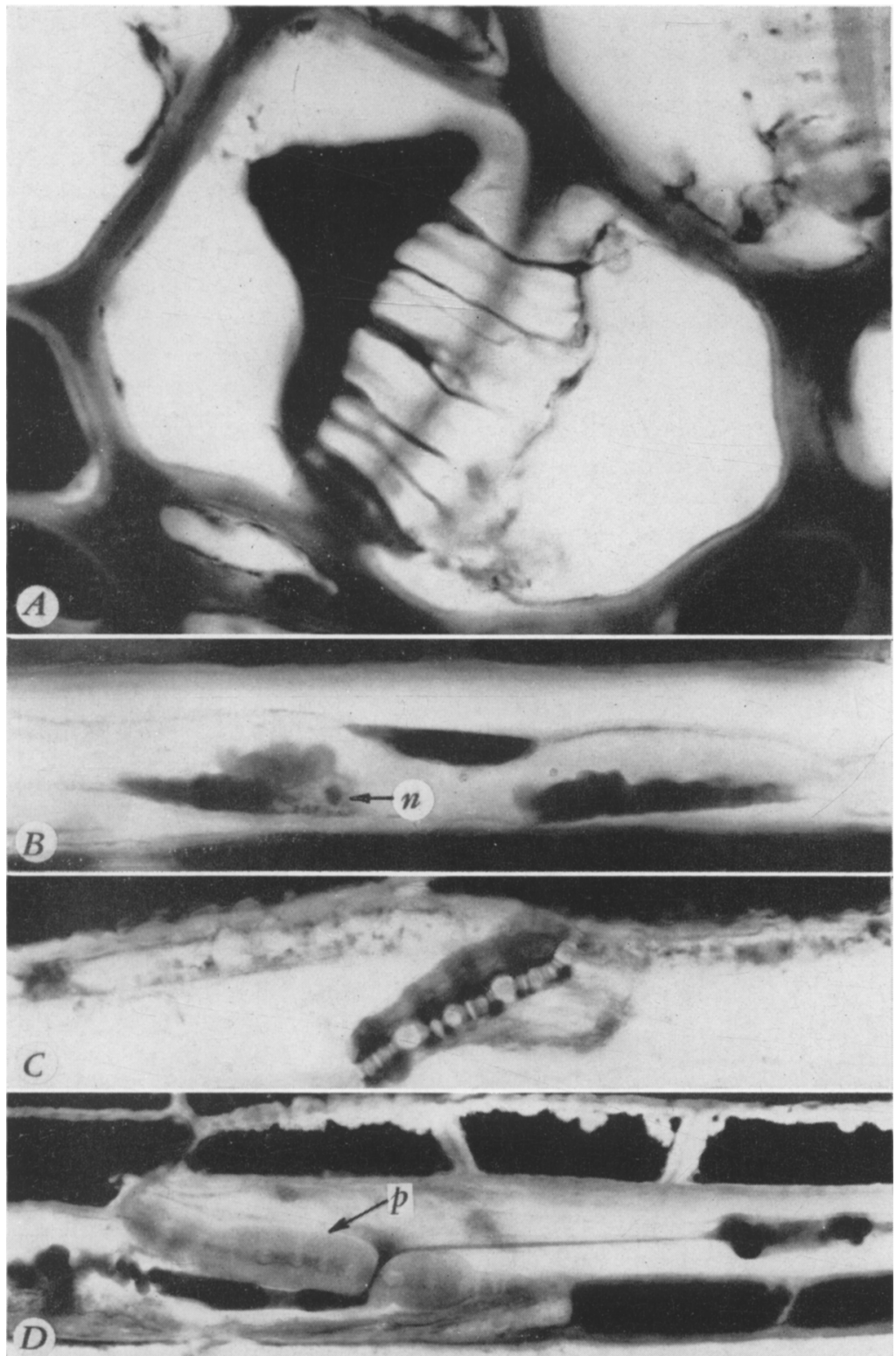

Plate 20. Transverse $(A)$ and longitudinal $(B-D)$ sections of sieve tubes showing different states of metamorphosis of sieve-tube slime. The material was collected on the following
dates in $1945: A$, April $25 ; B$, May $30 ; C$, September $13 ; D$, December 8 . In the center of the picture in $A$, the slime projects into the callus mass of the sieve plate from a reactivating sieve tube. $B$, Slime bodies and a nucleus $(n)$ in an immature sieve-tube element. $C$, Part of a sieve tube from functioning phloem. The slime on the sieve plate has projections passing through the plate. $D$. Part of a sieve tube from dormant phloem. The sieve plate $(p)$ is covered with callus, but in one place a strand of slime passes through it and connects the slimy accumulations on the two sides of the plate. $(A \times 1200 ; B$ and $C \times 750 ; D \times$ 290.) 
The journal Hilgardia is published at irregular intervals, in volumes of about 600 pages. The number of issues per volume varies.

Subscriptions are not sold. The periodical is sent as published only to libraries or to institutions in foreign countries having publications to offer in exchange.

You may obtain a single copy of any issue free, as long as the supply lasts; please request by volume and issue number from:

\section{Publications Office \\ College of Agriculture \\ Berkeley 4, California}

The limit to nonresidents of California is 10 separate issues on a single order. A list of the issues still available will be sent on request. 
